مجلة كلية التربية، جامعة الأزهر ، العلد: (19 17 الجزء الثالث) يوليو لسنة 17 ـ بام

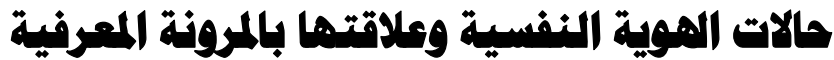

\section{لدى طلبة المرحلة الثانوية}

Psychological Identity Statuses and its Relation to Cognitive Flexibility Among High School Students

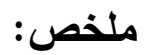

هدفت هذه الاراسة التعرف إلى العلاقة بين حالات الهوية النفسية والمرونة

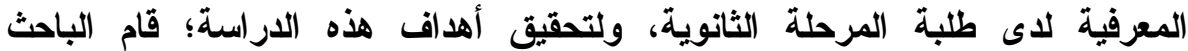

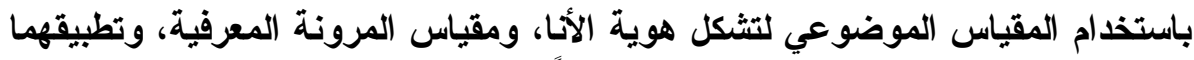

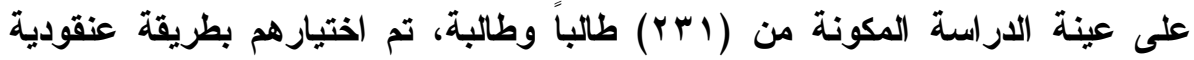

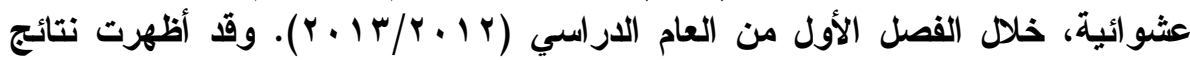

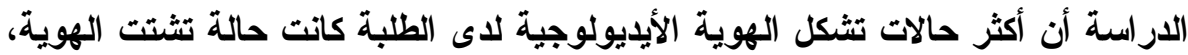

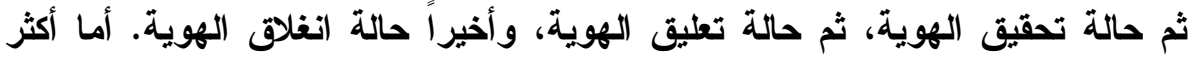

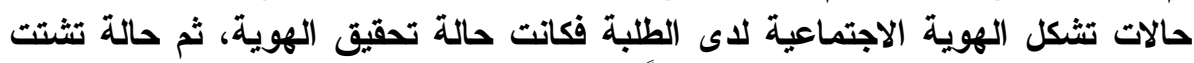

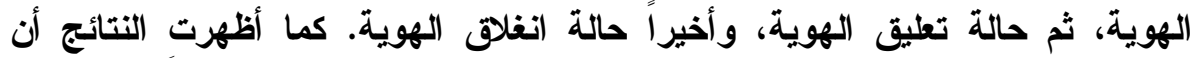

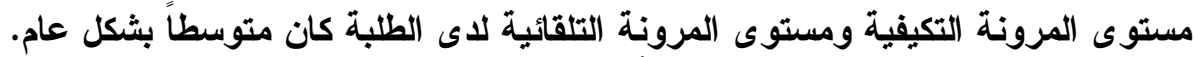

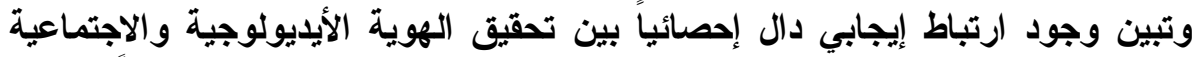

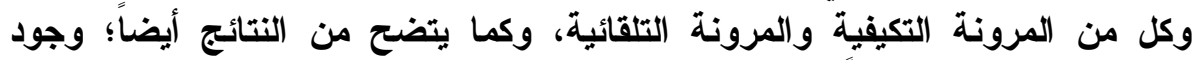

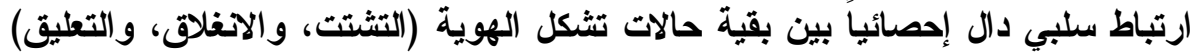

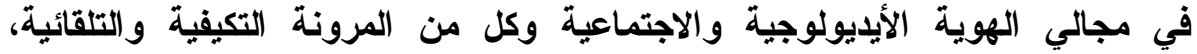

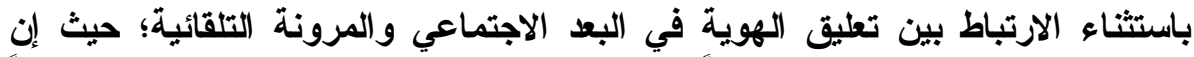

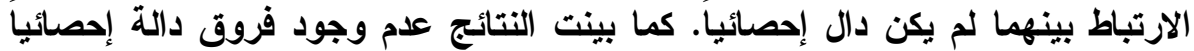

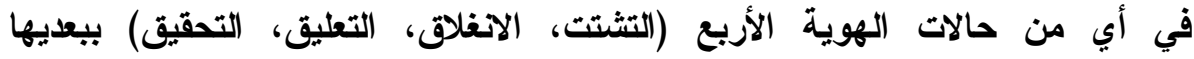

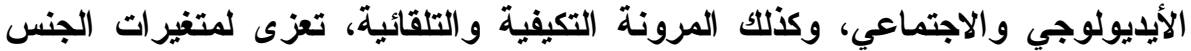
و المستوى الاراسي والتخصص واعص الأكاديمي.

الكلمات المفتاحية: حالات الهوية النفسية، المراهقة، المرونة المعرفية. 


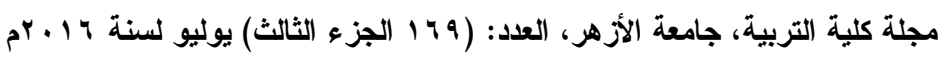

Abstract

This study aimed to investigate the relationship between psychological identity statuses and cognitive flexibility among high school students. To achieve the study goals; the researcher used Objective Measure of Ego-Identity Status (OMEIS), and cognitive flexibility scale, and applied to a sample consisting study of (231) male and female students, were selected cluster random manner, during the first semester of the academic year (2012/2013). The results of the study showed that more cases constitute the ideological identity of the students was the case of the identity diffusion, then the identity achievement, then identity moratorium, and finally the identity foreclosure. The most situations that interpersonal identity among students was identity achievement, then diffusion, then moratorium, and finally foreclosure. The results also showed that the level of adaptive flexibility and spontaneous flexibility of the students was average in general. And found a positive correlation significant differences between achieving the ideological and interpersonal identity and all the flexibility of adaptive and spontaneous flexibility, as evidenced by the results also; and there is a negative correlation significant differences between the rest of the cases constitute the identity (diffusion, foreclosure, and moratorium) in the aspects of ideology and interpersonal identity and all the flexibility of adaptive and spontaneous, with the exception of the correlation between the moratorium identity in the social aspect and spontaneous flexibility; as the correlation between them was not significant differences. The results also show a lack of significant differences in any of the four cases of identity (diffusion, foreclosure, moratorium, and achievement) two aspects ideological and interpersonal, as well as adaptive and spontaneous flexibility, due to gender and academic level and academic specialization.

Keywords: Psychological Identity Statuses, Adolescence, Cognitive Flexibility. 
يتطلب هذا العصر جهاً غير مسبوق من الفرد للتعامل مع ما ينتجه العلم

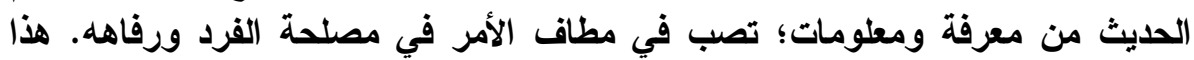

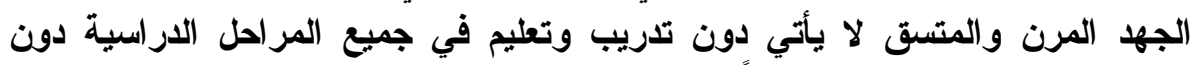
استثناء، بل يحتاج رعاية وصبراً من المعلمين خاصة، والئ والقائمين على العملية التعليمية عامة، تجاه طلبتهم.

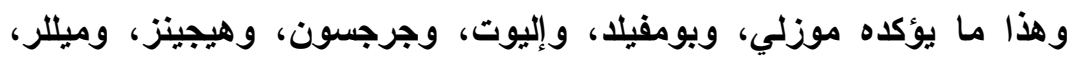

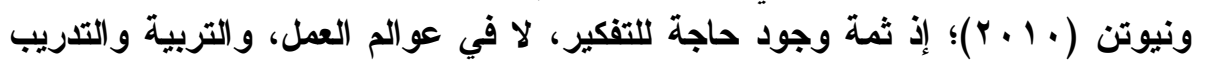

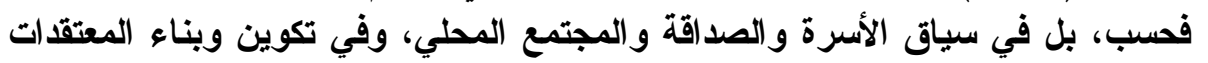

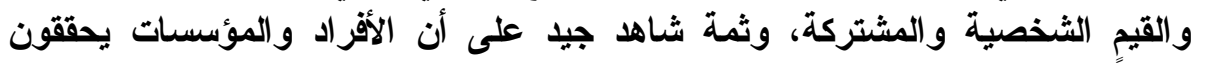

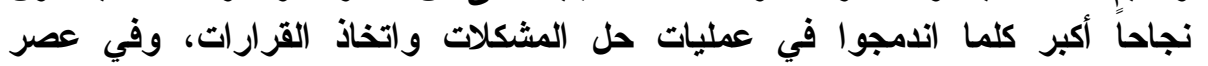

المطلومات أصبحت خصائص الاستقلال و المرونة ذات قيمة عالية.

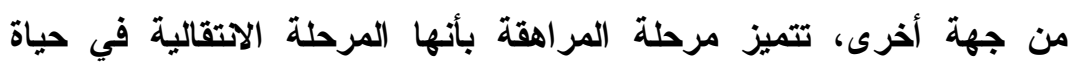

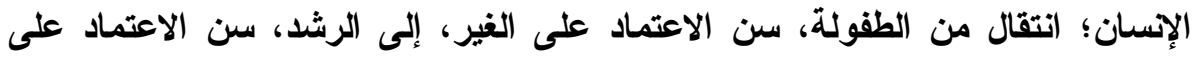

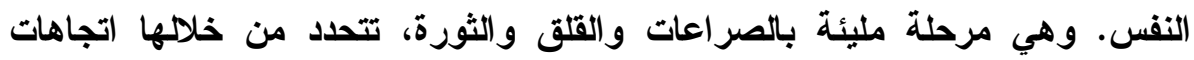

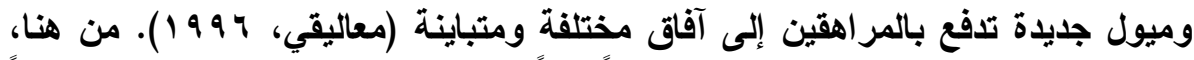

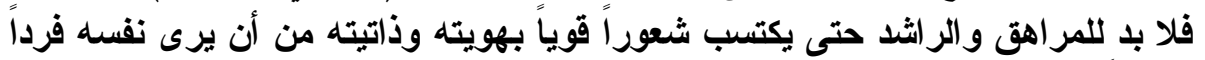

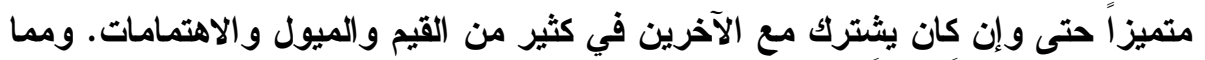

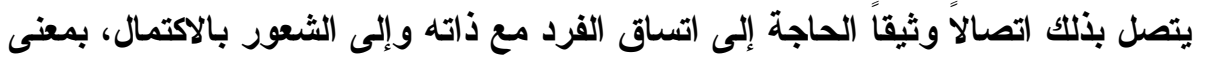

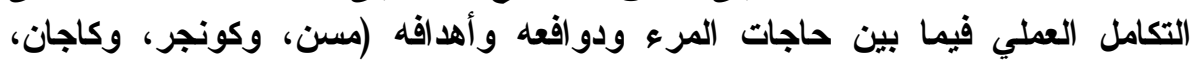

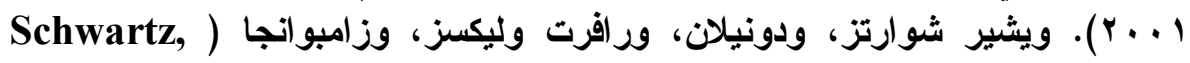
(Donnellan, Ravert, Luyckx, \& Zamboanga, 2013 الثخصية الإنساتية تتأثر بمجموعة من العوامل منها: التجارب الثخصية للفرد والثقافة الثافي

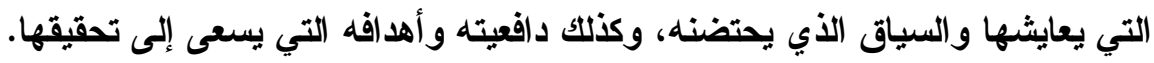
إن موضوع الدراسة الحالية يدور حول العلاقة بين مفهومين رئيسين؛ الأول:

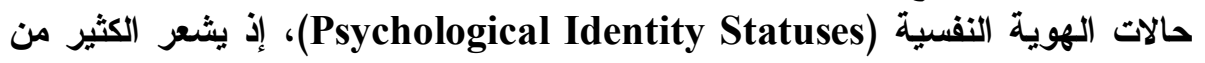

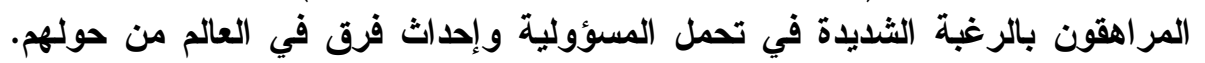

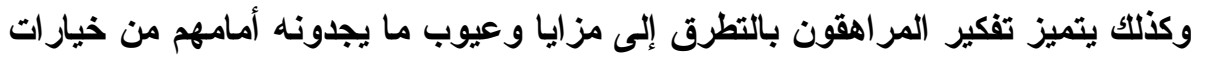

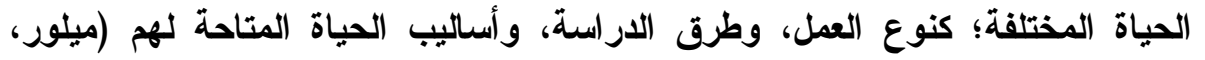

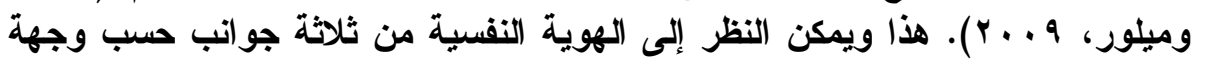

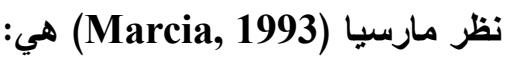




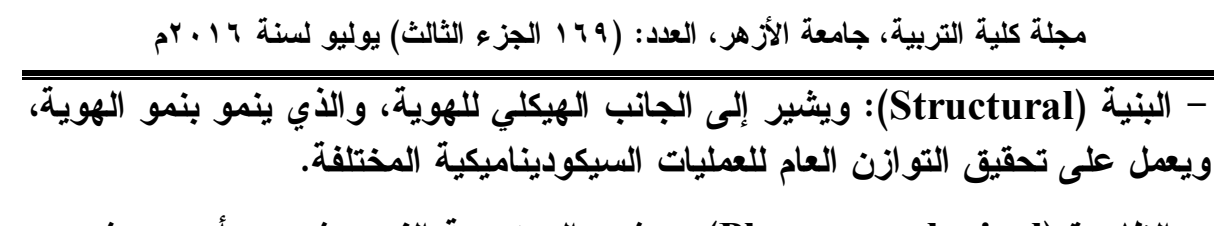
- الظاهرة (Phenomenological): ويشير إلى تجربة الفرد وشعوره أو عدم شعوره بهويته، أي شعوره بحالة الهوية التي يكون عليها.

- السلوك (Behavioural): تثكيل الهوية، بمعنى آخر، رؤية الآخرين لأسلوب هوية الفيكونات الفرد.

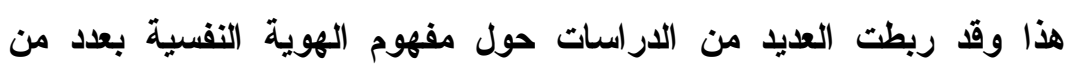

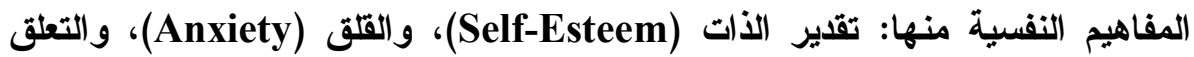

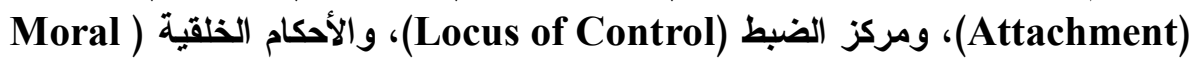
والأس (Intelligence) (Kroger, \& Marcia, 2011 و الأساليب المعرفية (Marcia, 1980) (Cognitive Styles) (التطور المعرفي (Cognitive Development) .(Adams, 1998)

جدول (1)

المفاهيم التي تمت دراستها بالتزامن والارتباط مع مفهوم الهوية النفسية

\begin{tabular}{|c|c|}
\hline المفهوم & s \\
\hline Social Cognitionsالمعارف الاجتماعية & 1 \\
\hline المظاهر السلوكية Behaviors & r \\
\hline المتغير ات الديمغر افية Demographic Variables & $r$ \\
\hline العوامل الأسرية Family Factors & $\varepsilon$ \\
\hline التسلطية-التصلبية Authoritarianism-Rigidity & 0 \\
\hline مؤشر ات التحصيل الدراسي Achievement Indices & 7 \\
\hline Major Field of Study \& مجال التخصص الدراسي والأهداف المهنية Career Objectives & $\mathrm{V}$ \\
\hline Family Environment المناخ الأسري & $\wedge$ \\
\hline التطور الخلقي Moral Development & 9 \\
\hline Personality الثخصية & 1. \\
\hline
\end{tabular}


مجلة كلية التربية، جامعة الأزهر، العدا: (199 الجزء الثالث) يوليو لسنة 19 بـام

\begin{tabular}{|c|c|}
\hline 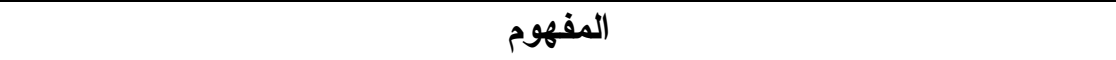 & s \\
\hline Racial Differences الفروق العرقية/ الطائفية & 11 \\
\hline رتب/ حالات الهوية الوالاية Parental Identity Status & ir \\
\hline الألفة Intimacy & ir \\
\hline الخجل Shyness & $1 \varepsilon$ \\
\hline Cross-Cultural Differences الفروق عبر الثقافات & 10 \\
\hline الثعور بالذات -إدر اكات الذات Self-Consciousness-Self-Perceptions & 17 \\
\hline الأنماط السلوكية الموائمة Conformity Behaviors & iv \\
\hline الفروق بين الجنسين Sex Differences & 11 \\
\hline الأكورة-الأنوثة Masculinity-Femininity & 19 \\
\hline الاستغراق في الأنشطة الطلابية Involvement in Student Activities & r. \\
\hline المستوى الاجتماعي-الاقتصادي Socio-Economic Status & Y \\
\hline أنماط المعرفة الاجتماعية Social Cognitive Styles & rr \\
\hline Social Influence Behavior السلوك المؤثر اجتماعياً & rr \\
\hline Social Desirability المرغوبية الاجتماعية & Y $\leqslant$ \\
\hline Substance Use \& Exposure استخدام وتداول المو اد المخدرة & ro \\
\hline الرضا الاجتماعي-الاحتراق النفسي Social Satisfaction-Burnout & rq \\
\hline حل المشكلات -اتخاذ القرار Problem Solving-Decision Making & rV \\
\hline
\end{tabular}

و الثاني: مهارة من مهارات التفكير العليا ألا وهي المرونة المعرفية

(CognitiveFlexibility)

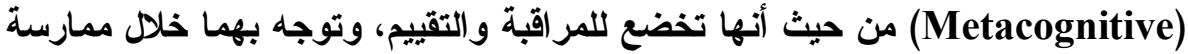

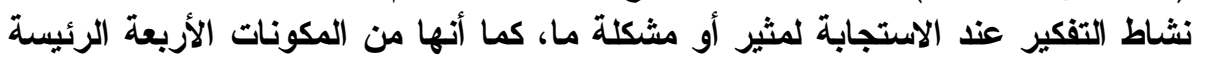

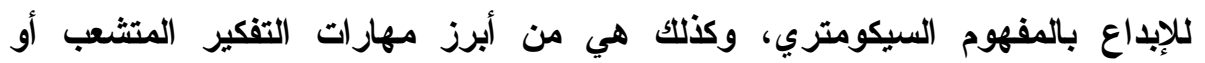

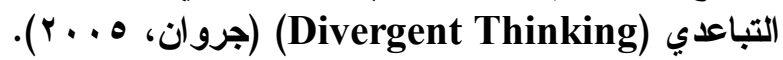




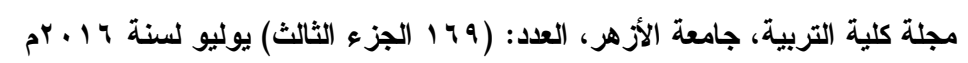

وكان إريكسون (Erikson) أول من استخدم مصطلح هوية الأنا (

الاقئ (Identity). (Kroger, 2004 الانتشار في لغة الحياة اليومية أكثر من مفهوم الهوية أو أزمة الهية الهوية (كوزن،

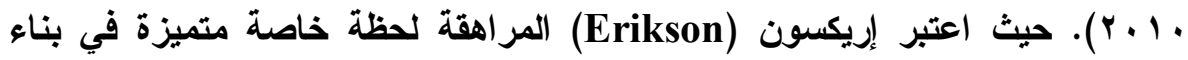

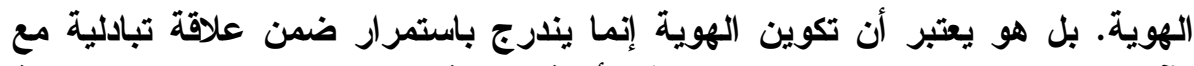

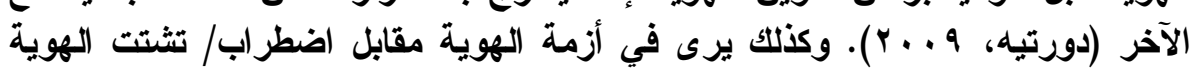
(Identity Vs. Identity Diffusion)

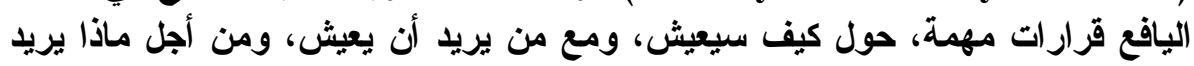

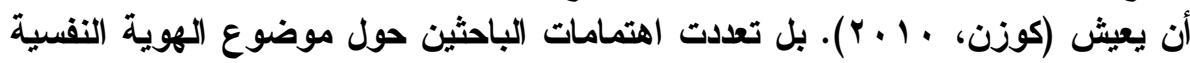

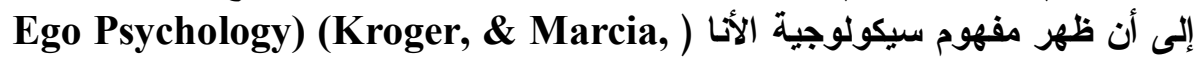
2011). ومن العوامل التي تؤثر في عمليات اكتساب الهوية الألاتية النفسية؛ العلاقة بين

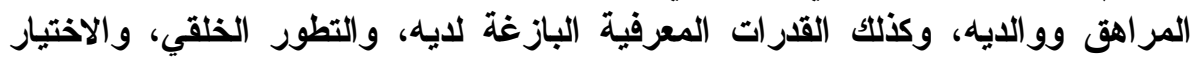

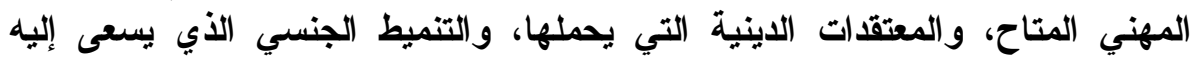

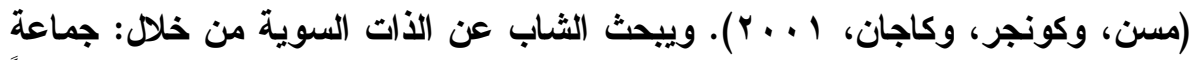

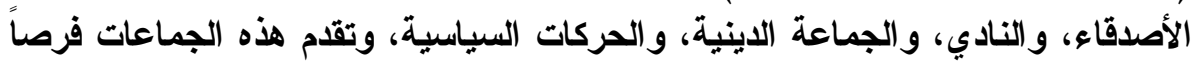

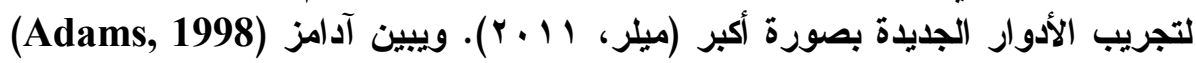

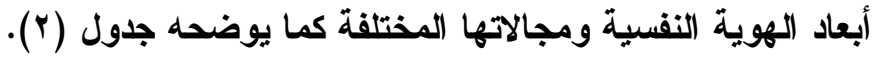

جدول (r)

\begin{tabular}{|c|c|c|}
\hline $\begin{array}{c}\text { مجالات الهوية النفسية } \\
\text { Psychological Identity ) } \\
\text { (Domains }\end{array}$ & $\begin{array}{c}\text { أبعاد الهوية (لنفسية } \\
\text { Psychological Identity ) } \\
\text { (Aspects }\end{array}$ & r \\
\hline $\begin{array}{l}\text { الاجتماعية/ العلاقات المتبادلة } \\
\text { (Interpersonal) }\end{array}$ & الأيديولوجية(Ideological) & 1 \\
\hline الصد(قة (Friendship) & المهني (Occupation) & $r$ \\
\hline 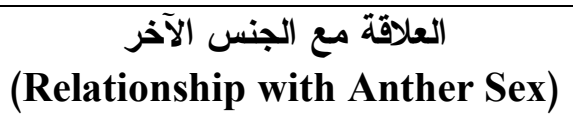 & الايني (Religion) & $r$ \\
\hline الأدوار الجنسية (Sex Roles) & السياسي (Politics) & $\varepsilon$ \\
\hline $\begin{array}{c}\text { الاستجمام/ الترفيه والترويت } \\
\text { (Recreation \& Leisure) }\end{array}$ & $\begin{array}{c}\text { فلسفة أسلوب الحياة } \\
\text { (Philosophical Life-Style) }\end{array}$ & 0 \\
\hline
\end{tabular}




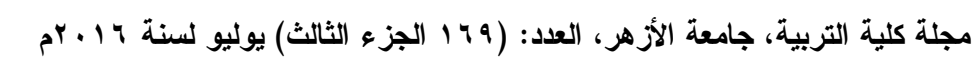

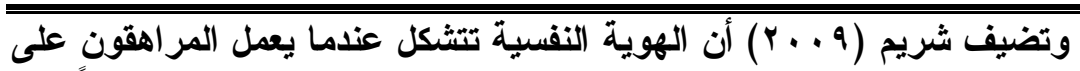

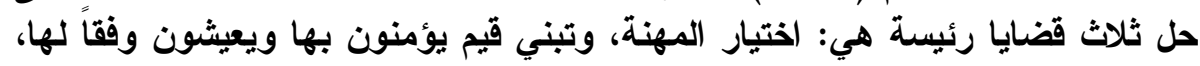

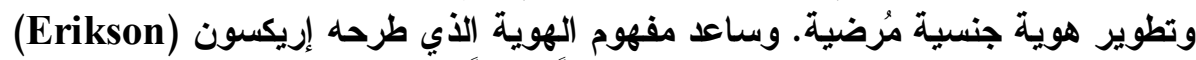

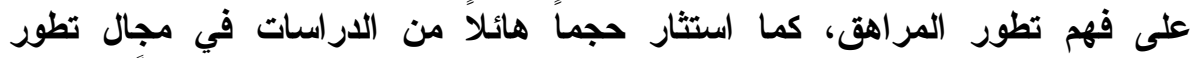

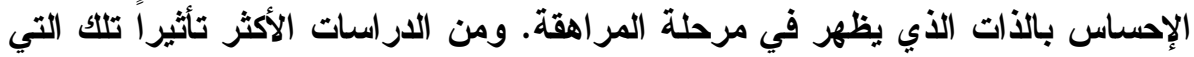

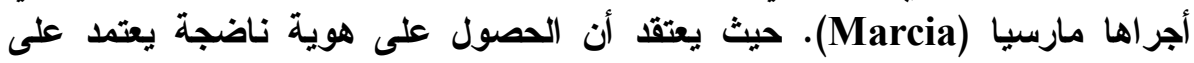

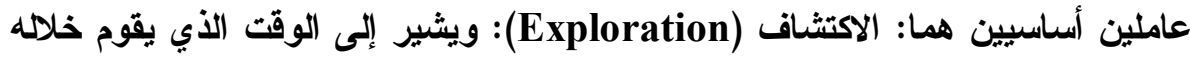

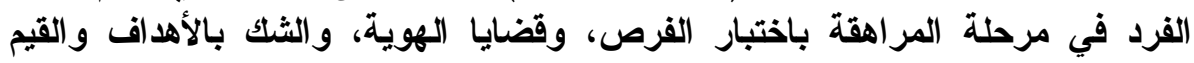

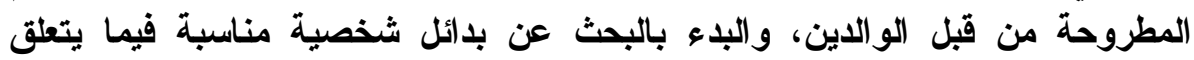

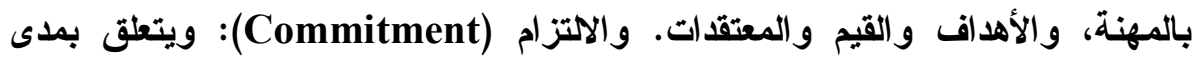

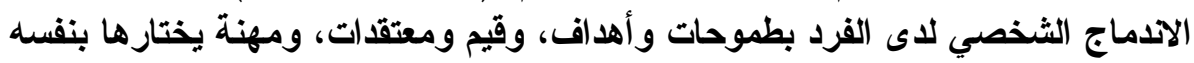

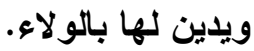

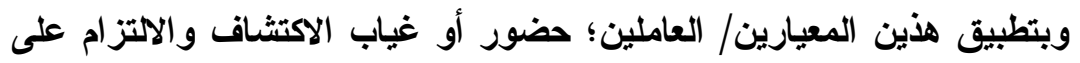

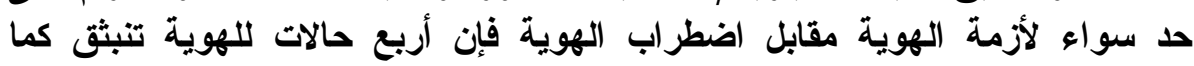

يوضحه جدول (r) (Bosma, \& Gelsb, 2005).

جدول (r)

الاكتشاف والالتز ام حسب نظرية مارسيا

\begin{tabular}{|c|c|c|}
\hline \multicolumn{2}{|c|}{ عوامل الهوية النفسية } & \multirow[t]{2}{*}{ حالات الهوية } \\
\hline الالتز ام & الاكتشاف & \\
\hline موجود & موجود & تحقيق الهوية \\
\hline غير موجود & موجود & تأجيل الهوية \\
\hline موجود & غير موجود & انغلاق الهوية \\
\hline غير موجود & غير موجود & اضطر اب الهوية \\
\hline
\end{tabular}

- الهوية المحققة/ المنجزة (Identity Achievement):

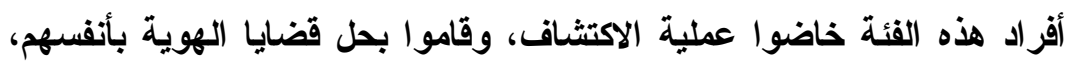

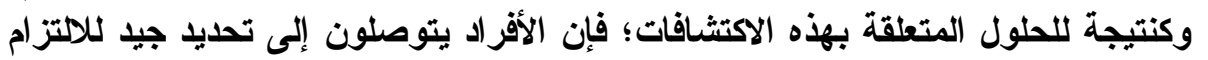

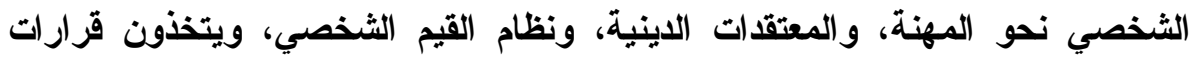

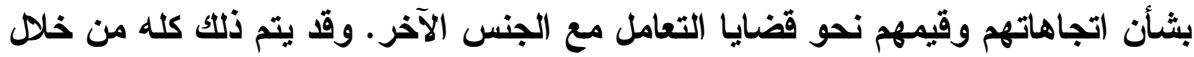

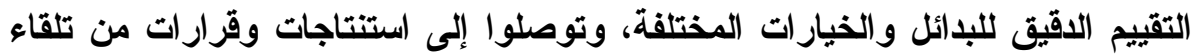




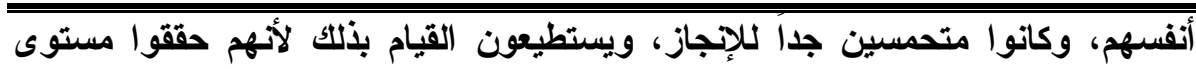

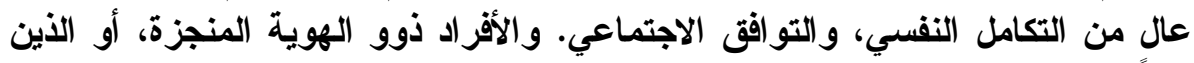

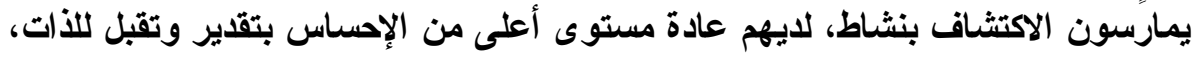

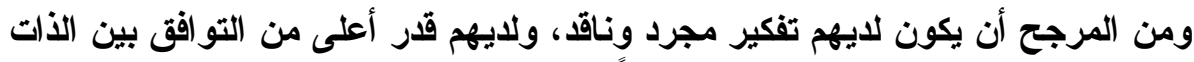

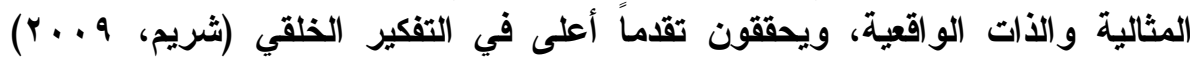

.(Marcia, 1980)

\section{- الهوية المؤجلة/ المعلقة (Identity Moratorium):}

هي حالة حادة من الاكتشاف، ويبحث أفراد هذه الفئة عن قيم ليتبنوها في

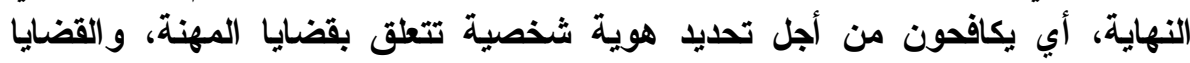

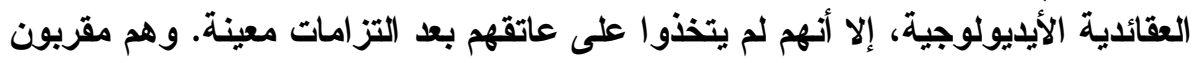

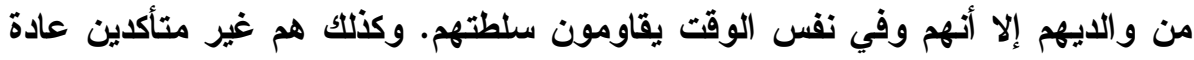

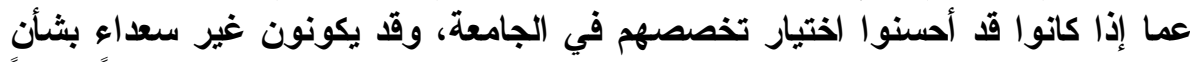

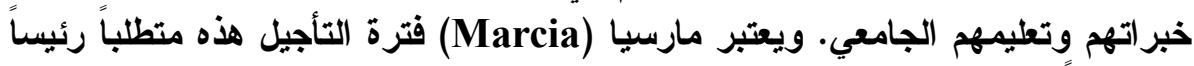

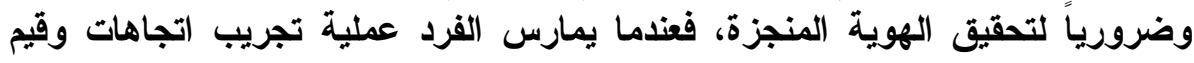

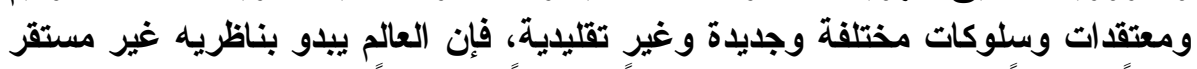

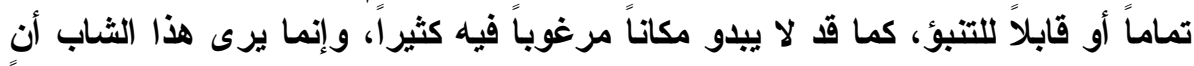

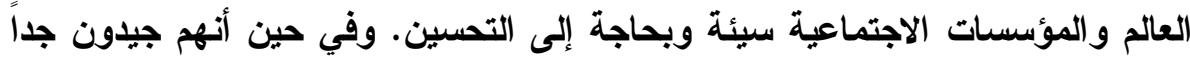

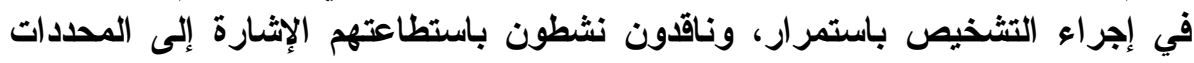

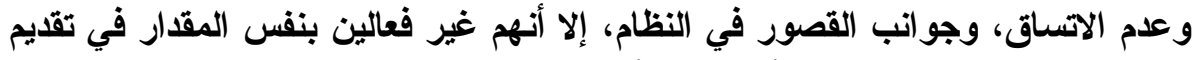

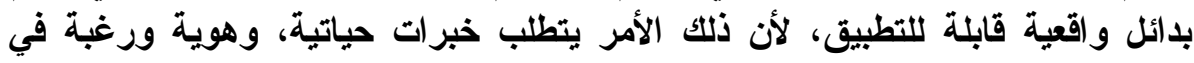

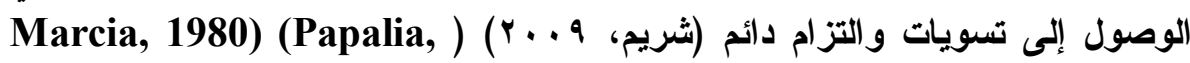

.(Olds, \& Feldman, 2001

- الهوية المنظقة/ المكبلة (Identity Foreclosure):

وتتضمن الأفراد الذين لم يمروا بخبرة الاكتشاف، إلا أنهم اتخذوا لألفسهر

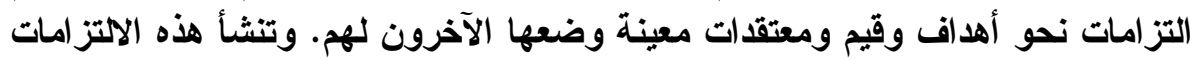

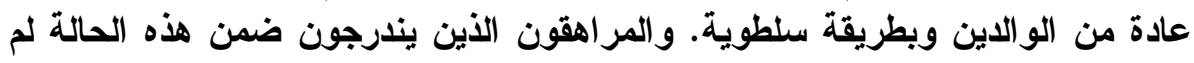

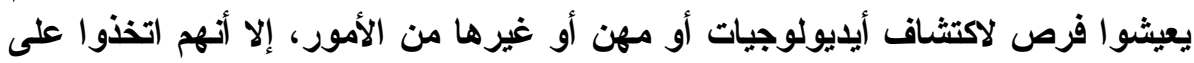

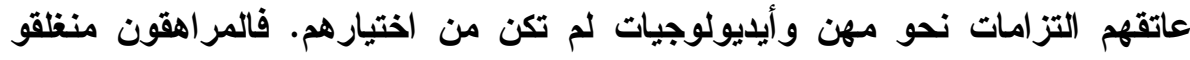

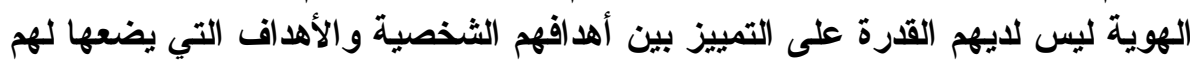

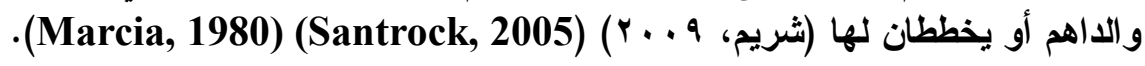




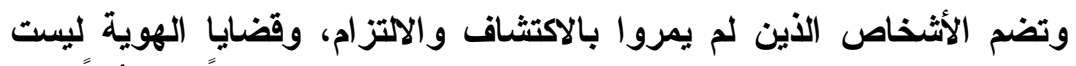

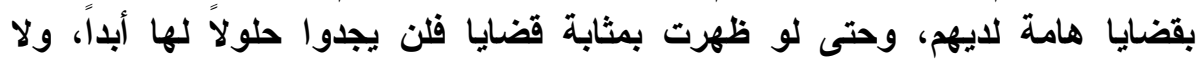

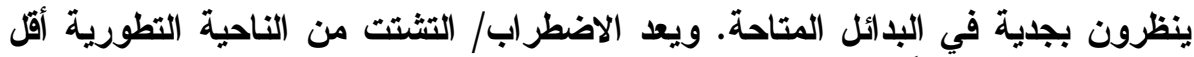

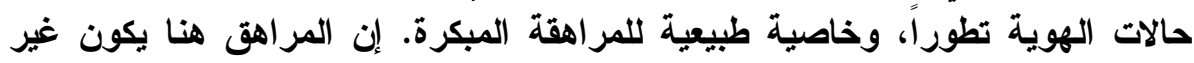

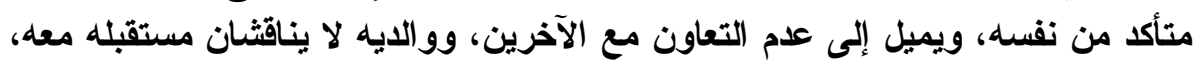

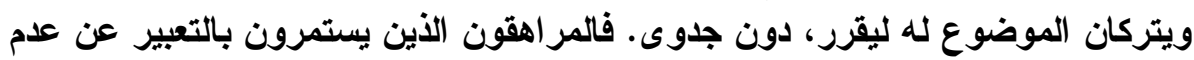

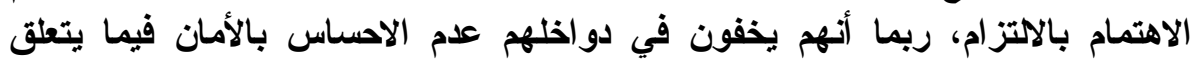

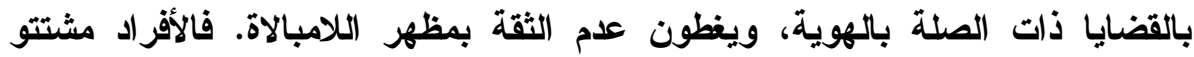

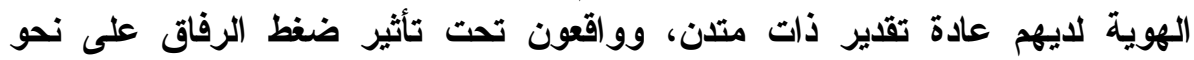

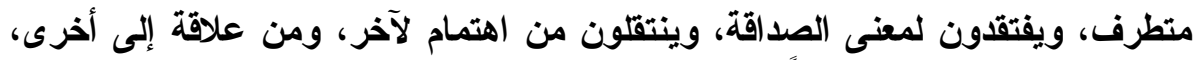

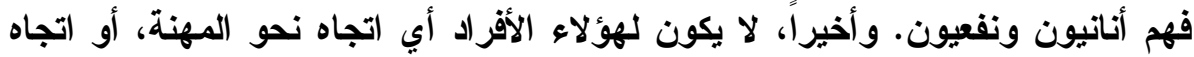

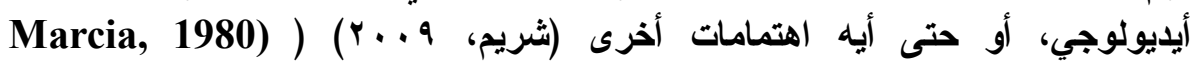
.((Papalia, Olds, \& Feldman, 2001

يمكن النظر إلى حالات الهوية في تسلسل تطوري، ولكن لا تثكل أية حالة الهالة

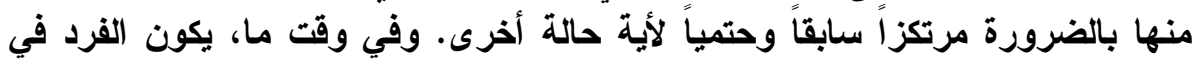

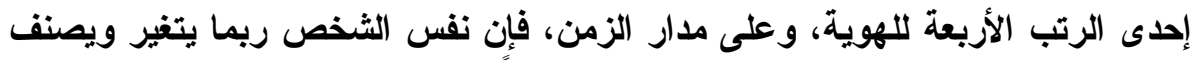

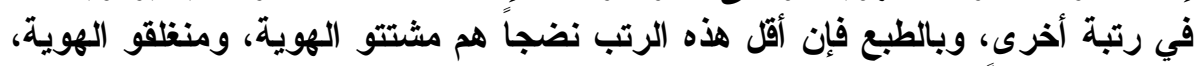

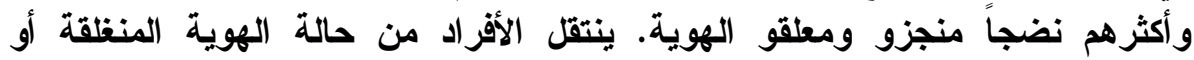

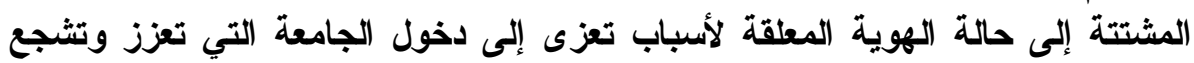

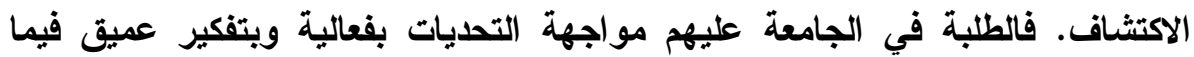

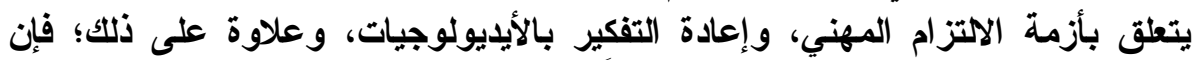

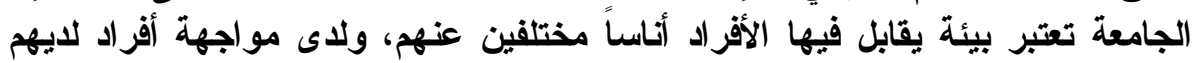

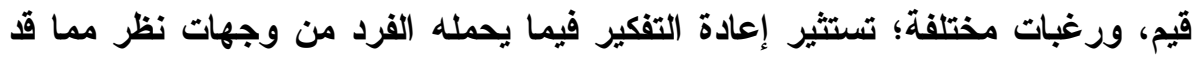

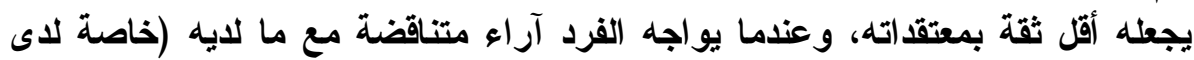

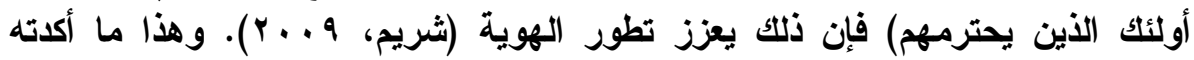

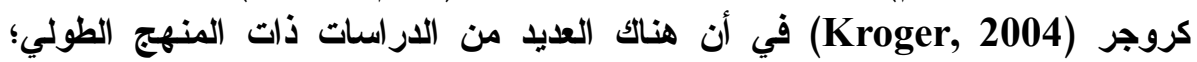

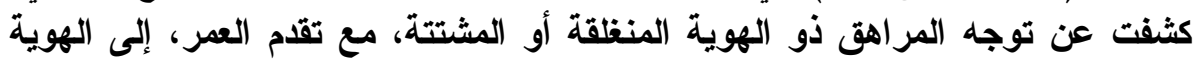
المعلقة/ المؤجلة أو المحققة.

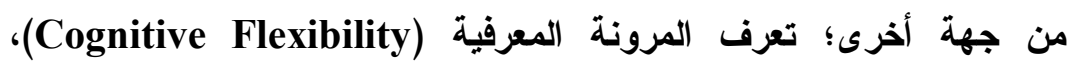
بالمعنى العام، بأنها القدرة على التغيير السريع والسهل للموفئ العف العقلية أو السلوكية، وفقاً للمقتيات الجديدة المتغيرة، وهي على نقيض الصفير الصلابة والجمود (روشكا، 
مجلة كلية التربية، جامعة الأزهر، العدد: (199 الجزء الثالث) يوليو لسنة 19 بـام

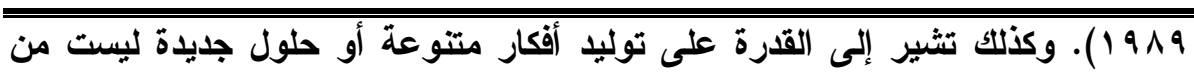
نوع الأفكار والحلول الروتينية، وهي كذلك تعمل على توجيه مسار التفكير أو تحويله

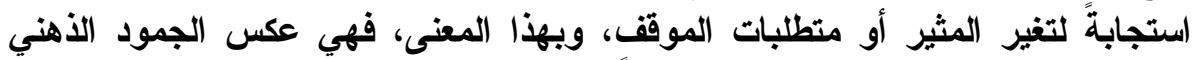

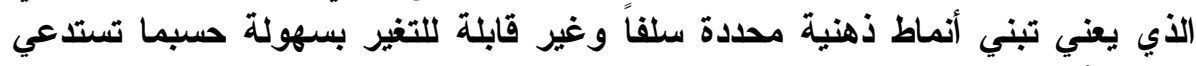

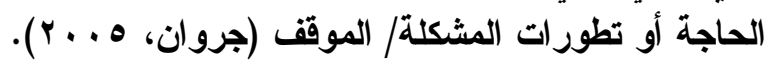

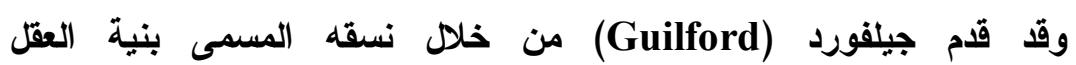

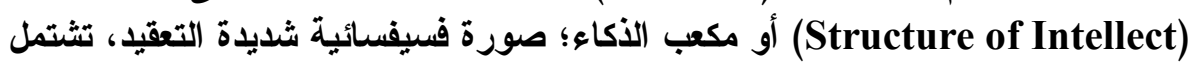

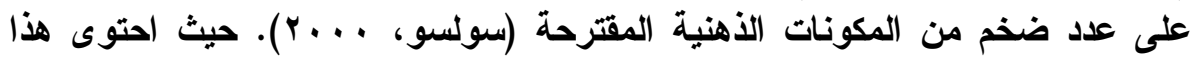

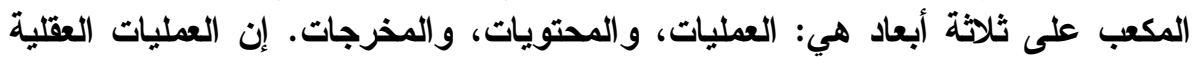

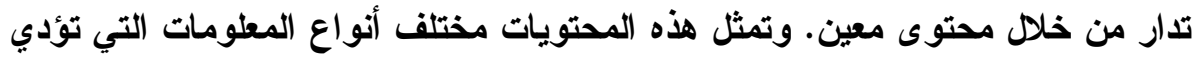
إلى إنتاج ما. وفيما يلي توضيح لهذئ دئه الأبعاد الثلاثة:

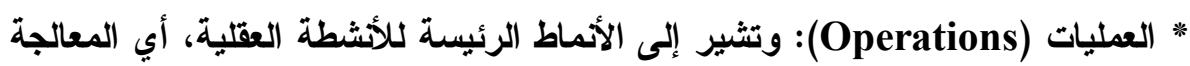

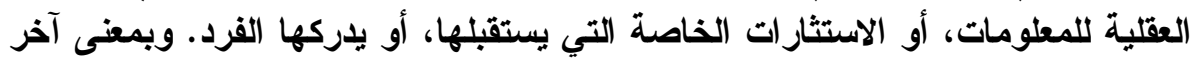

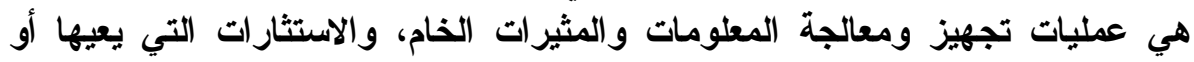

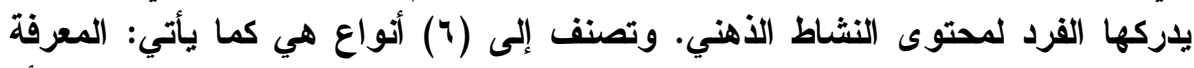

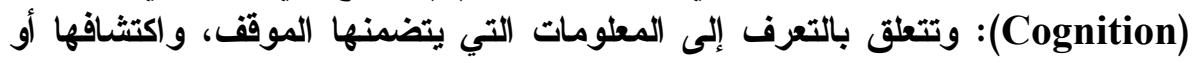

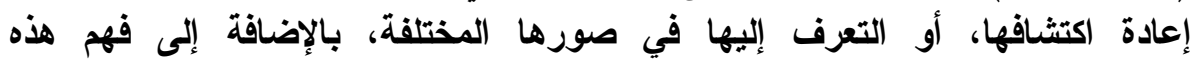

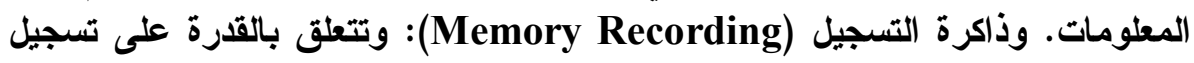

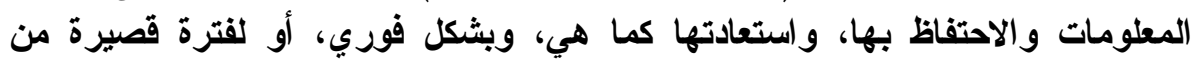

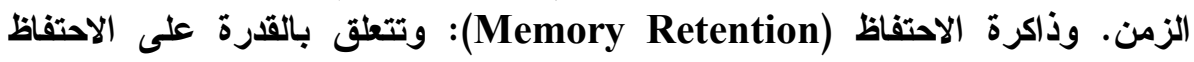

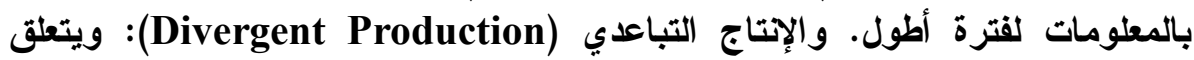

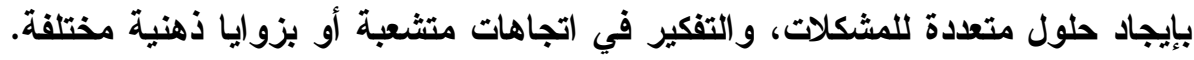

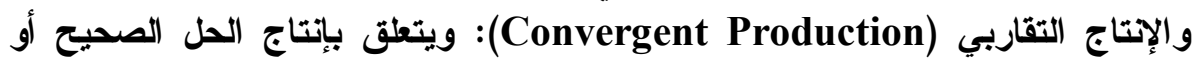

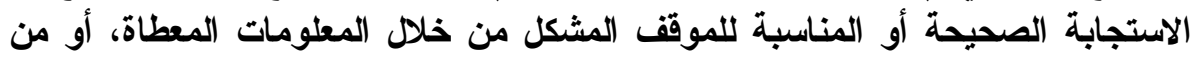

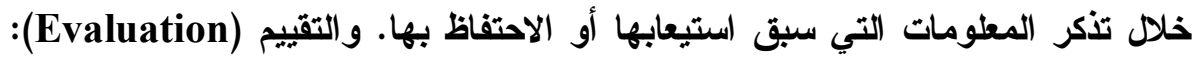

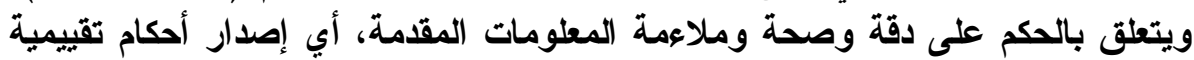

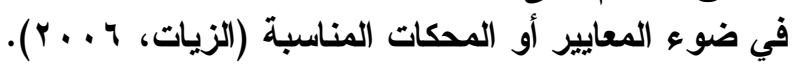

* المحتويات (Contents): ويقصد بها فئات أو أنماط المعلومات التي تخضع للمعالجة

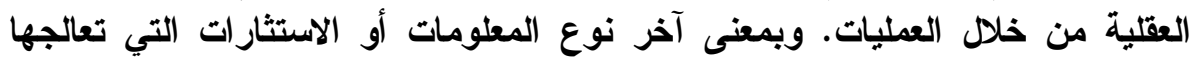

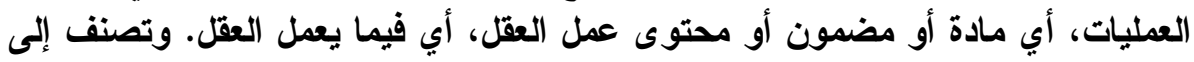

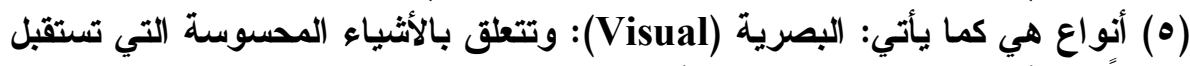

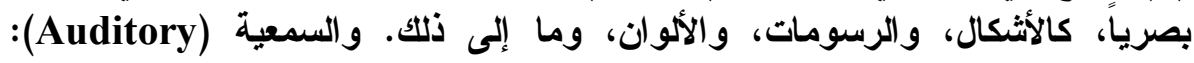




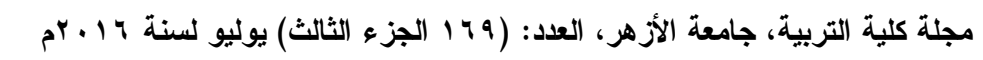

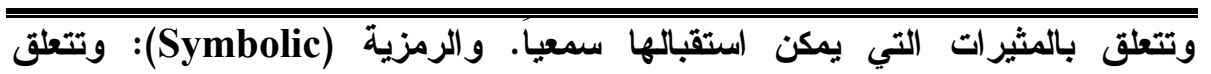

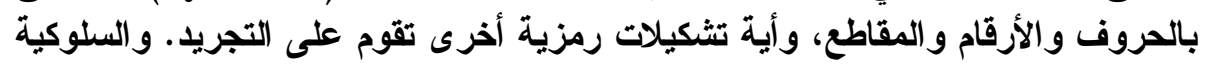

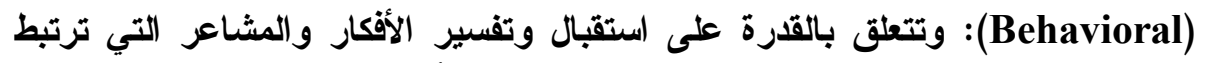

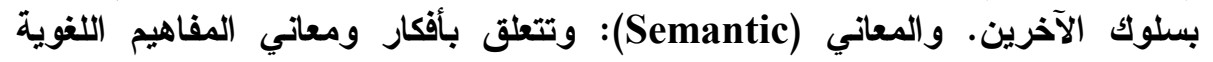

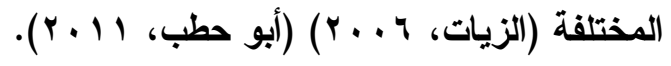

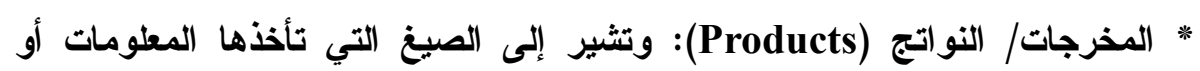

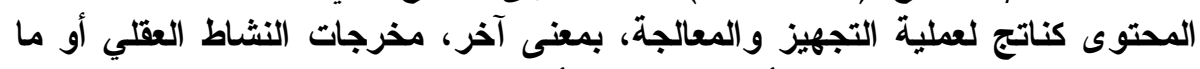

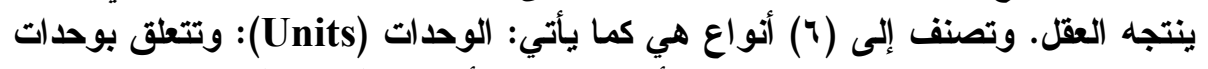

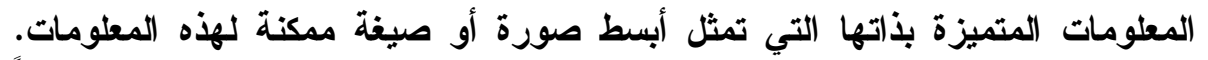

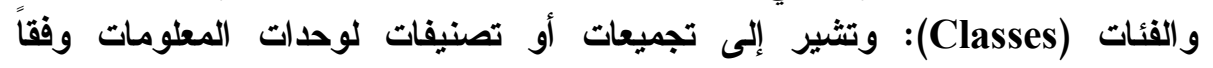

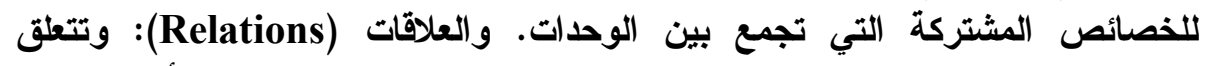

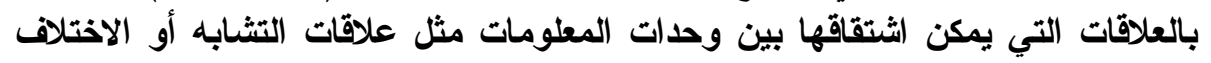

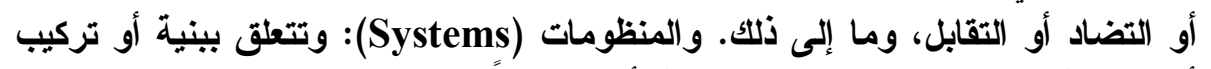

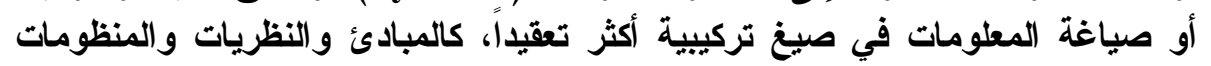

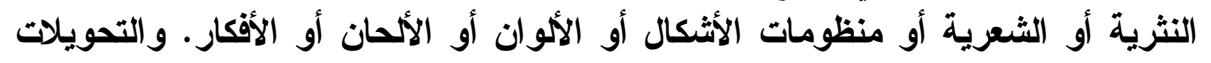
جايدة، (Transformations)

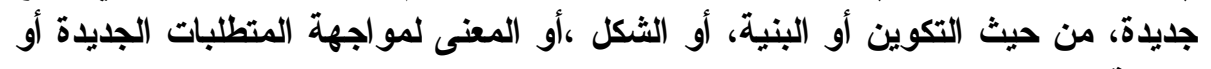

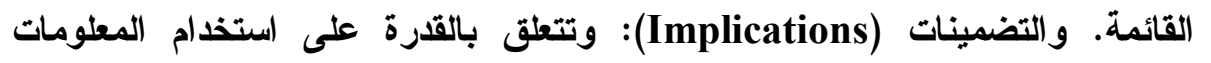

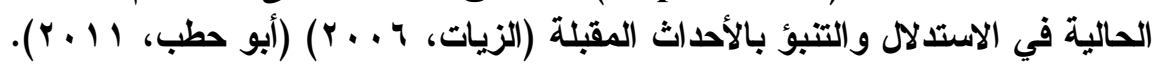

وحسب مكب القدرات العقلية الذي وضعه جيلفورد (Guilford) المشار إليه

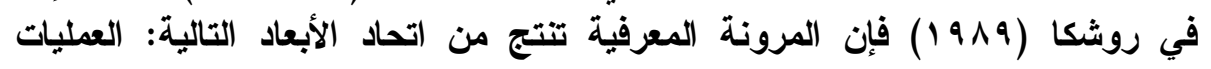

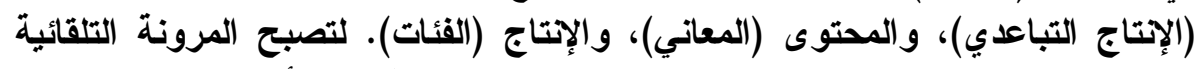

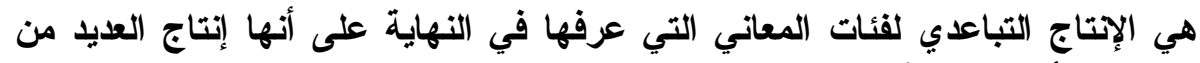

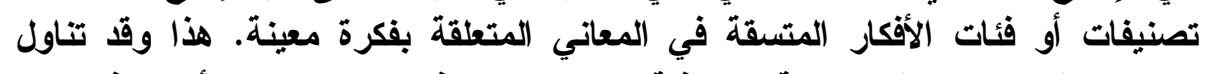

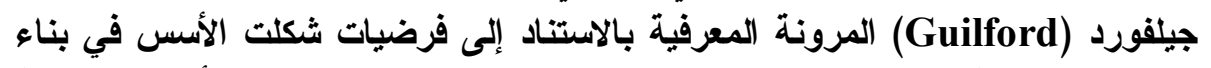

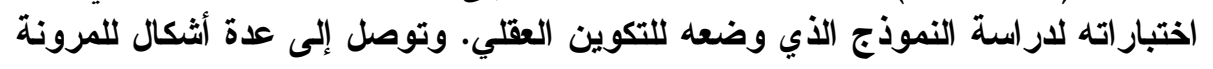

من بينها:

- المرونة التكيفية (Adaptive Flexibility): وهي القدرة على التكيف مع تغير

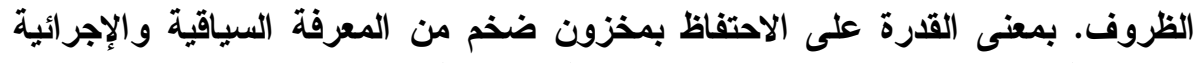

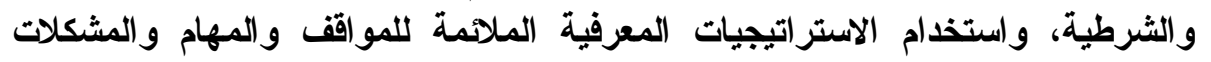

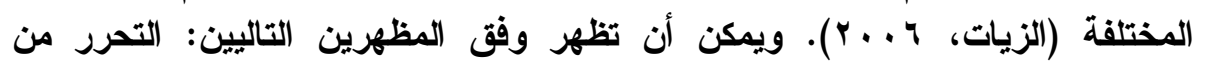




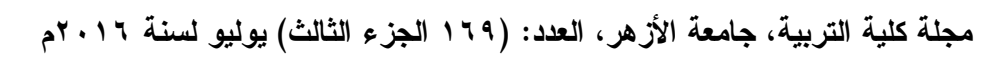

الجمود: ويشير إلى قدرة الفرد على تحويل اتجاه التفكير. وإعادة تفسير المعلومات:

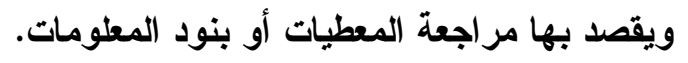

- المرونة التلقائية (Spontaneous Flexibility): وتعني العفوية في تغيير (الحالة الذهنية للفرد للقيام بعمل شيء بطريقة مختلفة (جروان، ه . . ب).

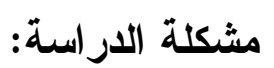

لا غنى عن مرونة التفكير في التكيف مع المستجدات والمعلومات الجديدة التي

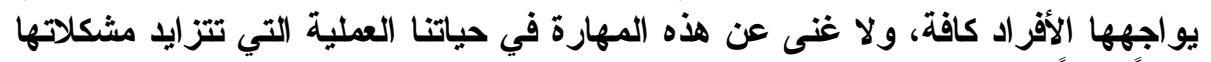

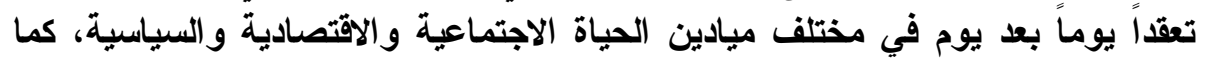

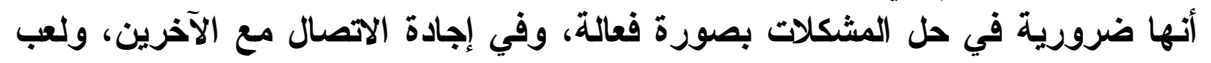

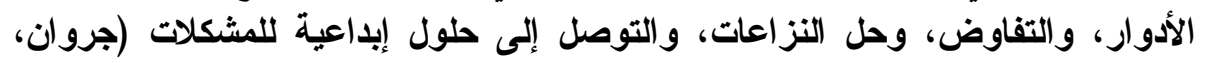

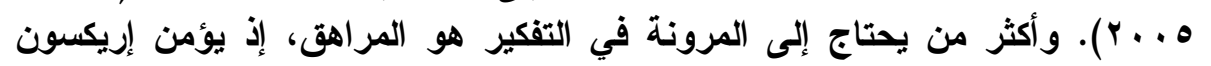

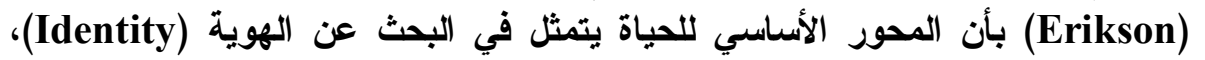

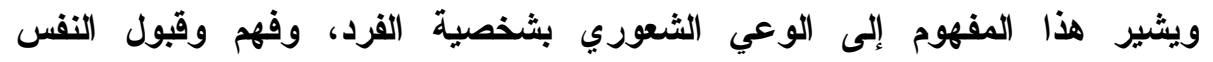

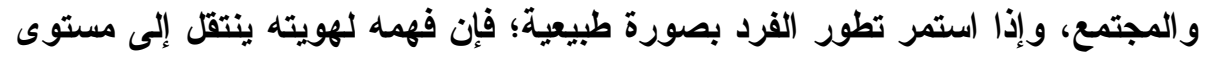

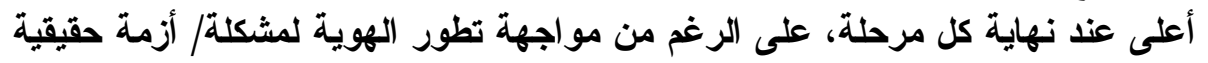

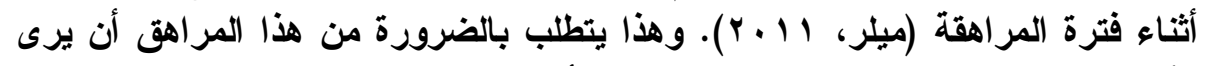

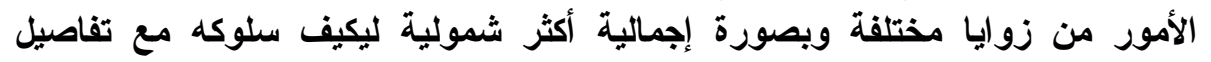

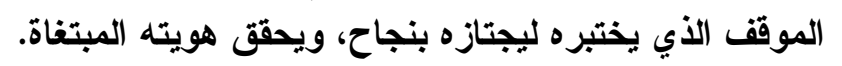

من هنا تتحدد مشكلة الاراسة بتقصي العلاقة بين حالات الهوية النفسية

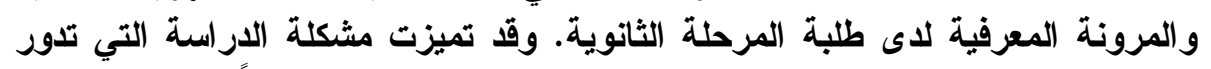
حول مفهوم المرونة المعرفية في جدة هذا المفهوم - على الأقل عربياً - وكذلك ربطة ربطه

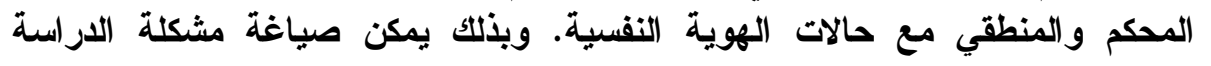

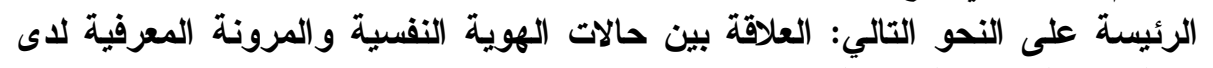
طلبة مرحلة الثانوية العامة.

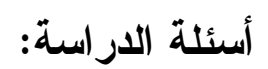

ا. ما حالات الهوية النفسية (التحقيق - التعليق - الانغلاق - التشتت) تبعاً لبعديها

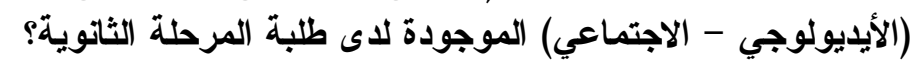
r. ما مستوى المرونة المعرفية ببعديها (التكيفية - التلقائية) لاى طلبة المرحلة الثانوية؛ 


\section{مجلة كلية التربية، جامعة الأزهر ، العلد: (19 17 الجزء الثالث) يوليو لسنة 17 ـ بام}

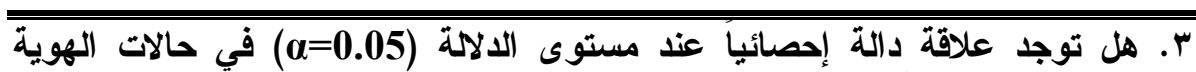

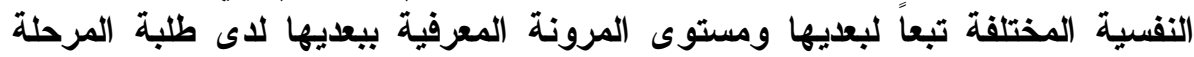

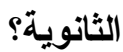

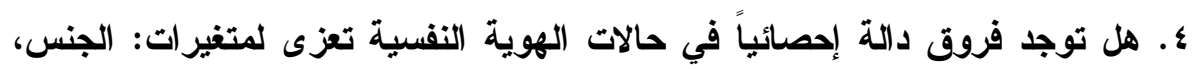

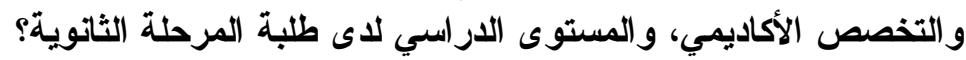

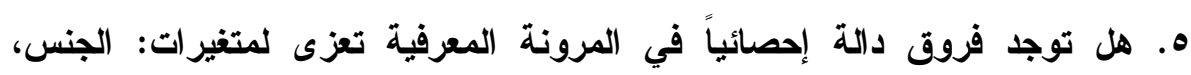

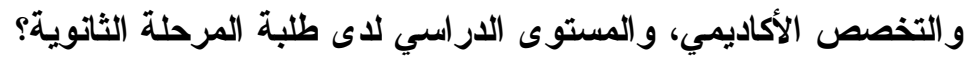

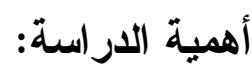

ربما تكون هذه الدراسة - حسب علم الباحث - من الاراسات القليلة التي

تقوم بالكثف عن العلاقة بين حالات الهوية النفسية والمرونة المبادة المعرفية. وتثمثل أهمية

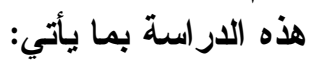

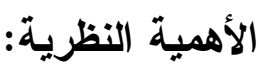

- يعد تكوين الإحساس بالهوية من المهمات التي على المراهق أن يحسمها لكي يواجه

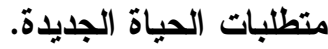

- بعد الرجوع إلى ما تيسر من الأدب التربوي والدراسات التي أجريت في مجال

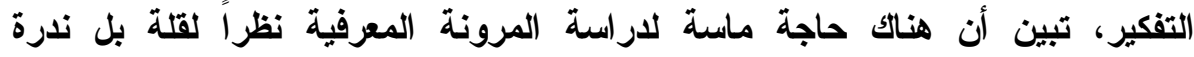

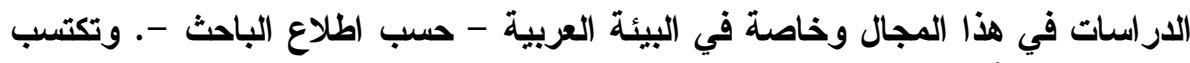

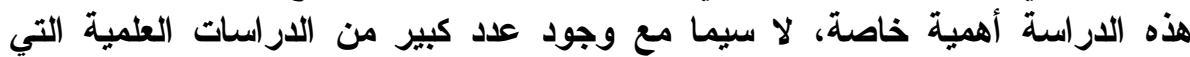

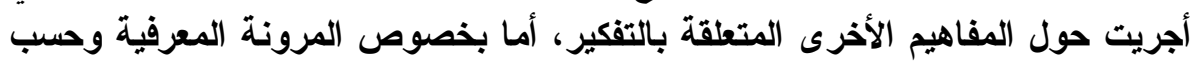

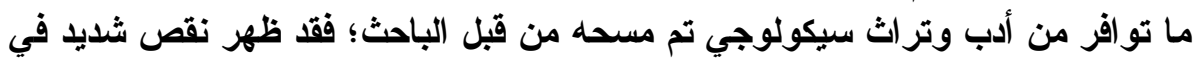

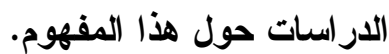

- تجيء هذه الار اسة لتضيف إلى المعرفة العلمية المتحصلة حول مفهوم التفكير عامة،

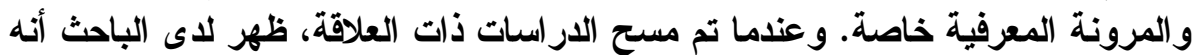
لا يوجد سوى بضع دراسات باللغة العربية تناولت مفهوم المرونة المعرفية.

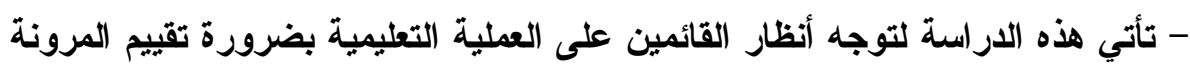
المعرفية لاى الطلبة، وضرورة الربط العملي بين هذا المكون المعرفي والنشاطات المنهجية و اللامنهجية المقدمة للطالب. 


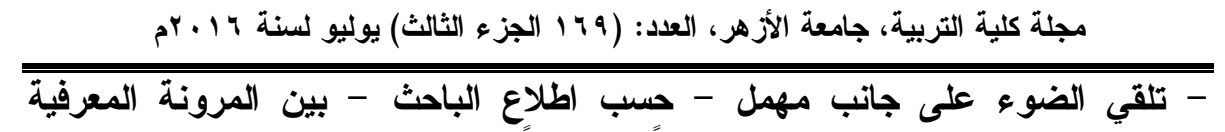

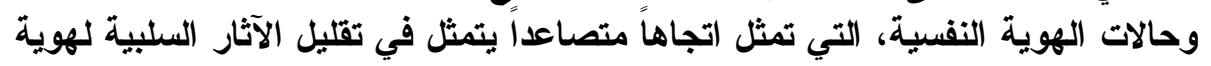

الأنا المضطربة عند المرات الهق.

- وبعكس الدراسات المحدودة التي أجريت حول مفهوم المرونة المعرفية؛ تبين وجود

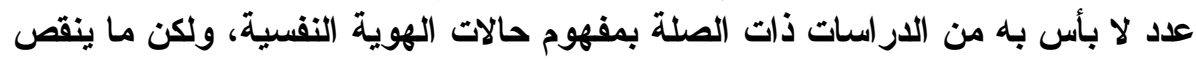

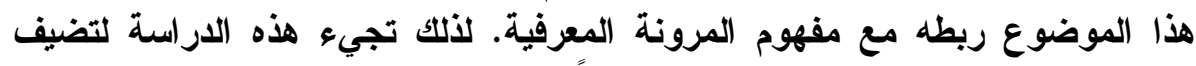

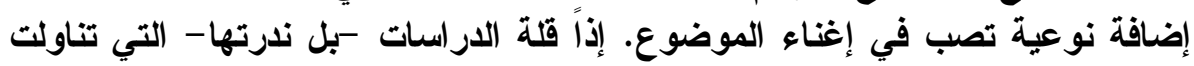

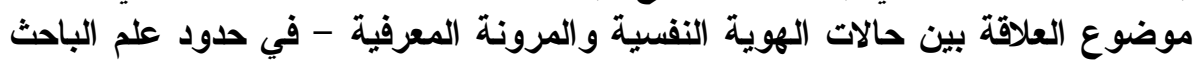

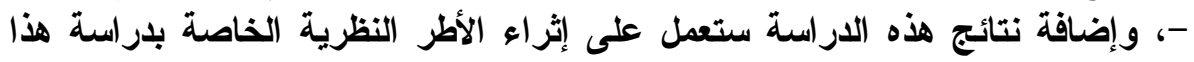

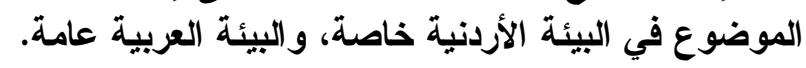

الأهمبة التطبيقية:

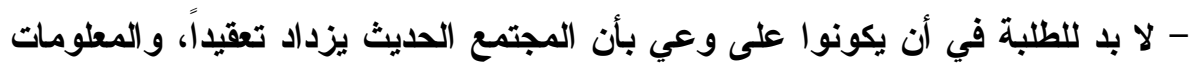

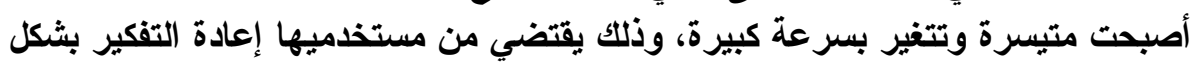

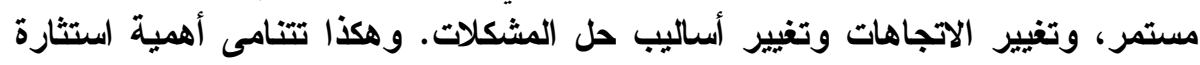

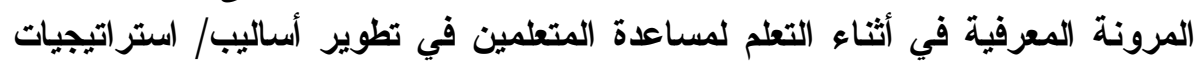
لتطبيق معرفة جديدة في المواقف الصعبة في نشاطاتهم اليومية. - التركيز على المرونة المعرفية؛ إذ يعمل على مساعدة الطلبة وتنمية قدراتهم المعرفية الأخرى للتعامل مع مستجدات الحياة المتغيرة.

- تقديم معلومات مهمة لصانع القرار التربوي حول حقيقة المخرجات التربوية بثكل عام.

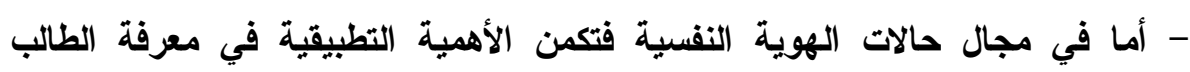

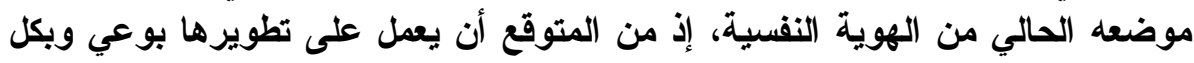
ما يساهم في إنضاج هذه الهوية الهوية النغية.

- وكذلك استفادة الباحثين في مجال علم النفس التربوي من نتائج الاراسة الحالية وتوصياتها في إجراء در اسات أخرى ذاتئن مجات صلة. 
الاراسات المتعلقة بحالات الهوية النفسية:

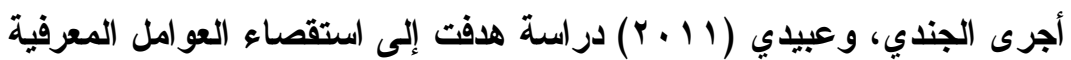

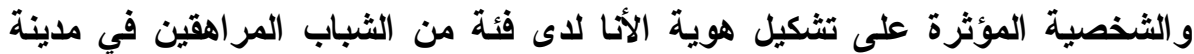

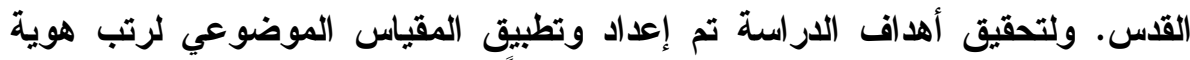

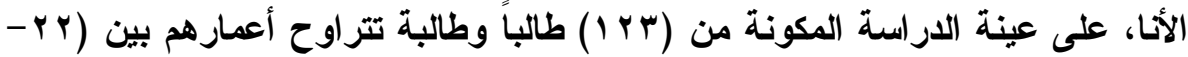

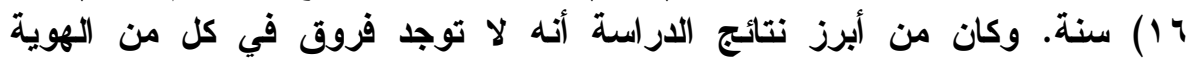

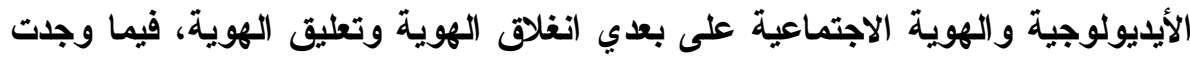

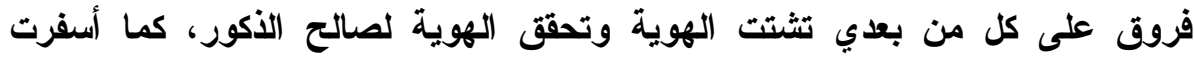

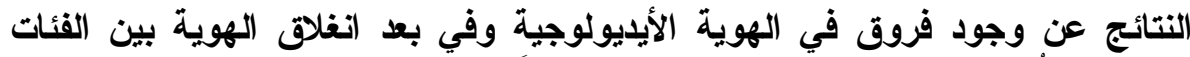
الأصغر سنا و الفئات الأكبر لصالح في الفئة الأكبر سناً.

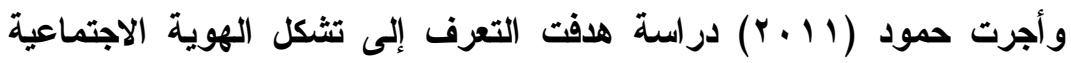

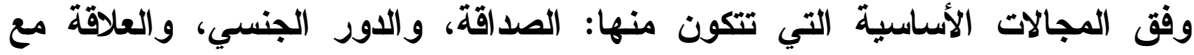

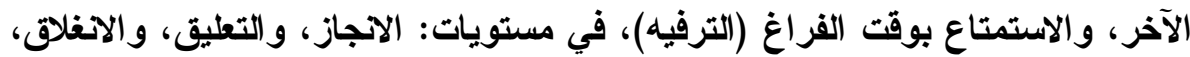

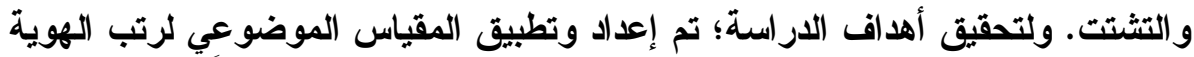

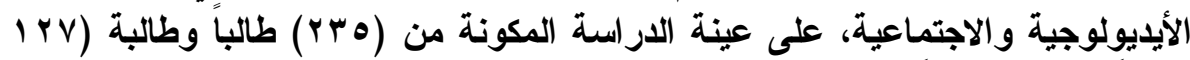

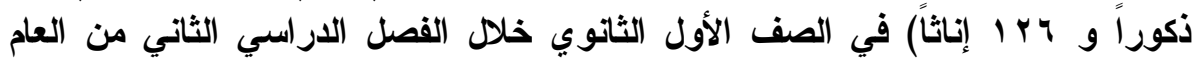

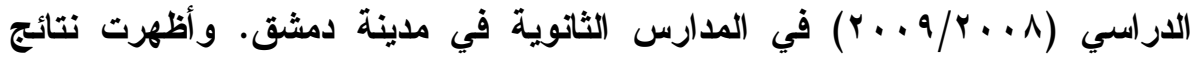

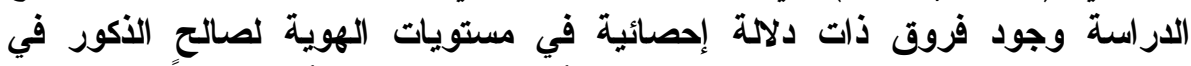

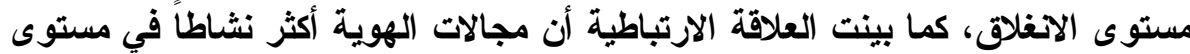

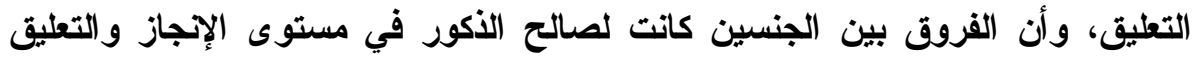

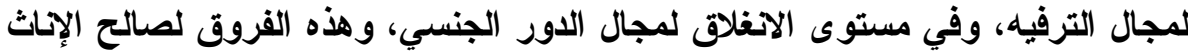
في مستوى الانغلاق لمجال العلاقة مع الآخر.

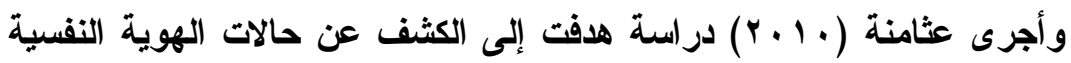

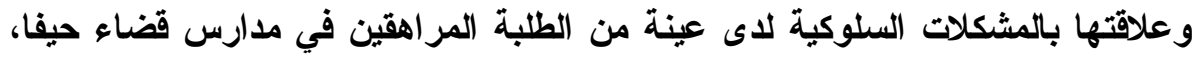

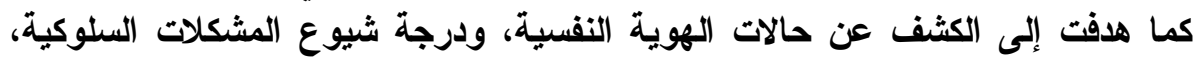

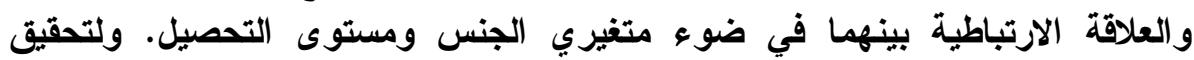

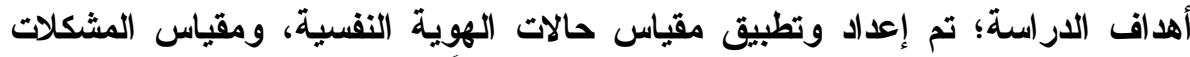

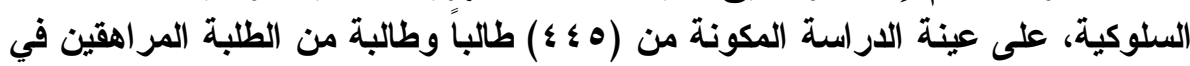

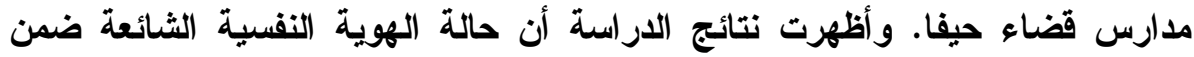
البعد الاجتماعي والبعد الأيديولوجي هي تحقيق الهوية النفسية حيث جاعت في المرتبة 


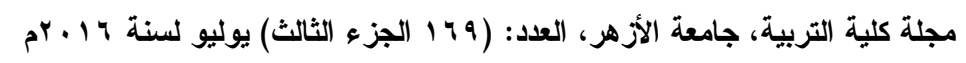

الأولى، بينما جاءت حالة اضطراب الهوية النفسية في المرتبة الأخيرة، كما أظهرت

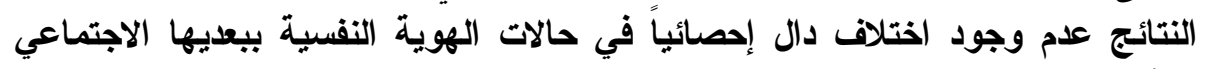

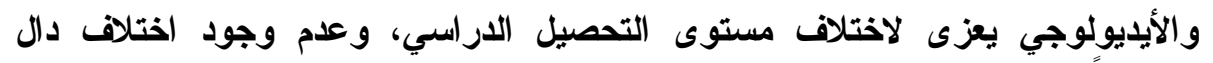

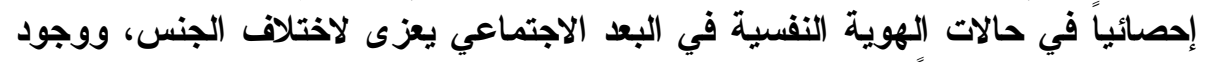

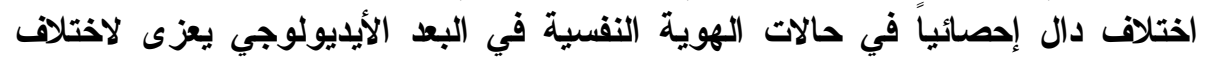

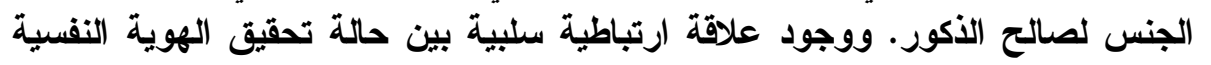

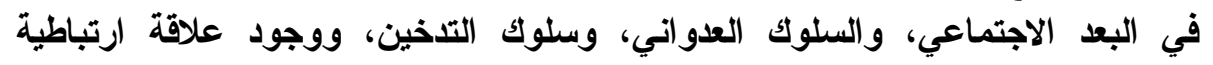

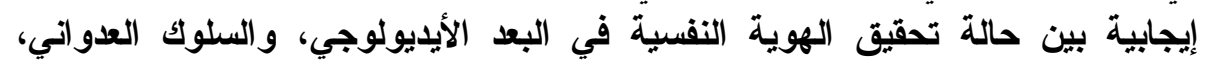

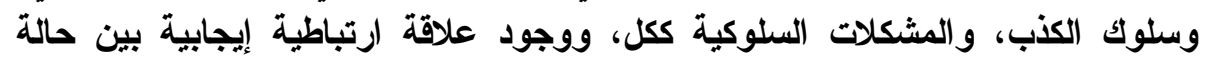

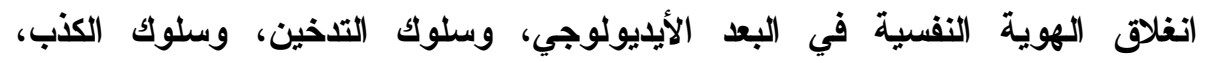

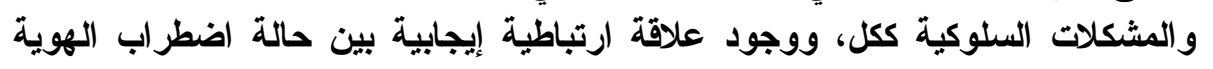

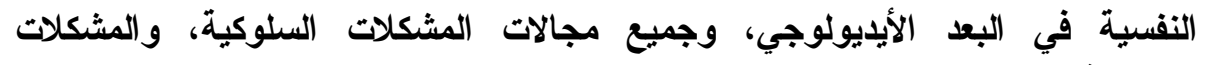
السلوكية ككل.

وقام نجيس، وجونسون (Njus, \& Johnson, 2008) بدراسة هدفت إلى (إلى

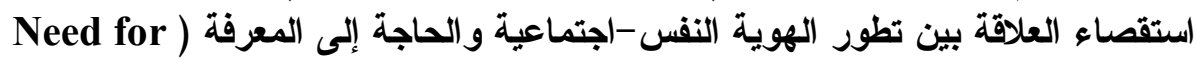
Cognition (NFC

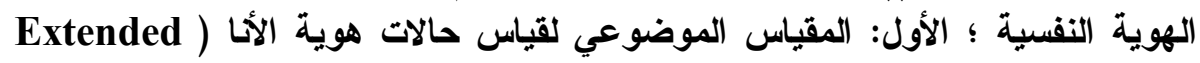
(Objective Measure of Ego Identity Status (EOMEIS

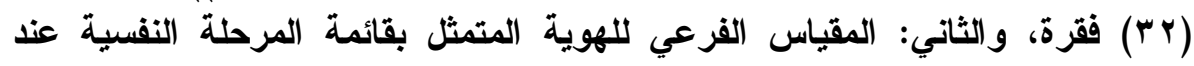

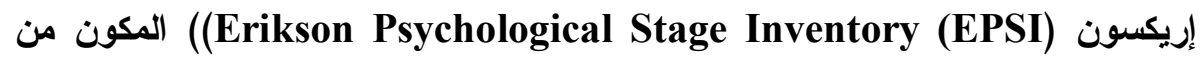

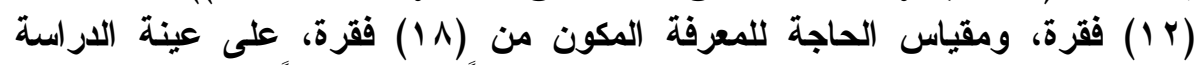

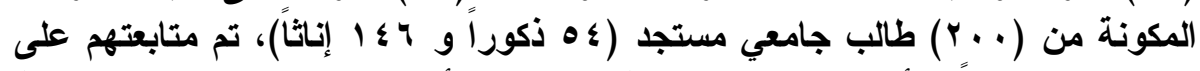

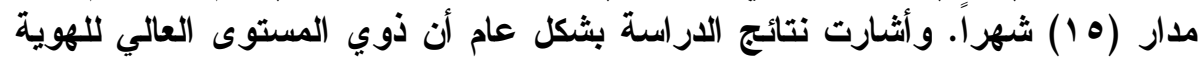

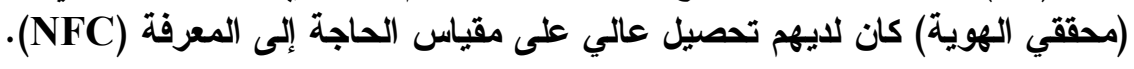

وأجرت باساك، وغوش (Basak, \& Ghosh, 2008) دراسة هدفت إلى لأل بحث العلاقة بين حالات هوية الأنا، وتقدير الذات الدات لاى عينة من الطلبة الجامعيين في

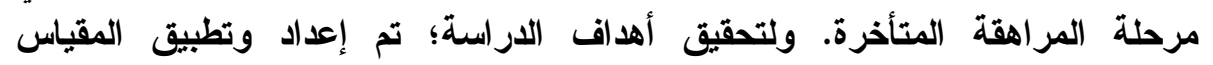
Extended Objective Measure of Ego ( الموضوعي لقياس حالات هوية الأنا (Identity Status (EOMEIS

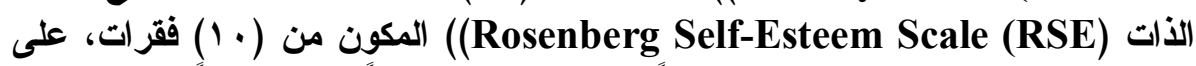

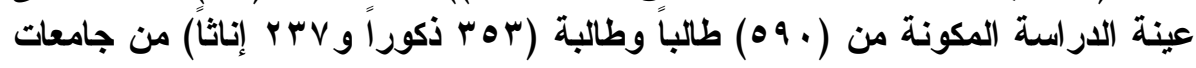

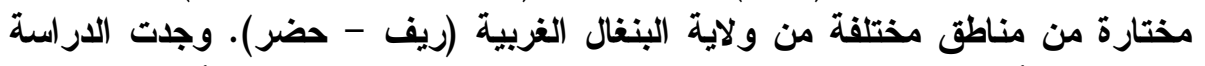

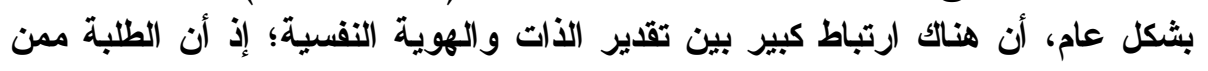




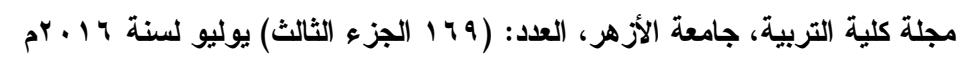

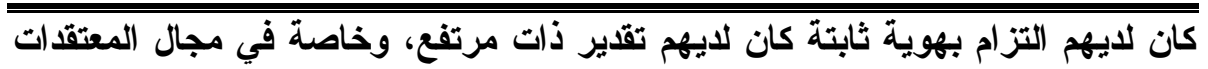

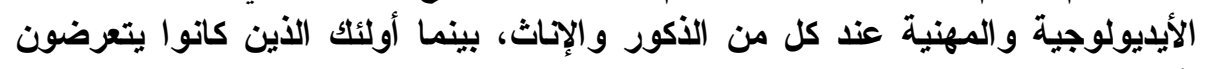

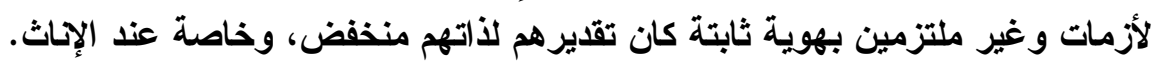

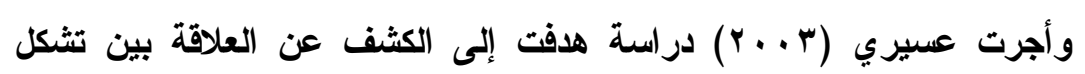

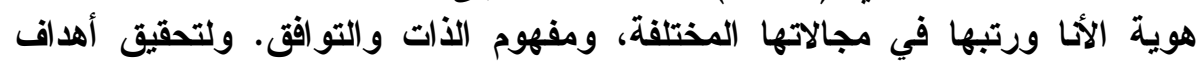

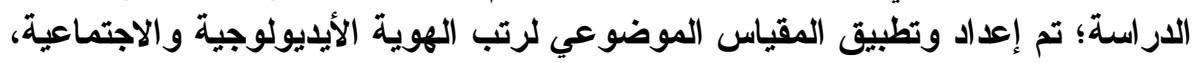

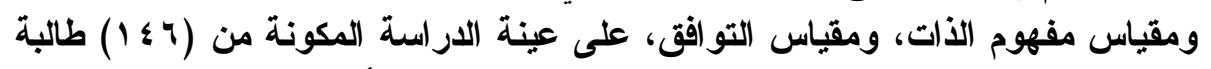

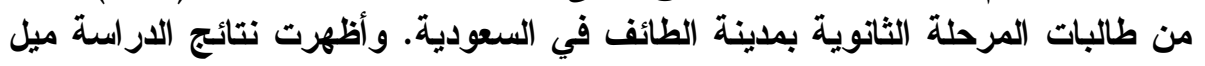

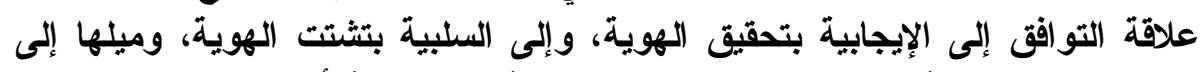

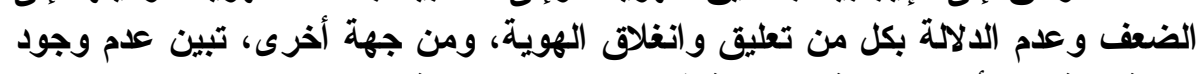

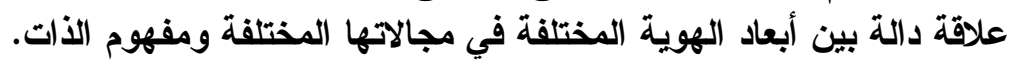

وأجرت آدامز (Adams, 2003) دراسة هدفت إلى معرفة العلاقة بين الهوية

والألفة كعوامل تنبؤية للتكيف السلوكي في مرحلة المراهقة. ولتحقيق أهداف الف الدراسة؛

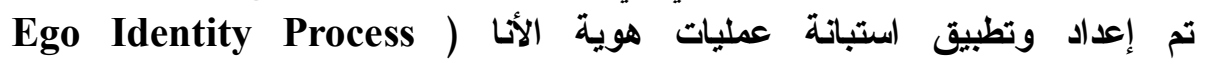
Erikson (Questionnaire (EIPQ Intimacy (Psychological Stage Inventory (EPSI (Assessment Scale (IAS

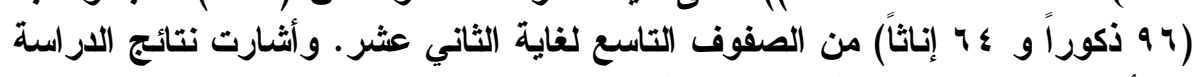

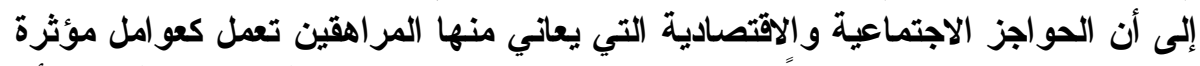

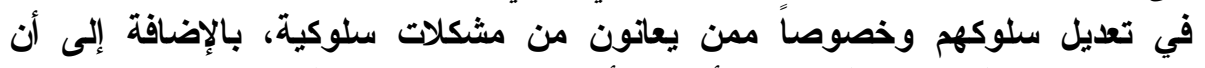

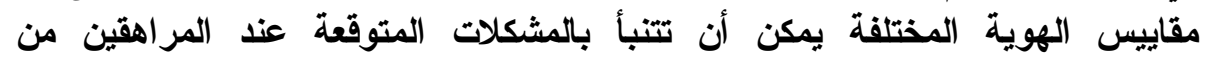
الجنسين،؛ كل حسب حالة الهوية التي يتموضع فيها.

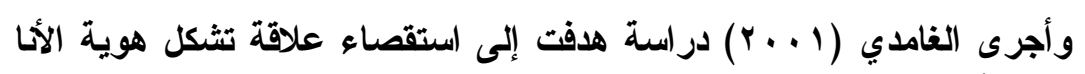

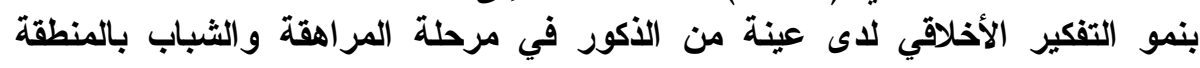

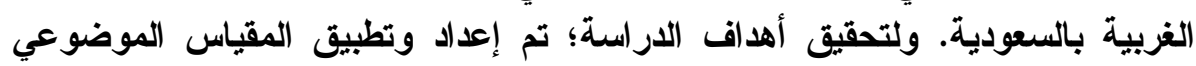

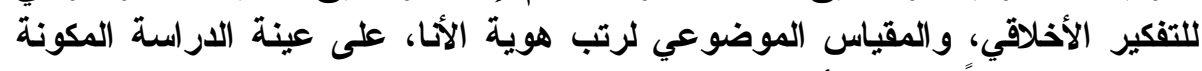

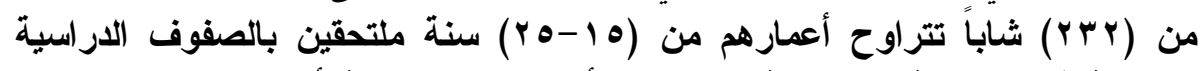

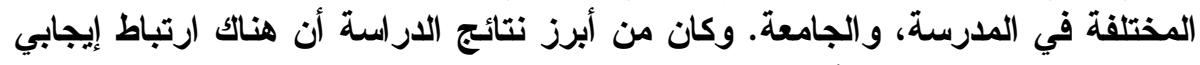

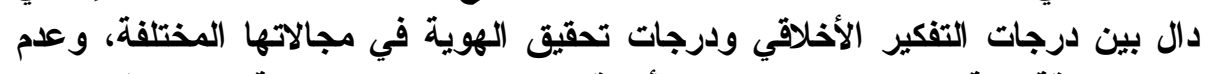

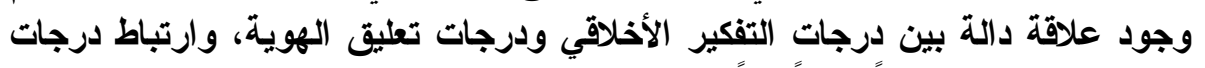
التفكير الأخلاقي ارتباطاً سلبياً دالاً بدرجات انغلاق دالير ودتثتت الهوية في مجالاتها المختلفة. 
مجلة كلية التربية، جامعة الأزهر ، العدد: (19 17 الجزء الثالث) يوليو لسنة 17 ـrم

وأجرى سلوجوزسكي، ومارسيا، وكويمان (

(Koopman, 1984

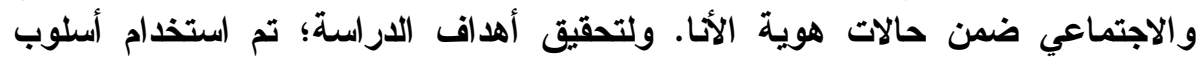

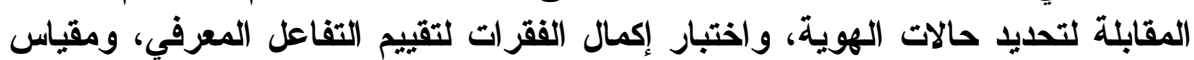

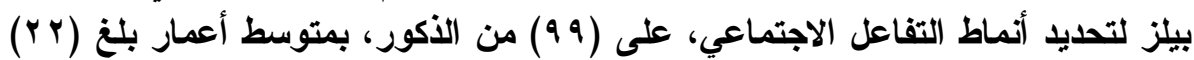

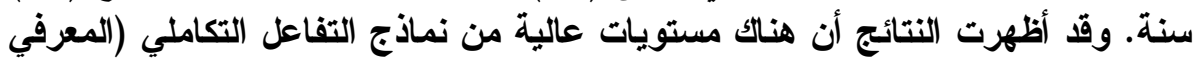

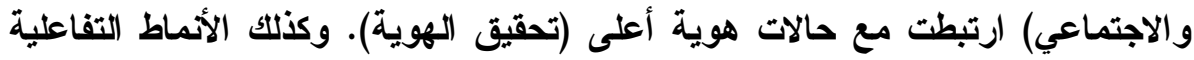

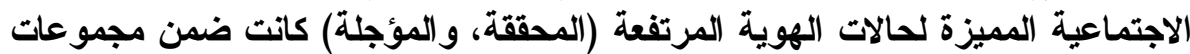

متعاونة ومسهيلة. وأظهرت بعض الاعت حالات الهوية المغلقة نماذج للاستجابة العابة العدوانية.

الار اسات المتعلقة بالمرونة المعرفية:

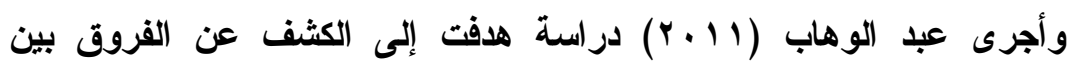

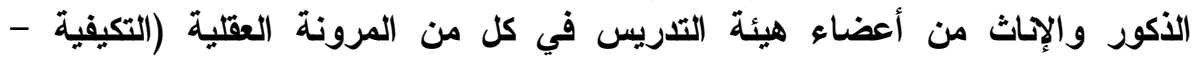

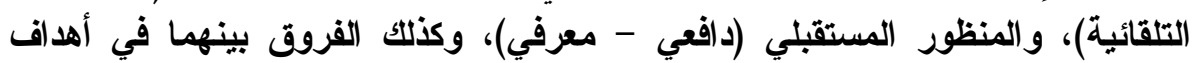

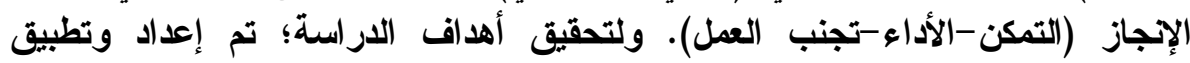

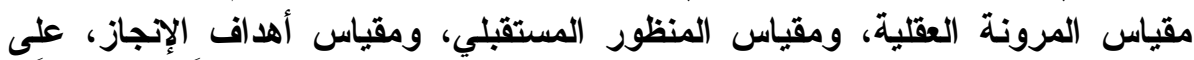

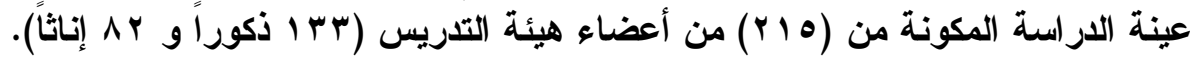

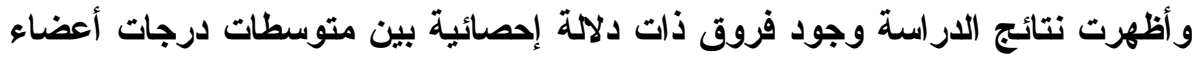

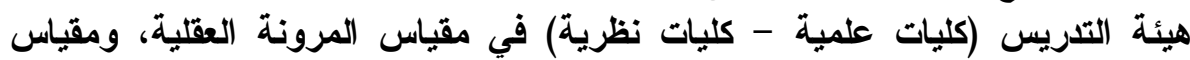

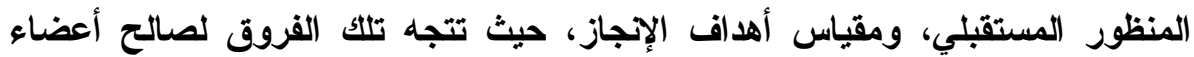

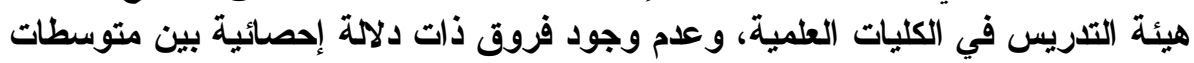

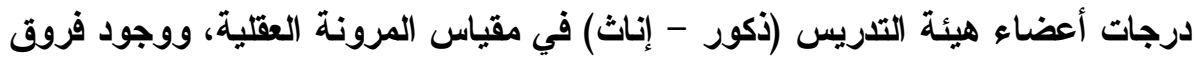

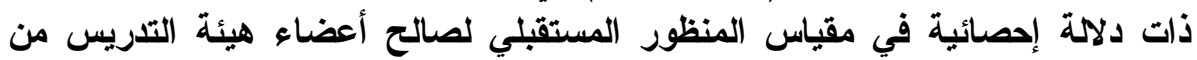

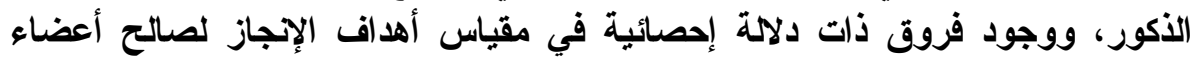

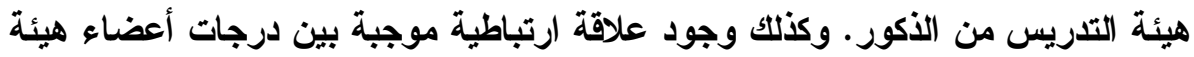

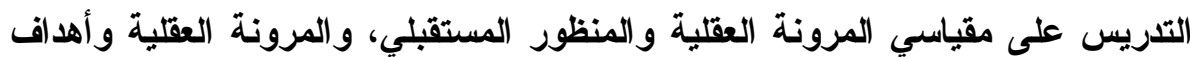

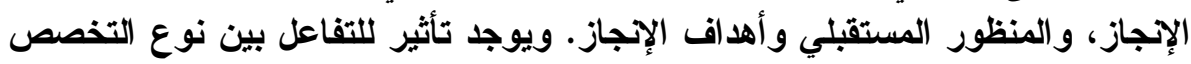

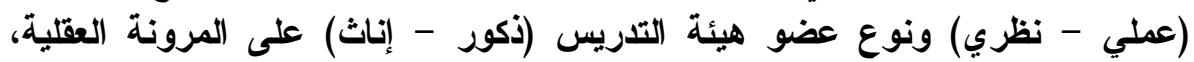
وعلى المنظور المستقبلي، وأهداف الإنجاز.

وقام مور، ومالينوسكي (Moore, \& Malinowski, 2009) بلرب اسة هدفت

إلى بحث العلاقة بين التأمل (Meditation)، والينوسئة (Mindfulness)، واليقة)، والمرونة

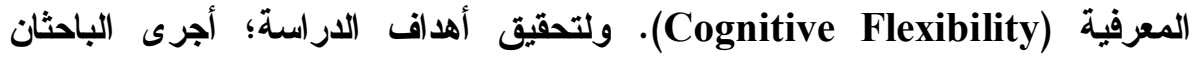
مقارنة بين مجموعة من المتأملين اليقظين بصفتهم خبراء في هذا المجال، ومتأملين 


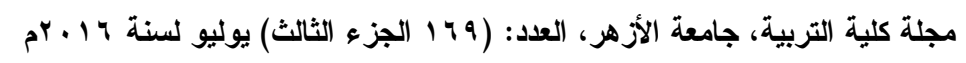

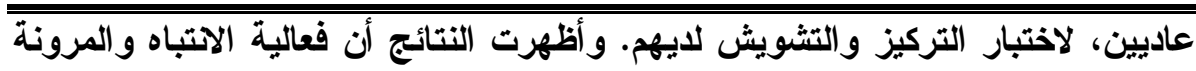

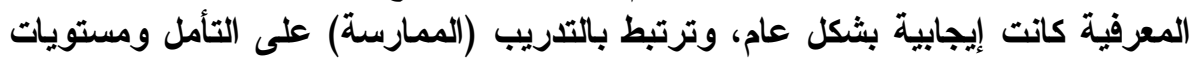

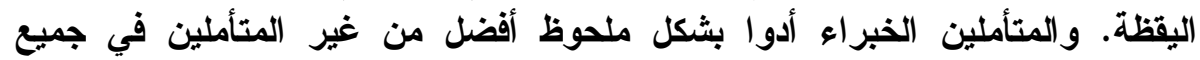

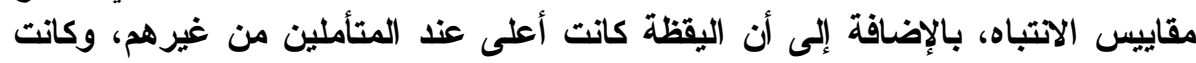

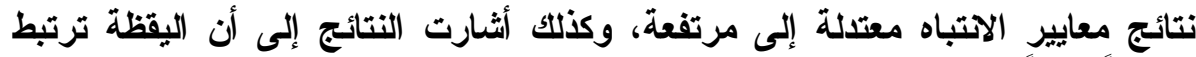

ارتباطاً وثيقاً بتحسن وظائف الاتباه معثلة إلهر والمرونة وكعة المعرفية.

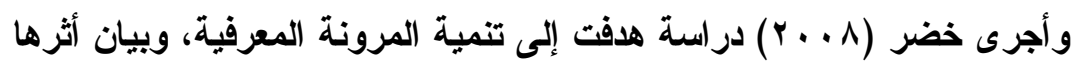

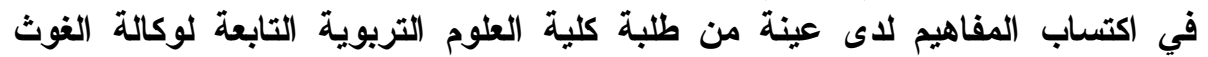

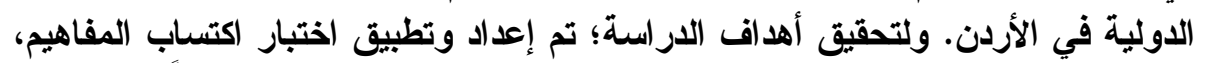

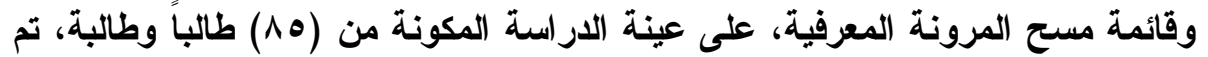

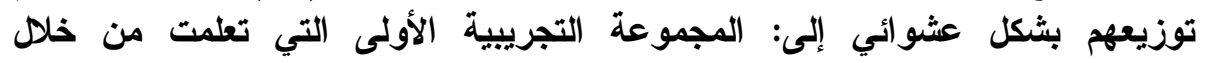

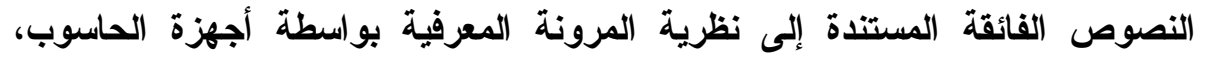

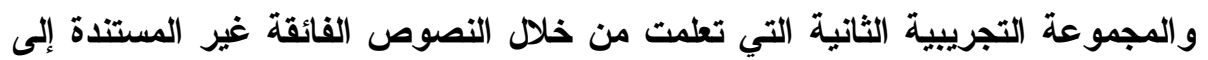

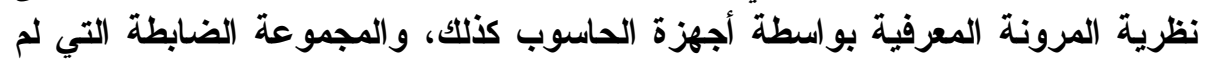
تتعرض لأي تدريب، وتعلمت وفق الطريقة التقليدية. وأظهرت نتائج الاراسة وجودة

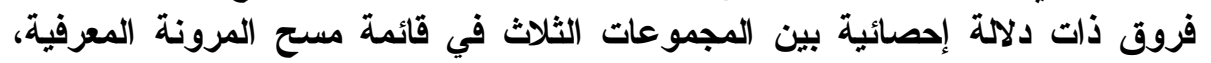
وفي اختبار اكتساب المفاهيم، ولصالح المجموعة التجريبية الأولى.

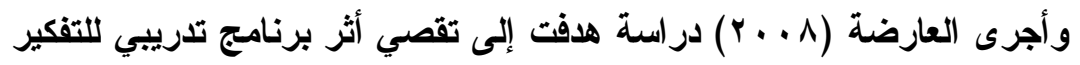

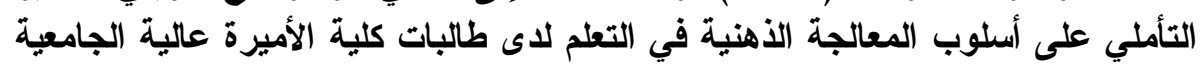

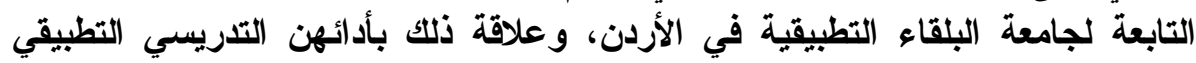

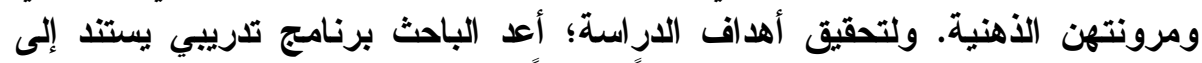

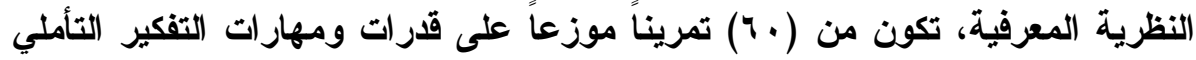

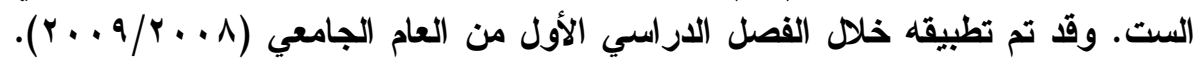
وطبق الباحث مجموعة من المقاييس قام بتطويرها وهي: مقياس السلوب الإب المعالجة

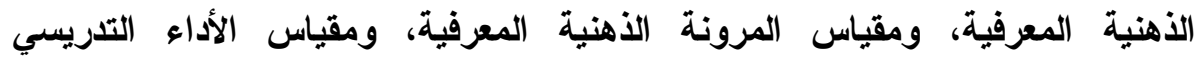

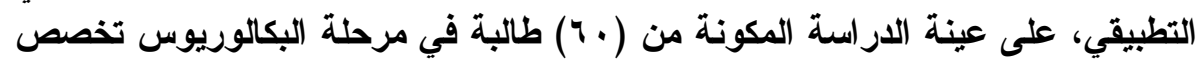
تربية الطقل، وتم تقسيمهن إلى مجموعتين مناصفة إحداهما تجريبية، والأخرى ضائة ضابطة.

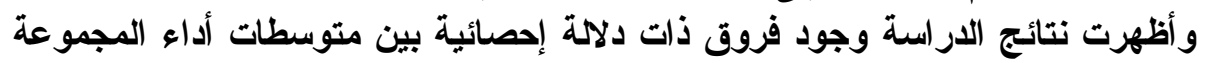

التجريبية والمجموعة الضابطة على المقاييس الثلاث لصالح المجموعة التجريبية.

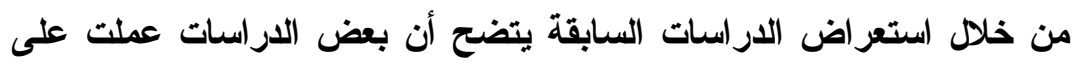

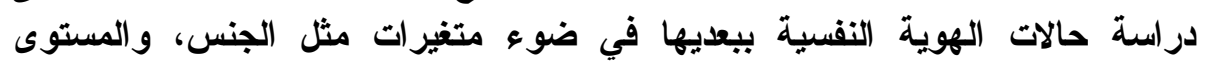

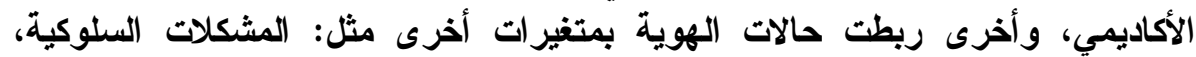




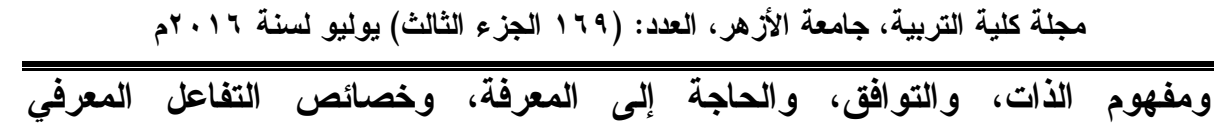

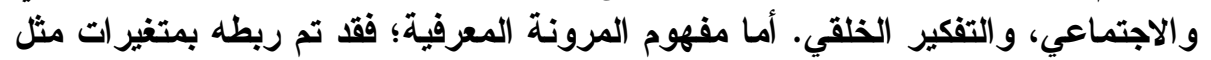

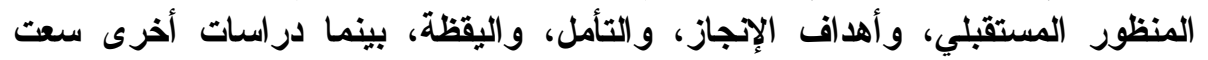
لتنمية المرونة المعرفية عن طريق برامج تلريبية متنوعة.

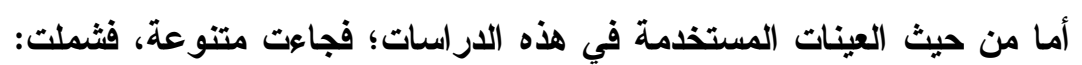

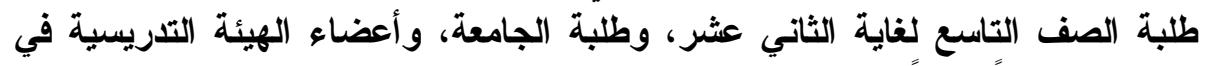
الجامعة، ذكوراً و إناثاً.

أما من حيث المنهجية، فقا تعددت المنهجيات المستخدمة؛ فكاتت: إما وصفية،

أو تجريبية.

وتجدر الإثارة إلى أن الباحث قد استفاد من الاراسات السابقة في تحديد

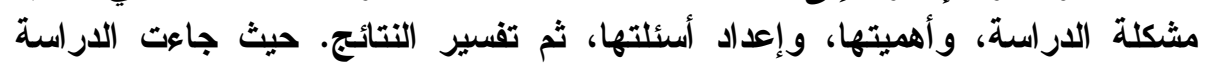

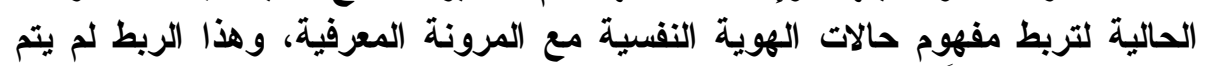

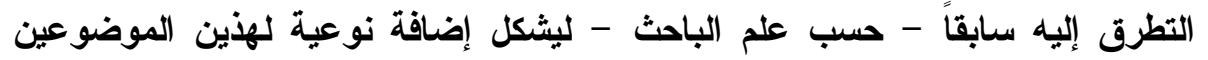

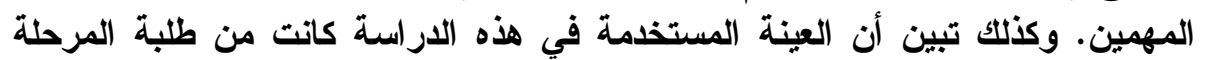

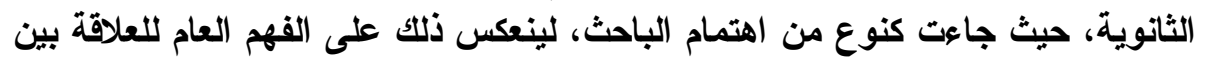

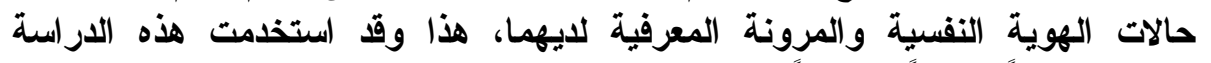
كغيرها أسلوباً وصفياً ارتباطياً. محددات الار اسة: مدئة

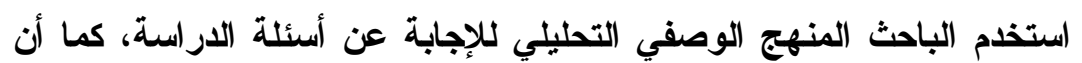

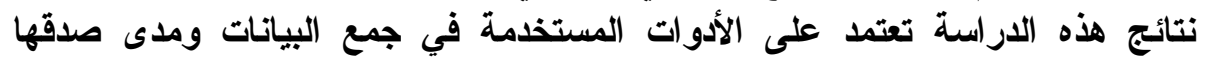
وثباتها. التعريفات النظرية والاجر ائية: التعريفات النظرية

- حالات الهوية النفسية (Psychological Identity Statuses) تعرف حالة الهوية النفسية بأنها التفاعلات بين إمكاتيات الفرد البيولوجية، والنفسية، والاجتماعية، والاستجابة ضمن سياق ثقافي تاريخي (Kroger, 2006).

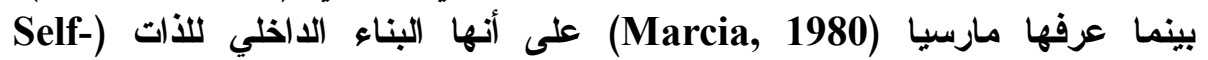
Dynamic Organization of (Structure (Drives)، والقدرات (Abilities)، والمعتقدات (Beliefs)، والتاريخ (الخاص بالفرد (Dt) 
منفزد)

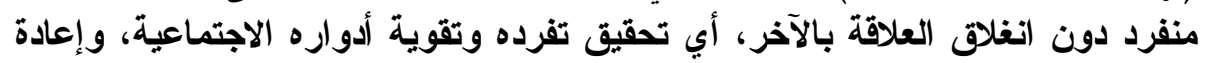

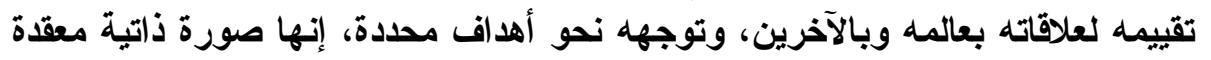

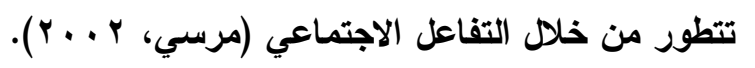

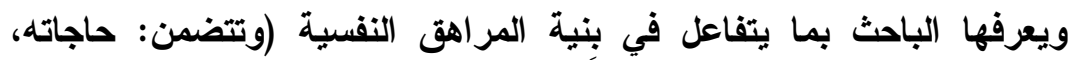

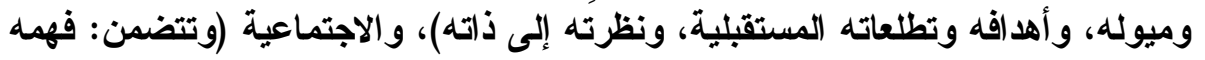

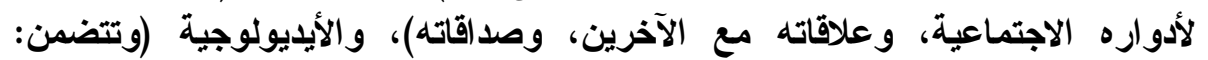

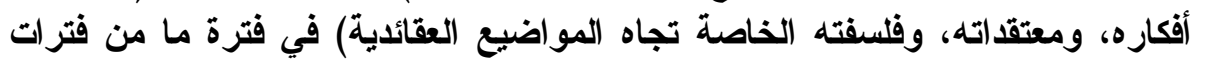
مراهقته.

- المرونة المعرفية (Cognitive Flexibility)

تعبر المرونة المعرفية عن قدرة الفرد أو مهارته في عدم الاستمرار في العمل

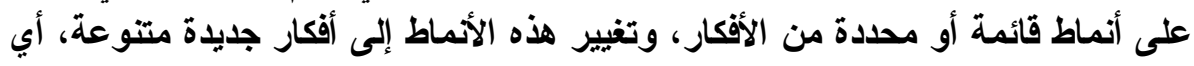

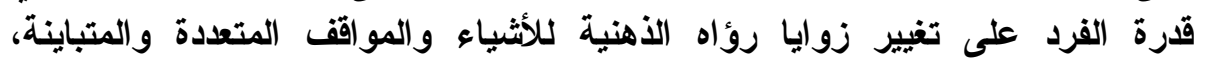

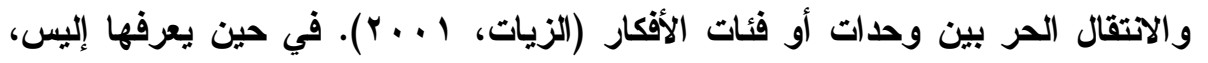

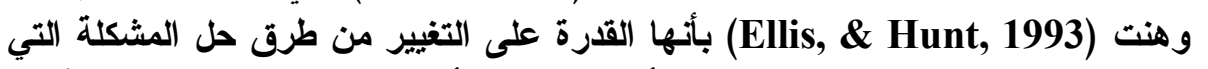

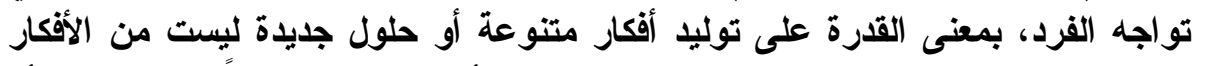

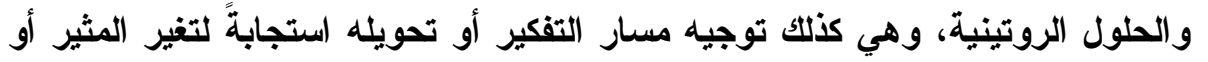

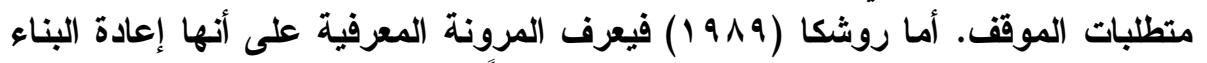

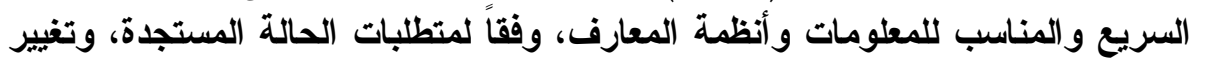

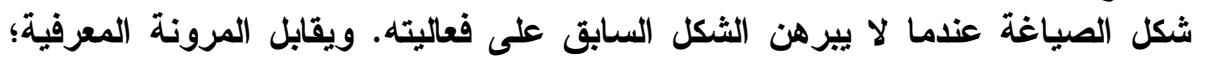

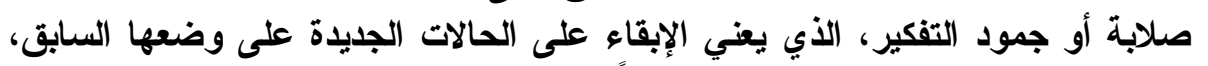

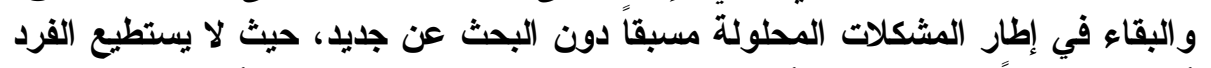

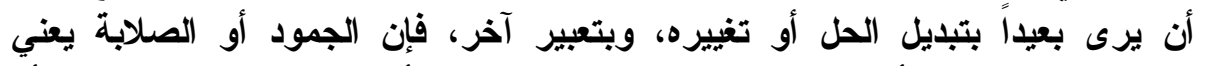

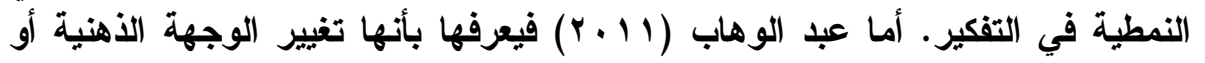

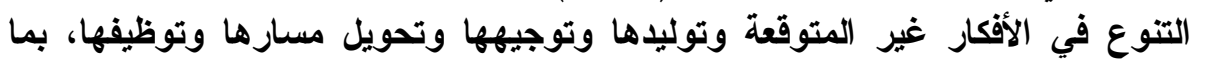
يتناسب مع المثير أو متطلبات الموقف، مع سلاسة التفكير وعدام الجمود الفكري. ويعرفها الباحث بأنها قدرة عقلية ذات مرتبة عليا، ويمكن تعلمها واكتسابها

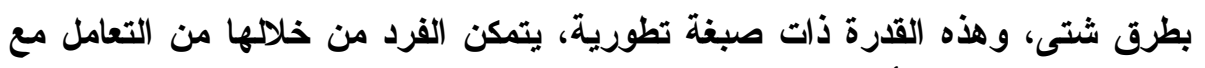

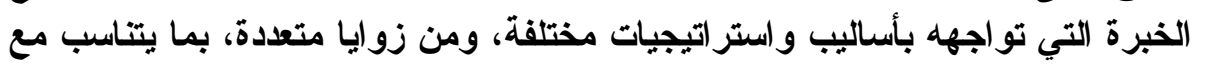

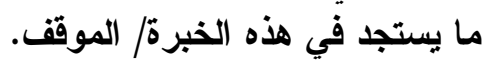




$$
\text { التعريفات الإجر ائية: }
$$

- حالات الهوية النفسية: محصلة استجابات طلبة المرحلة الثاتوية على المقياس المخصص لقياسه في هذه الار اسة.

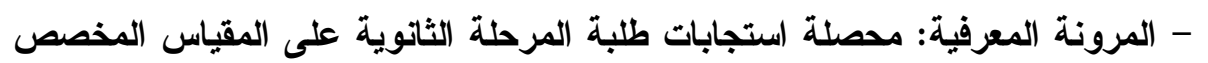
لقياسه في هذه الدر اسة.

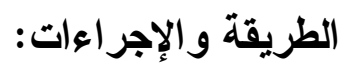

استخدم الباحث المنهج الوصفي الارتباطي كونه الأنسب للإجابة عن أسئلة

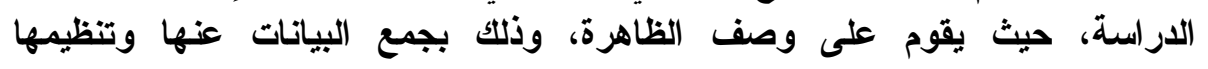
وتلخيصها والربط بين مدلولاتها للوصول إلى فهم الظاهرة، وتحديد العوامل المؤثرة فيها.

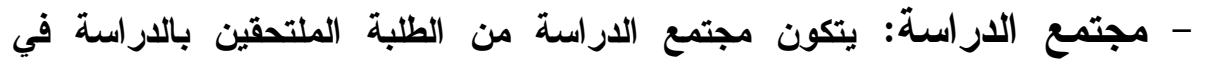

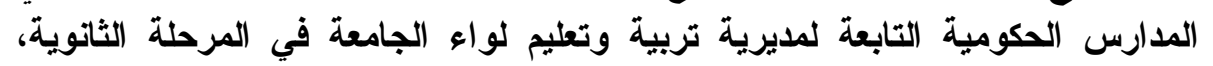

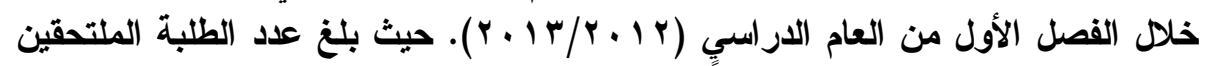

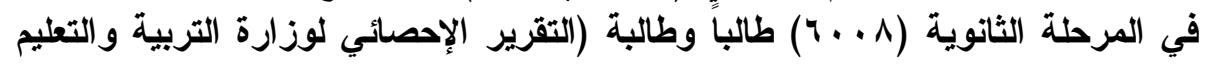

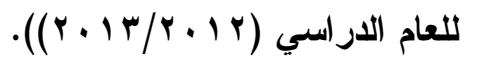

- عينة الار اسةة: تم اختيار عينة الاراسة بطريقة عنقودية عشوائية، حيث تم اختيار

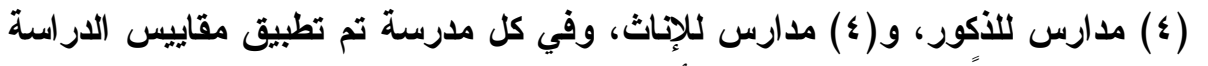

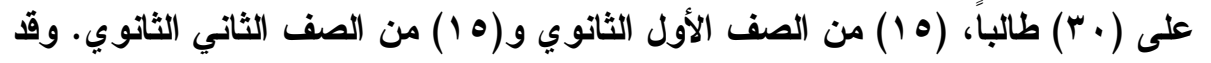

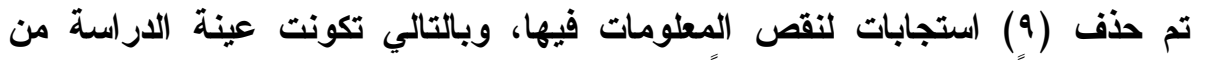

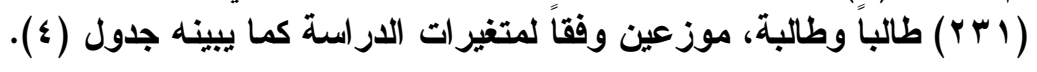

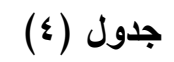

توزيع عينة الدراسة وفقاً لمتغيرات: الجنس، والتخصص الأكاديمي، والمستوى الدراسي

\begin{tabular}{|c|c|c|c|}
\hline \multicolumn{4}{|c|}{ المتغير } \\
\hline المجموع الكلي & \multicolumn{2}{|c|}{ العدد } & مستوى المتغير \\
\hline \multirow[t]{2}{*}{ rr } & أنثى & ذكر & \multirow[t]{2}{*}{ الجنس } \\
\hline & $11 \varepsilon$ & 118 & \\
\hline \multirow[t]{2}{*}{ rr } & الأدبي & العلمي & \multirow[t]{2}{*}{ التخصص الأكاديمي } \\
\hline & $1 \cdot \varepsilon$ & IYV & \\
\hline \multirow[t]{2}{*}{ Yr } & الثاني الثاتوي & الأول الثانوي & \multirow[t]{2}{*}{ المستوى الار اسي } \\
\hline & 118 & $11 \varepsilon$ & \\
\hline
\end{tabular}


- أدوات الار اسة: لقياس حالات الهوية النفسية، والمرونة المعرفية استخدم الباحث:

- مقياس حالات الهوية النفسية:

Objective ) استخلم الباحث المقياس الموضوعي لتثكل هوية الأنا الأبي عربه الغامدي (Y. Measure of Ego Identity Status

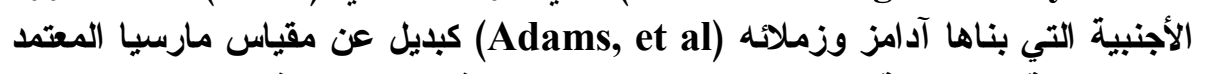

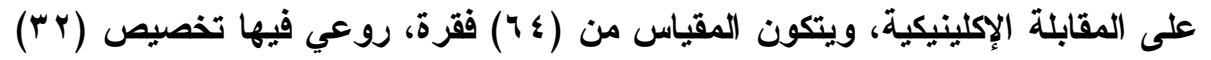

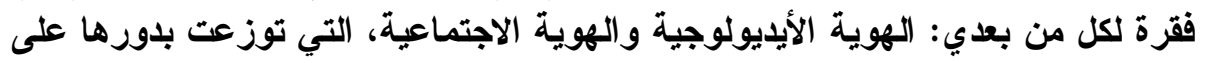

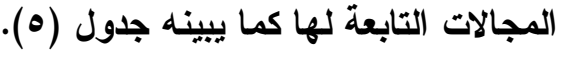

(0) جدول

توزيع فقرات مقياس الهوية النفسية على أبعاد الهوية ومجالاتها وفقاً لحالات/ رتب التب

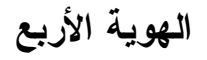

\begin{tabular}{|c|c|c|c|c|c|c|c|c|c|c|}
\hline & & & & & & & & & الهوية & الهجادية الهوالات \\
\hline الفقرات & \multicolumn{2}{|c|}{ التشتت } & \multicolumn{2}{|c|}{ الانغلاق } & \multicolumn{2}{|c|}{ التأجيل } & \multicolumn{3}{|c|}{ التحقيق } & \multirow{5}{*}{ 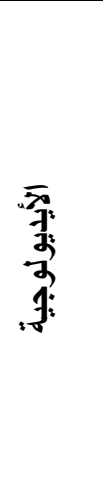 } \\
\hline$(\wedge)$ & $\left(r_{0}\right)$ & (1) & $(\leqslant 1)$ & (Iv) & $(\Delta v)$ & (9) & $(\leqslant 9)$ & $(r r)$ & المهني & \\
\hline$(\wedge)$ & $(1 \cdot)$ & $(Y)$ & $(\bullet \wedge)$ & $(0 \cdot)$ & $(r \leq)$ & $(Y Y)$ & $(\xi Y)$ & $(1 \wedge)$ & الايني & \\
\hline$(\wedge)$ & $(07)$ & (17) & (7 & $(Y \leqslant)$ & $(\leqslant \Lambda)$ & $(r Y)$ & $(\xi \cdot)$ & $(\wedge)$ & السياسي & \\
\hline$(\wedge)$ & $(O Y)$ & $(\xi)$ & $(\leqslant \varepsilon)$ & $\left(\Upsilon^{\prime}\right)$ & (rד) & $(I Y)$ & $(7 \cdot)$ & $(r \cdot)$ & أسلوبة & \\
\hline$(\wedge)$ & $(\Delta r)$ & $\left(r^{q}\right)$ & $(r v)$ & (Y) & (7) & (०) & $(\leqslant 0)$ & $(1 T)$ & الصداقة & \\
\hline$(\wedge)$ & $(Y M)$ & (v) & (ז) & $(r q)$ & $(\leqslant V)$ & $\left(\begin{array}{rl} \\
(\mu)\end{array}\right.$ & $(00)$ & $(10)$ & التعامل مع الآلاقة & 凫. \\
\hline
\end{tabular}


مجلة كلية التربية، جامعة الأزهر، العلد: (19 19 الجزء الثالث) يوليو لسنة 17 ـ بام

\begin{tabular}{|c|c|c|c|c|c|c|c|c|c|}
\hline$(\wedge)$ & $(\bullet 9)$ & (19) & $(r v)$ & $(\boldsymbol{r})$ & $(\leqslant r)$ & $(11)$ & $(01)$ & (ro) & الجنسية \\
\hline$(\wedge)$ & $(r \cdot)$ & (7) & (TY) & $(r \wedge)$ & $(0 \leqslant)$ & $(1 \leqslant)$ & $(\leqslant 7)$ & $(Y Y)$ & الاستجمام/ الترفيه \\
\hline (7 & (1 & & & & & 7) & & 7) & الفقر ات \\
\hline
\end{tabular}

وقد صممت فقرات هذا المقياس باستخدام مقياس ليكرت سداسي التّريج،

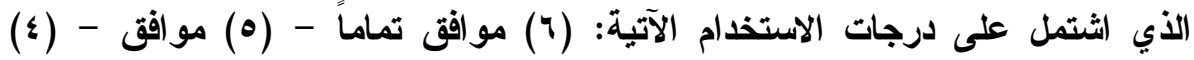

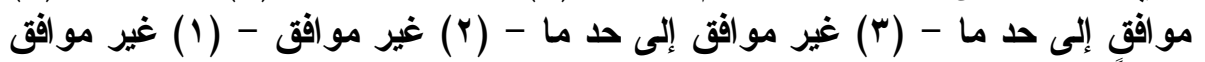

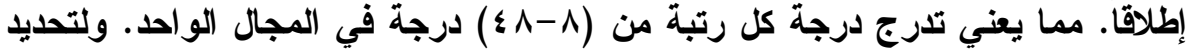

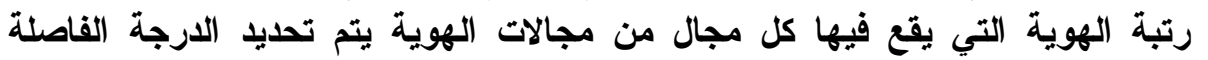

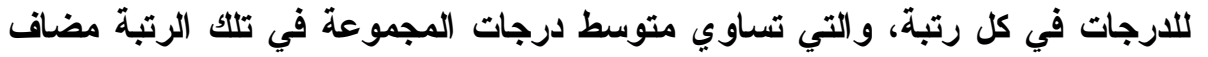

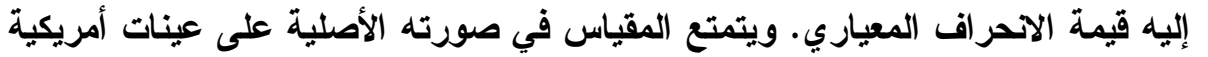

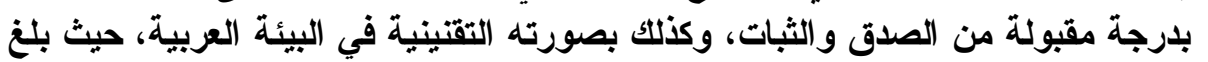

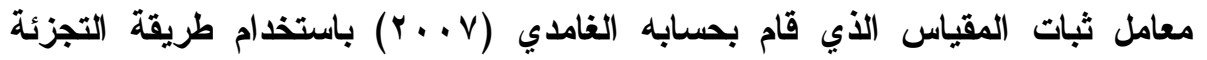

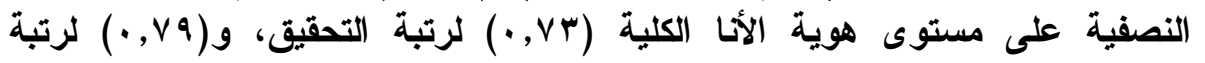

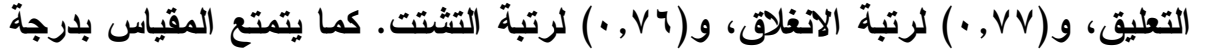

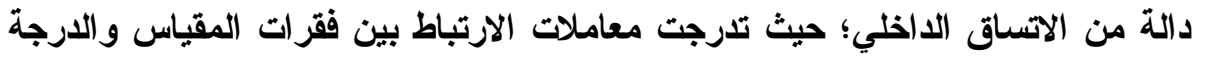

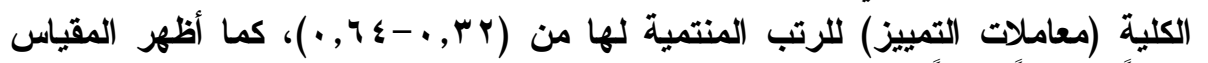

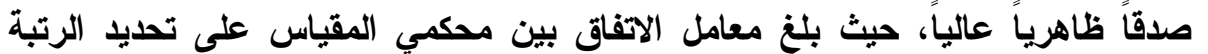
و المجال الأي تقيسه كل فقرة (ع 9 و • ).

قام الباحث في الدراسة الحالية بالتحقق من ثبات المقياس بطريقتين هما: - طريقة الإعادة: حيث تم تطبيق المقياس على († ب) طالباً وطالبة من خارج عينة الاراسة، مع وجود فاصل زمني مقاره أسبوعين، ومن ثم تم إعادة تطبيق المقياس

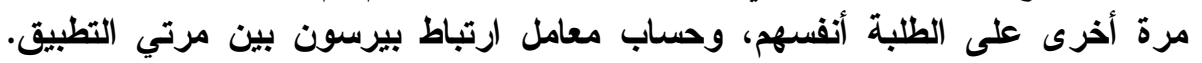
وجدول (؟) يوضح النتائج. 
مجلة كلية التربية، جامعة الأزهر، العدد: (79 19 الجزء الثالث) يوليو لسنة 7 ا ـ بم

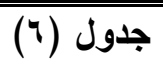

معامل الثبات باستخدام طريقة الإعادة لمقياس حالات الهوية النفسية لكل بعد من أبعاد المقياس

\begin{tabular}{|c|c|c|c|}
\hline معامل الثبات & عدد الفقر ات & حالات الهوية & أبعاد الهوية \\
\hline$\cdot, \vee \vee \neg$ & $\Lambda$ & تشتت الهوية & \multirow[t]{4}{*}{ الأيديولوجية } \\
\hline$\cdot, \wedge 1$ & $\Lambda$ & انغلاق الهوية & \\
\hline$\cdot, \mathrm{VV}$ & $\Lambda$ & تعليق الهوية & \\
\hline$\cdot, \vee \vee q$ & $\Lambda$ & تحقيق الهوية & \\
\hline$\cdot, \vee \wedge$ & $\wedge$ & تشتت الهوية & \multirow[t]{4}{*}{ الاجتماعية } \\
\hline$\cdot, \wedge 1$ & $\wedge$ & انغلاق الهوية & \\
\hline$\cdot, \wedge \varepsilon$ & $\wedge$ & تعليق الهوية & \\
\hline$\cdot, \wedge \varepsilon$ & $\Lambda$ & تحقيق الهوية & \\
\hline
\end{tabular}

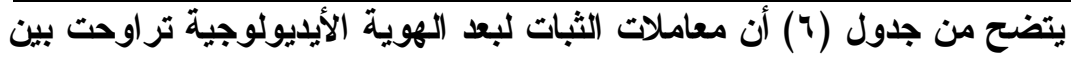

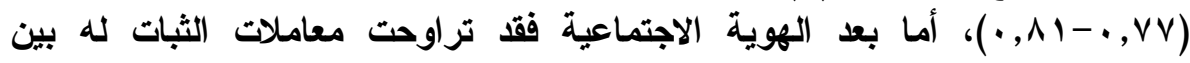

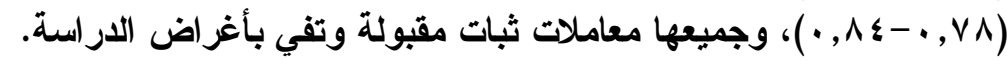
- طريقة الاتساق الداخلي: حيث تم استخدام معادلة كرونباخ ألفا لحساب الثبات للارجة الثابة الكلية على المقياس، وللمجالات الفرعية التي يتألف منها المقياس. وجدول كرول (V) يوضح 
مجلة كلية التربية، جامعة الأزهر، العدد: (9 1 الجزء الثالث) يوليو لسنة 7 أ بام

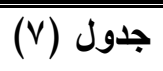

معامل الثبات باستخام طريقة الاتساق الداخلي لمقياس حالات الهوية النفسية لكل بعد من أبعاد المقياس المياس

\begin{tabular}{|c|c|c|c|}
\hline معامل الثبات & عدد الفقرات & حالات الهوية & أبعاد الهوية \\
\hline$\cdot, \wedge \varepsilon$ & $\Lambda$ & تثتت الهوية & \multirow[t]{4}{*}{ الأيديولوجية } \\
\hline$\cdot, \wedge \mathrm{V}$ & $\Lambda$ & انغلاق الهوية & \\
\hline$\cdot, \wedge 1$ & $\Lambda$ & تعليق الهوية & \\
\hline$\cdot, \wedge q$ & $\Lambda$ & تحقيق الهوية & \\
\hline$\cdot, \wedge \wedge$ & $\wedge$ & تثتت الهوية & \multirow[t]{4}{*}{ الاجتماعية } \\
\hline$\cdot, 91$ & $\wedge$ & انغلاق الهوية & \\
\hline$\cdot, \wedge \mathrm{V}$ & $\wedge$ & تعليق الهوية & \\
\hline., 91 & $\Lambda$ & تحقيق الهوية & \\
\hline
\end{tabular}

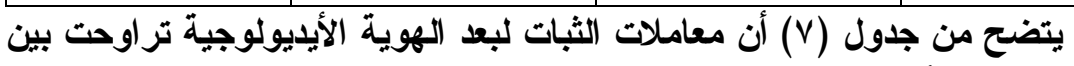

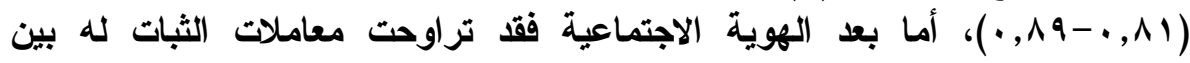

)

- مقياس المرونة المعرفية:

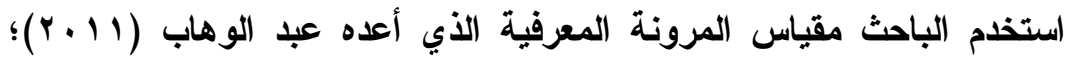

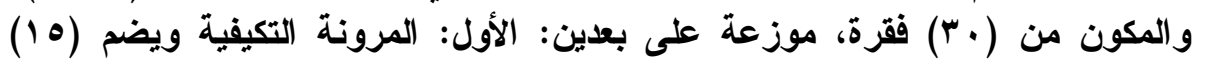

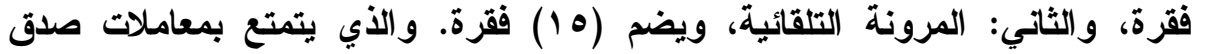

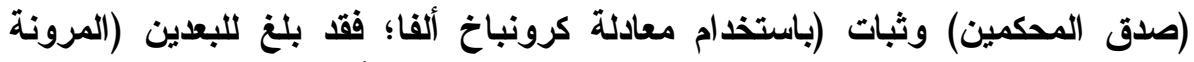

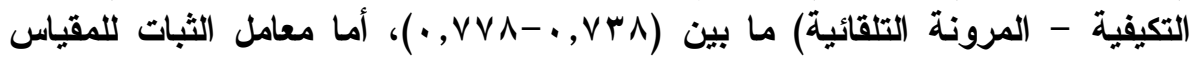

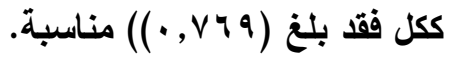

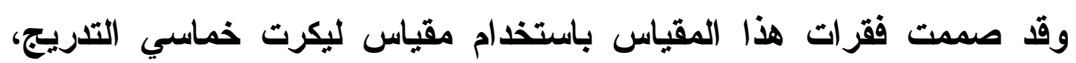

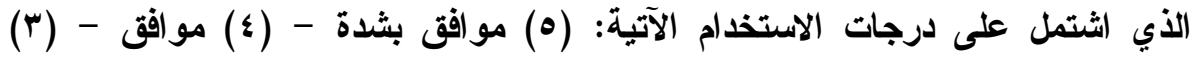

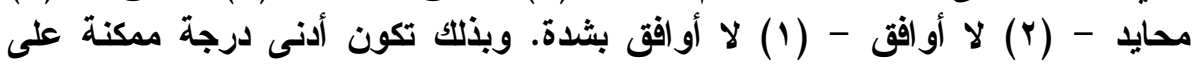

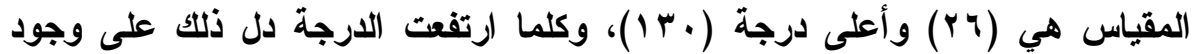

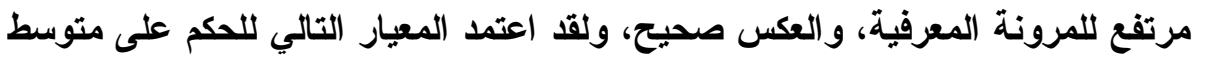

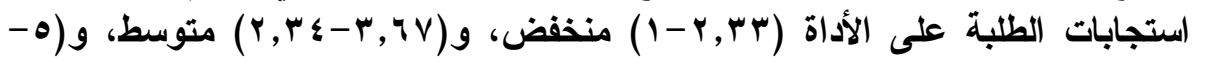




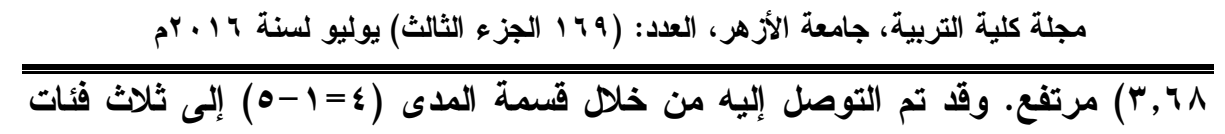

$$
\text { متساوية (ع ( }
$$

وقبيل تطبيق هذا المقياس؛ استخرج الباحث صدق محتوى الأداة بعرضها

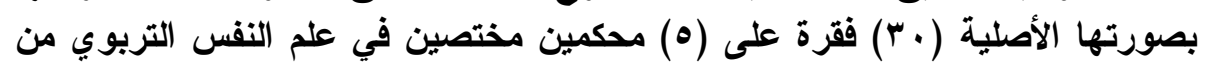

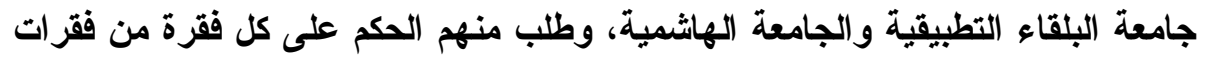

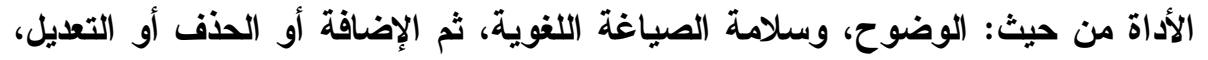

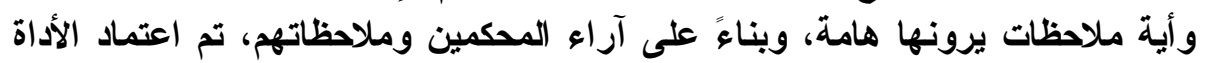

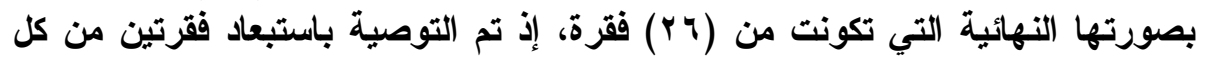

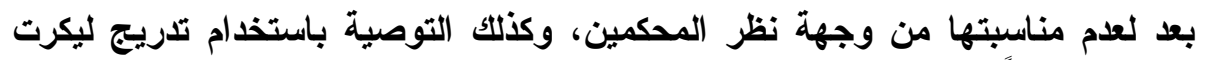

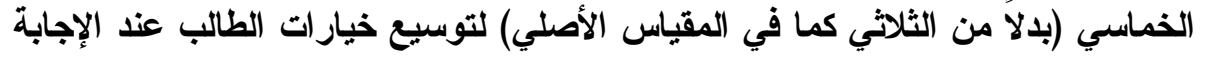
على فقرات المقياس.

وقد قام الباحث في الاراسة الحالية بالتحقق من ثبات المقياس بطريقتين هما:

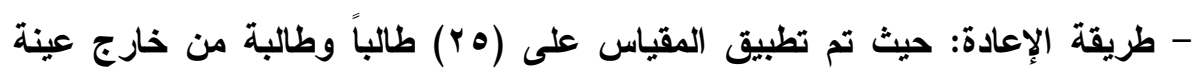

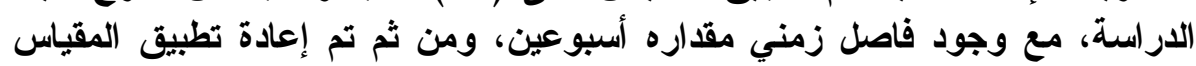

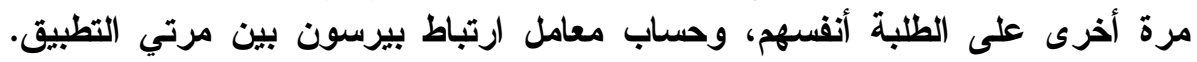
وجدول (^) يوضح النتائج.

جدول (^)

معامل الثبات باستخدام طريقة الإعادة لمقياس المرونة المعرفية ككل، ولكل بعد من أبعاد المقياس

\begin{tabular}{|c|c|c|}
\hline معامل الثبات & عدد الفقرات & الأبعاد \\
\hline$\cdot, \wedge \vee$ & 14 & المرونة التكيفية \\
\hline$\cdot, \lambda r$ & 14 & المرونة التلقائية \\
\hline$\cdot, \wedge 9$ & Y & معامل الثبات الكلي للمقياس \\
\hline
\end{tabular}

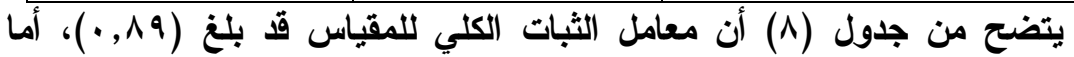

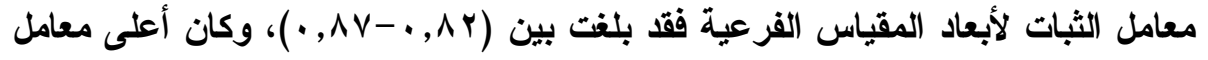

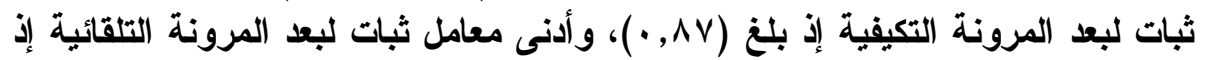

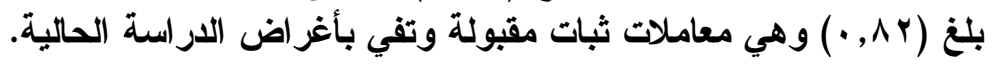




\section{مجلة كلية التربية، جامعة الأزهر ، العلد: (179 الجزء الثالث) يوليو لسنة 17 1. بم}

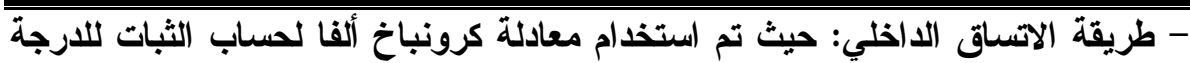

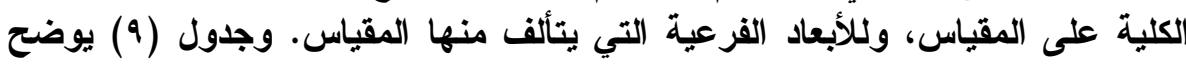

\section{جدول (9)}

معامل الثبات باستخدام طريقة الآساق الداخلي لمقياس المرونة المعرفية ككل، ولكل بعد من أبعاد المقياس المياس

\begin{tabular}{|c|c|c|}
\hline معامل الثبات & عدد الققرات & الأبعاد \\
\hline$\cdot, 9 r$ & 14 & المرونة التكيفية \\
\hline$\cdot, 90$ & 15 & المرونة التلقائية \\
\hline$\cdot, 97$ & Y & معامل الثبات الكلي \\
\hline
\end{tabular}

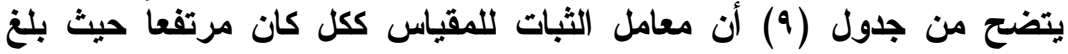

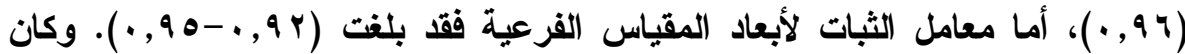

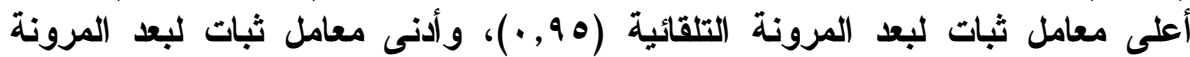
التكيفية ( ب 9 ، •)، وهي معاملات ثبات مقبولة وتفي بأغر اض الدراسة الحالية. - إجراءات الدراسة: بعد أن قام الباحث بتجهيز أداتي الدراسة، تم تطبيق هاتين

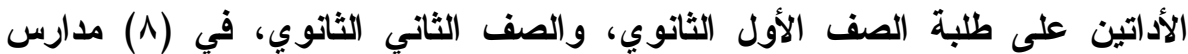

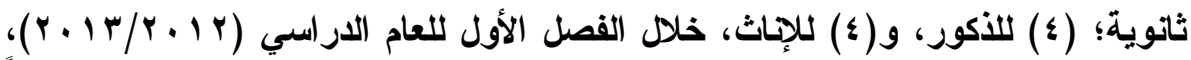

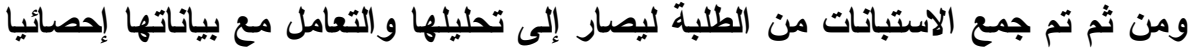

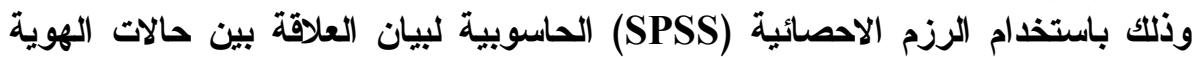
النفسية و المرونة المعرفية.

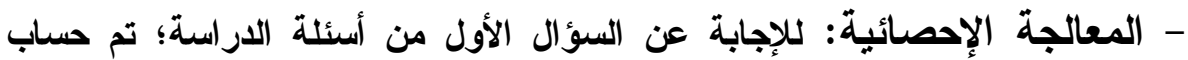

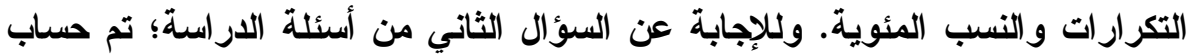

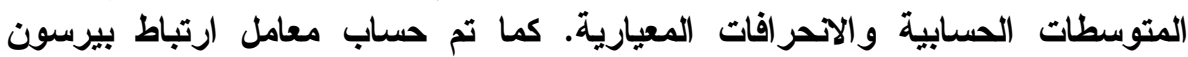

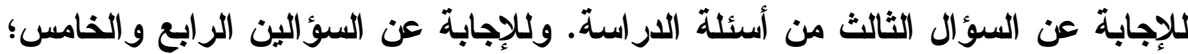

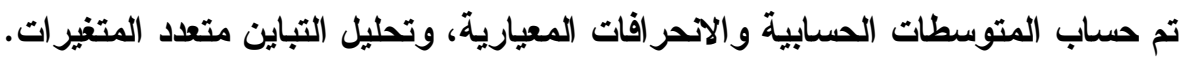


النتائج:

- نتائج السؤال الأول: ما حالات الهوية (التحقيق - التعليق - الانغلاق -

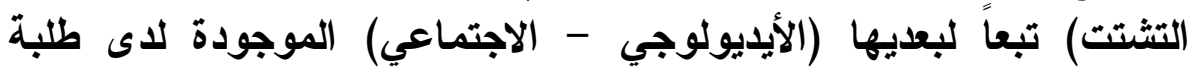

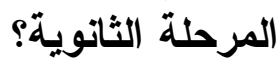

للإجابة عن السؤال الأول تم حساب تصنيف الطلبة إلى حالات تثكل الهِوية

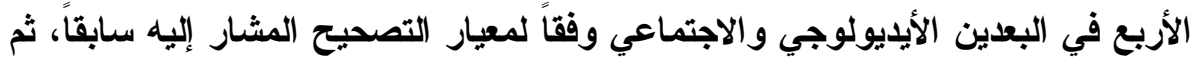

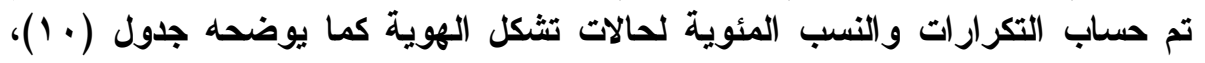

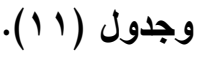

$$
\text { جدول (1.) }
$$

التكرارات والنسب المئوية لحالات تثكل الهوية لدى طلبة المرحلة الثانوية في بعد

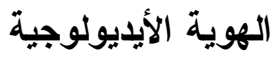

\begin{tabular}{|c|c|c|c|}
\hline النسبة المئوية & التكرار & حالة الهوية & \multirow{6}{*}{$\begin{array}{l}7 \\
7 \\
3 \\
3 \\
3 \\
3 \\
3 \\
3\end{array}$} \\
\hline r., \& & $\Lambda \varepsilon$ & تثتت الهوية & \\
\hline $1 r, \cdot$ & $r$. & انغلاق الهوية & \\
\hline 10,7 & rq & تعليق الهوية & \\
\hline$r_{0,1}$ & 11 & تحقيق الهوية & \\
\hline $1 \ldots$ & r & المجموع & \\
\hline
\end{tabular}

يتضح من جدول (· (1) أن أكثر حالات تثكل الهوية الأيديولوجية لاى الطلبة

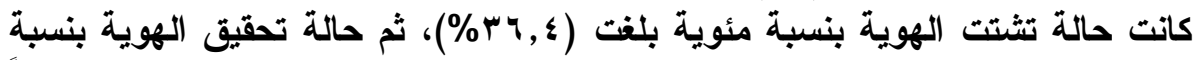

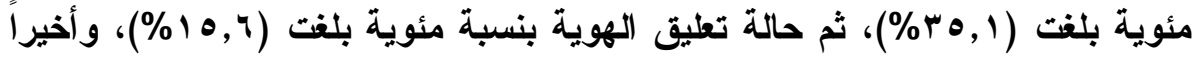

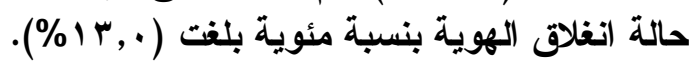


مجلة كلية التربية، جامعة الأزهر، العدد: (9 1 ( الجزء الثالث) يوليو لسنة 1 أ بrم

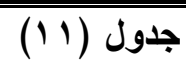

التكرارات والنسب المئوية لحالات تثكل الهوية لدى طلبة المرحلة الثانوية في بعد الهوية الاجتماعية

\begin{tabular}{|c|c|c|c|}
\hline النسبة المئوية & التكرار & حالة الهوية & \multirow{6}{*}{ 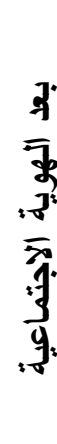 } \\
\hline$r 0,1$ & $\wedge 1$ & تشتت الهوية & \\
\hline $1 \cdot, 1$ & ro & انغلاق الهوية & \\
\hline 17,9 & rq & تعليق الهوية & \\
\hline$r V, r$ & 17 & تحقيق الهوية & \\
\hline $1 \cdots$ & r & المجموع & \\
\hline
\end{tabular}

يتضح من جدول (11) أن أكثر حالات تثكل الهوية الاجتماعية لدى الطلبة

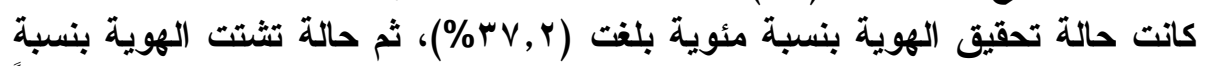

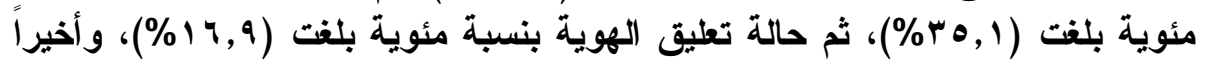

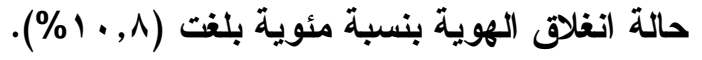

- نتائج السؤال الثاني: ما مستوى المرونة المعرفية ببعديها (التكيفية -

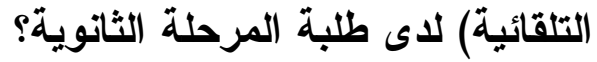
للإجابة عن السؤال الثاني تم حساب المتوسطات الحسابية والاحمرافات

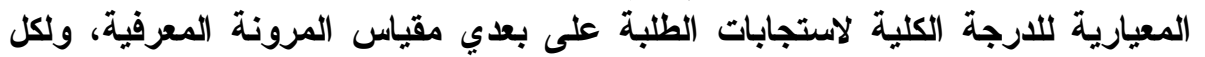

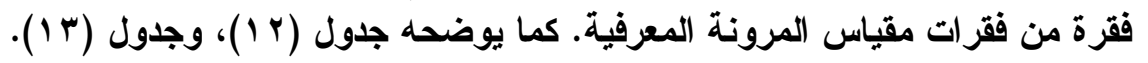




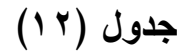

المتوسطات الحسابية والاحررافات المعيارية لاستجابات الطلبة على فقرات بعد المرونة التكيفية مرتبة ترتيباً تنازلياً الطياً

\begin{tabular}{|c|c|c|c|c|}
\hline المرونة & الالمحر افت & الحستوسط & الفقرة & الفقرة \\
\hline متوسط & $1,0 \wedge$ & $r, 1 r$ & 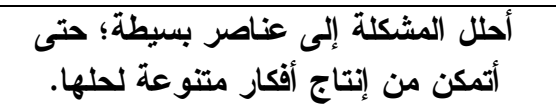 & 11 \\
\hline 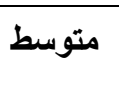 & $1,7 r$ & $r, 1$. & أعمل على إعادة بناء المشكلة؛ لكي أصل & 1 \\
\hline 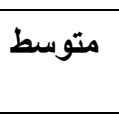 & $1,7$. & $r, \cdot v$ & أدخل في نقاثـات وحكن من إنتاج أفكار متتوعة حول المشكلة؛ & Ir \\
\hline 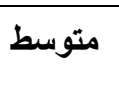 & $1,0 \leqslant$ & $r, \cdot q$ & 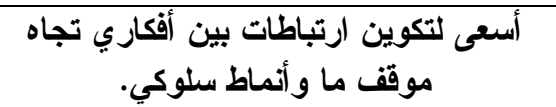 & 1. \\
\hline متوسط & $1,7$. & $r, \cdot \tau$ & 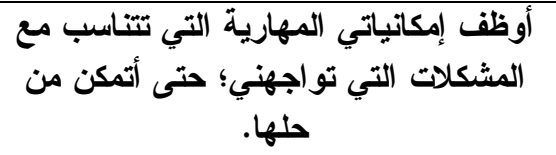 & Ir \\
\hline 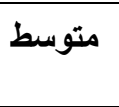 & 1,71 & $r, q q$ & 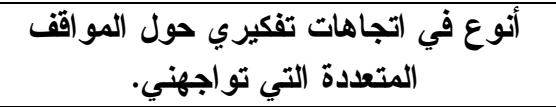 & $\varepsilon$ \\
\hline 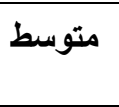 & 1,74 & $r, q \wedge$ & أعتبر أن من يتمسك برأيها تجاه موقف ماء & $r$ \\
\hline 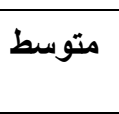 & 1,00 & $r, q \wedge$ & أحاول التعايش مع المشكلة التي تواجهني؛ أتمكن من حلها. & 9 \\
\hline متوسط & $1,0 \mathrm{~V}$ & Y,q & أسعى لكي أتو ائم مع مكونات المشكلة؛ لكي & 0 \\
\hline متوسط & 1, 1, & Y, qo & يمكنتي تغيير وجهتي الذهنية حول المشكلة & $r$ \\
\hline متوسط & 1,09 & $r, 90$ & أعدل من سلوكي؛ بناءً على متطلبات المشكلات التي تواجني. & $\Lambda$ \\
\hline متوسط & $1,7 \varepsilon$ & $r, q r$ & لا تزعجني الظروف الطارئة التي تواجهني & $V$ \\
\hline متوسط & 1,7 & $r, q$. & أسعى للوصول إلى حلول للمشكلة؛ حتى لو & 7 \\
\hline متوسط & $1,0$. & $r, \ldots$ & المرونة التكيفية (الكلي) & \\
\hline
\end{tabular}

$-9.9-$ 
مجلة كلية التربية، جامعة الأزهر، العلد: (19 19 الجزء الثالث) يوليو لسنة 17 ـ بام

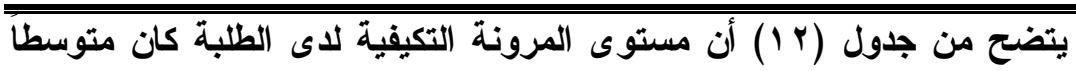

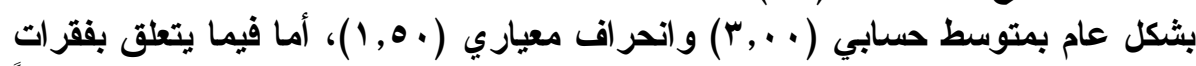

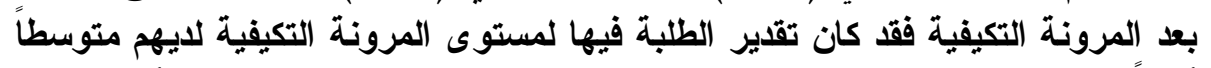

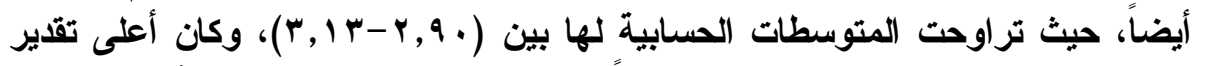

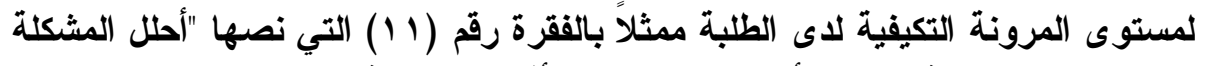

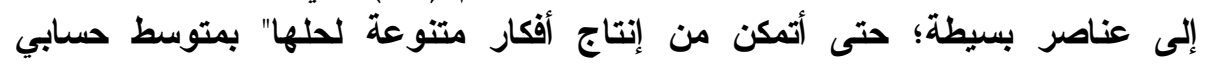

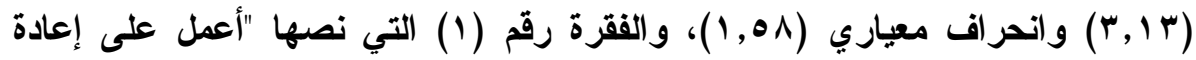

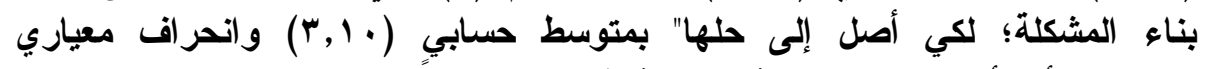

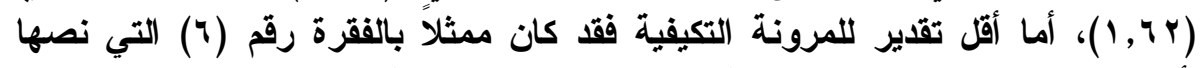

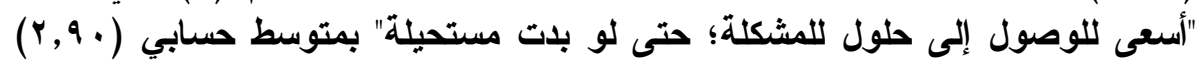

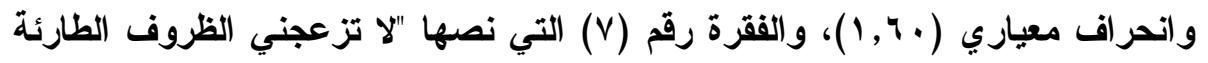

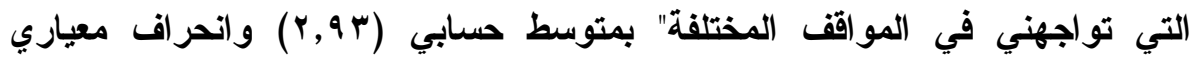

ب. المرونة التلقائية:

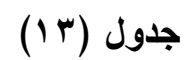

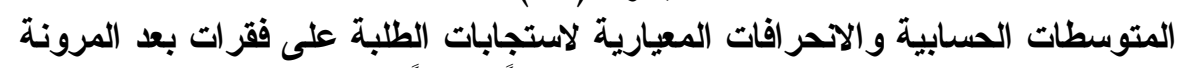

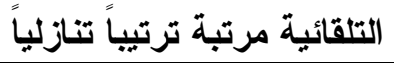

\begin{tabular}{|c|c|c|c|c|}
\hline المرونة التقائية & 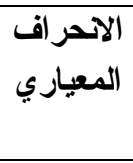 & 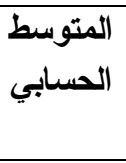 & الفقرة & الفقرة \\
\hline متوسط & $1,0 r$ & $r, 1 r$ & أسعى لإتاج أكبر قدر ممكن من الأفكار حول & $r$. \\
\hline متوسط & $1,0 r$ & $r, 1$. & 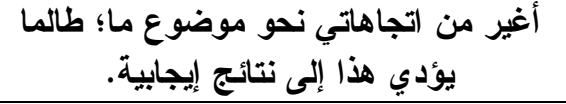 & 19 \\
\hline متوسط & 1,01 & $r, \cdot \Lambda$ & أنتقل من فكرة لأخرى ؛ طالما يفيدني ذلك في موقف ما. & 11 \\
\hline متوسط & 1,00 & $r, \cdot \Lambda$ & أهتم بالأفكار المتنوعة؛ حتى لو بلت غريبة التشئة & YY \\
\hline متوسط & 1,74 & $r, \cdot v$ & 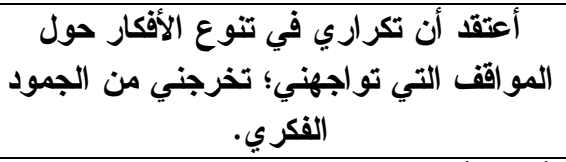 & YT \\
\hline متوسط & 1,01 & $r, \cdot r$ & أطوع أفكاري حتى تتناسب مع المشكلة التي & 17 \\
\hline
\end{tabular}

$-91 .-$ 
مجلة كلية التربية، جامعة الأزهر، العلد: (19 19 الجزء الثالث) يوليو لسنة 1 ـ ب Yم

\begin{tabular}{|c|c|c|c|c|}
\hline الترونة التقائية & 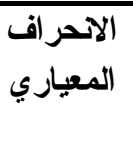 & الحسابي & الفقرة & الفقرة \\
\hline متوسط & 1,09 & $r, \cdot r$ & أسعى لإلتاج أكبر قدر ممكن من الأفكار حول & $r r$ \\
\hline متوسط & 1,7 & $r, \cdot r$ & موضوع ما؛ حتى لو لو بدت إنتاج تلك الأفكار غريبة. & $r \varepsilon$ \\
\hline متوسط & 1,71 & $r, \cdot r$ & لا أقيد أفكاري تحت إطار محدلد أثناء & IV \\
\hline متوسط & $1,0 \mathrm{~V}$ & $r, \ldots$ & أعتبر الفرد المتقيد بأفكاره؛ فردا لا مباليا & 10 \\
\hline متوسط & $1,0 \%$ & $r, \ldots$ & أؤمن بأن استخدام الأفكار غير التقليدية؛ & YI \\
\hline متوسط & 1,7 & r,q9 & أؤمن بأن تنوع الفرد في أفكاره؛ يجعله & $1 \varepsilon$ \\
\hline متوسط & 1,71 & $r, q \wedge$ & 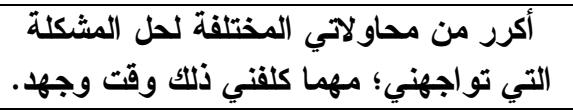 & ro \\
\hline متوسط & $1, \leqslant \Lambda$ & $r, \cdot \varepsilon$ & المرونة التلقائية (الكلي) & \\
\hline
\end{tabular}

يتضح من جدول (r ا I أن مستوى المرونة التلقائية لاى الطلبة كان متوسطا

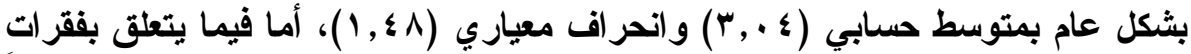

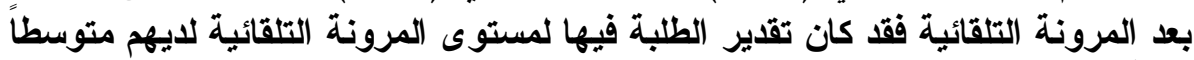

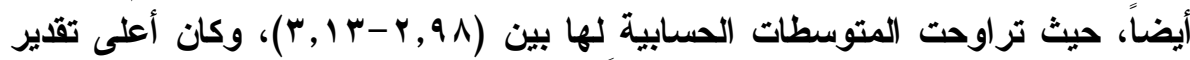

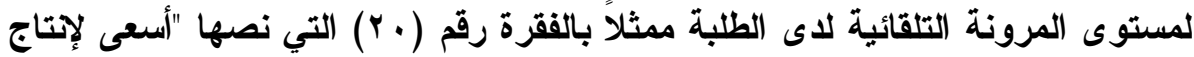

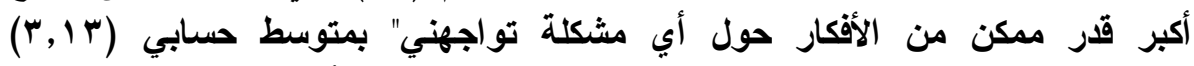

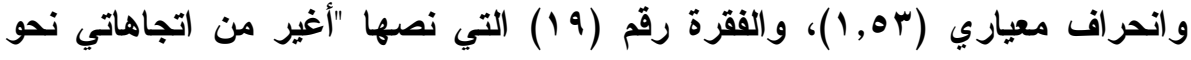

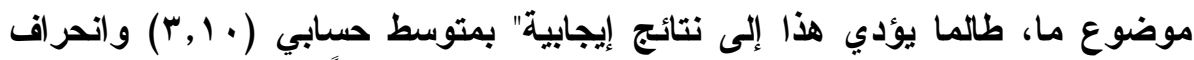

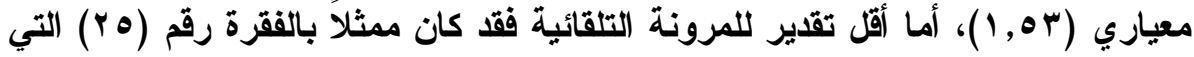

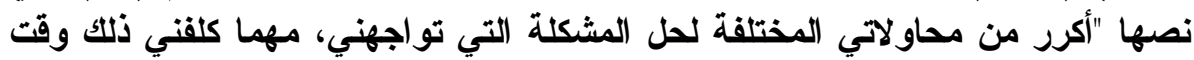

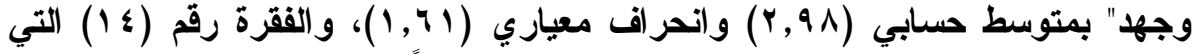

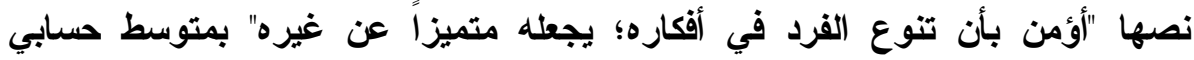

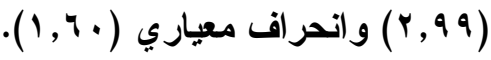


مجلة كلية التربية، جامعة الأزهر ، العلد: (19 19 الجزء الثالث) يوليو لسنة 17 ـأم

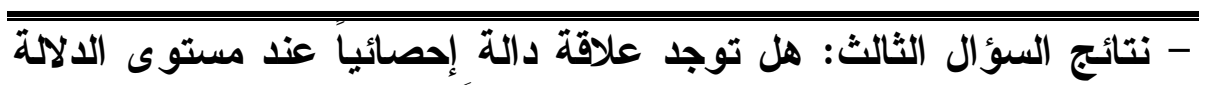

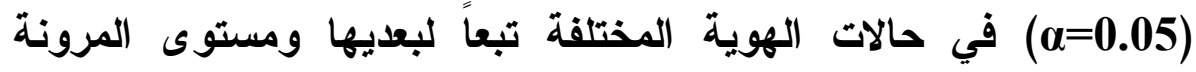
المعرفية ببعديها لاى طلبة المرحلة الثات الثوية الثانه

للإجابة عن السؤال الثالث تم حساب معاملات ارتباط بيرسون بين المرونة التكيفية

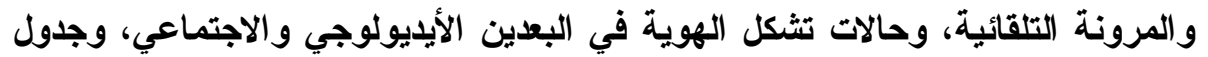

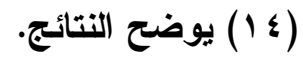

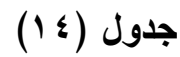

معاملات ارتباط معاملات ارتباط بيرسون بين المرونة التكيفية و التلقائية وحالات الهوية

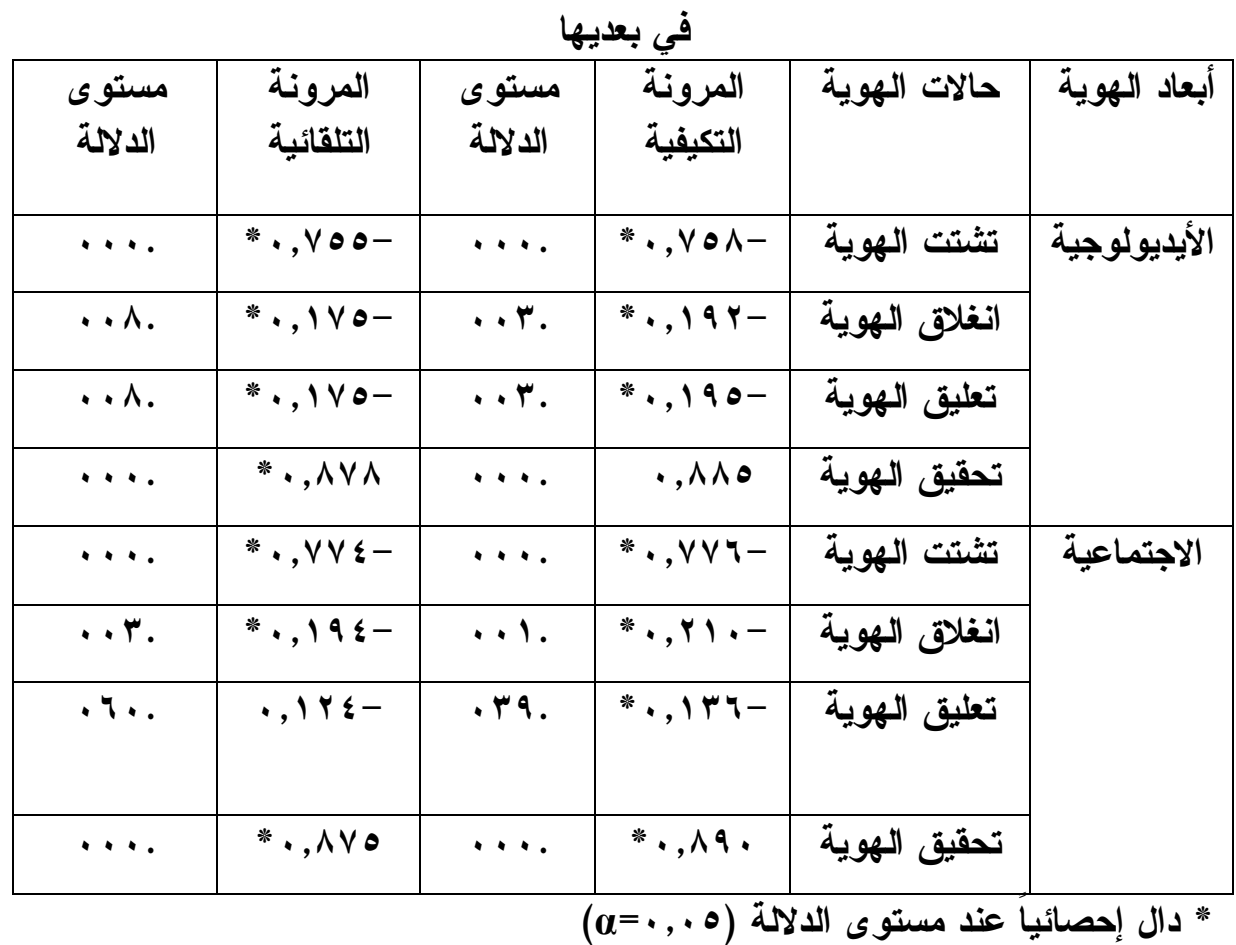
أ. بعد الهوية الأيديولوجية:

يتضح من جدول (؛ 1) وجود ارتباط إيجابي دال إحصائياً بين تحقيق الهوية

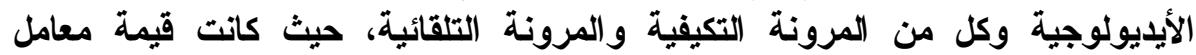

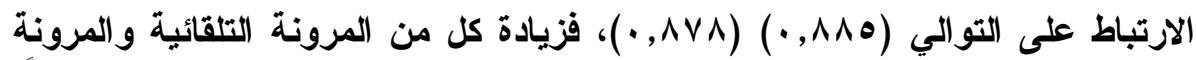
التكيفية يزيد من تحقيق الهوية الأيديولوجية لاى الطلبة، كما يتضح من الثانية النتائج أيضاً وجود ارتباط سلبي دال إحصائياً بين بقية حالات الائ تثكل الهوية (التثتت، والانغلاق، 
مجلة كلية التربية، جامعة الأزهر، العلد: (19 19 الجزء الثالث) يوليو لسنة 17 ـأبم

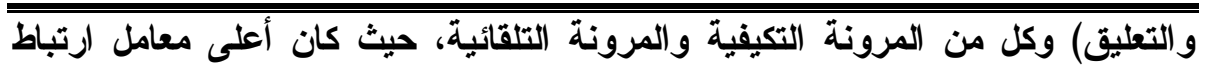

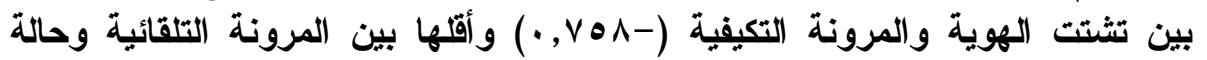

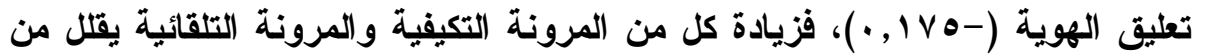

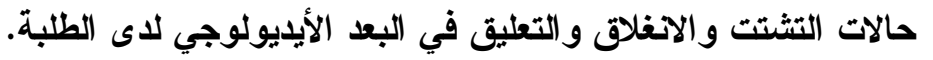

$$
\text { ب. بعد الهوية الاجتماعية: }
$$

يتضح من جدول (؛ 1) وجود ارتباط إيجابي دال إحصائياً بين تحقيق الهوية

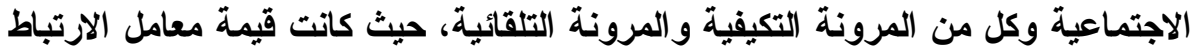

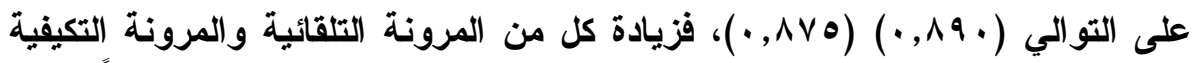

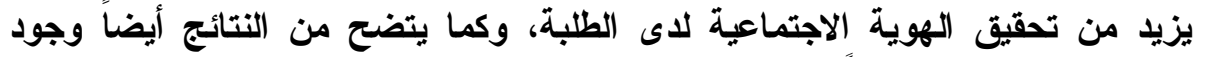

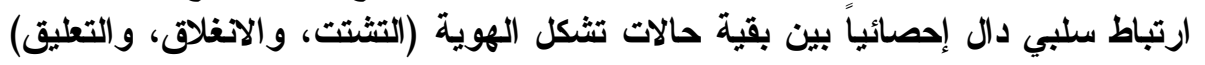

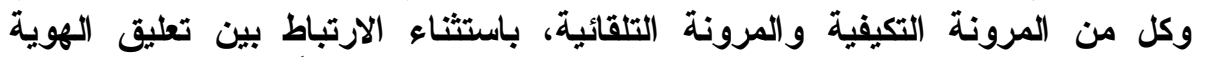
والمرونة التلقائية حيث أن الارتباط بينهما لم يكن دال إحصائياً عند مستوى الدالاية

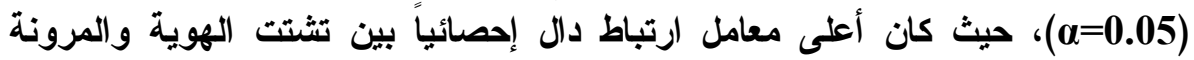

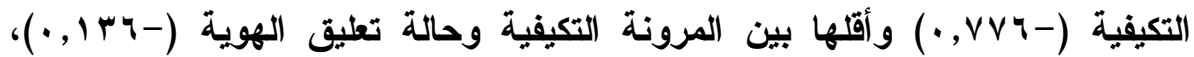

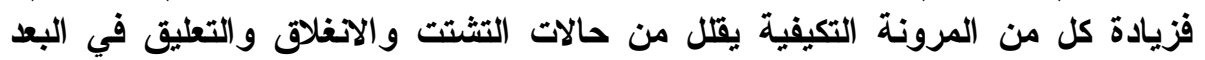

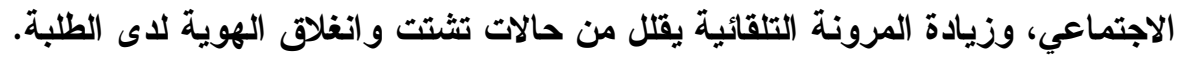
- نتائج السؤال الرابع: هل توجد فروق دالة إحصائياً في حالات الهوية تعزى الجئي

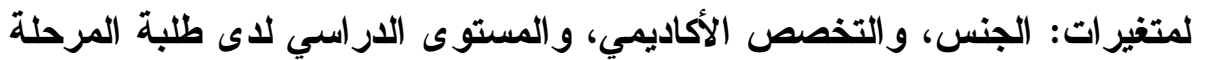

الثانويةٌ

للإجابة عن السؤال الرابع تم حساب المتوسطات الحسابية والاحر افات

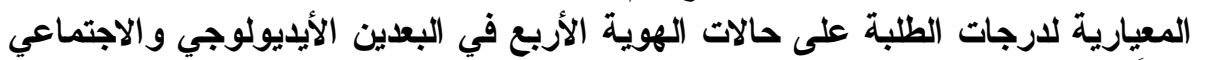

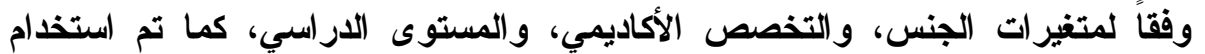

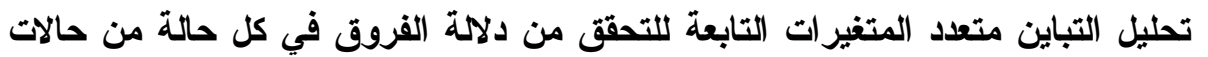

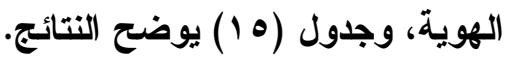




$$
\text { جدول (10) (10) }
$$

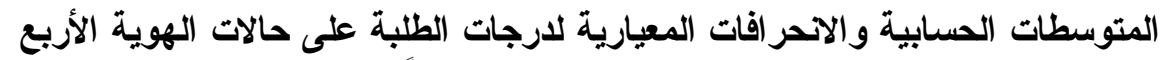

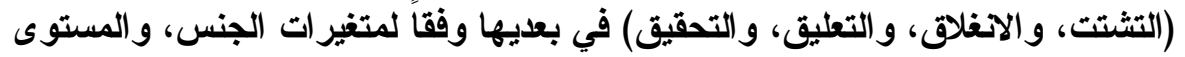

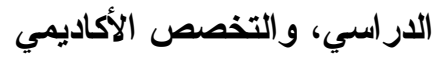

\begin{tabular}{|c|c|c|c|c|c|c|c|c|c|c|c|}
\hline |المعياري & الحسابي & الالحعراف & المتوسط الحسبي & الكهوية & التهوية & الغهوية & الهوية & العدد & أمتغيرات & المتغير & أبعاد \\
\hline$I Y, \Lambda V$ & $r v, r \wedge$ & 1,10 & $19, r r$ & $9,0$. & $19, \mathrm{rV}$ & $1 r, 19$ & $r v, 79$ & $11 \mathrm{~V}$ & ذكر & & 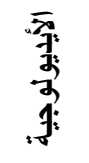 \\
\hline 14,90 & 0,94 & $1 \cdot, r q$ & $41, .9$ & $1 \cdot, \cdot r$ & $\mid 9,11$ & $11, \leqslant \leqslant$ & $r \checkmark, \vee \wedge$ & 115 & أنثى & & \\
\hline $\mid r, q V$ & $r q, \vee q$ & $\wedge, \uparrow \leq$ & $r \cdot, 1 r$ & $9, \wedge 7$ & $19, \wedge 0$ & $11, \wedge 9$ & $r v, \wedge 0$ & $11 \leqslant$ & الثانوي & |المستوى & \\
\hline $\mid r, \wedge q$ & $r q, O V$ & $1 \cdot, \cdot r$ & $r \cdot, r q$ & 9,77 & $\mid 9, r)$ & 11,87 & $r \%, 7 r \mid$ & $11 \mathrm{~V}$ & الثانوي & & \\
\hline$M, r Y$ & $r \checkmark, r \wedge$ & $9, \wedge \wedge$ & $r \cdot, r r$ & $1 \cdot, \cdot v$ & $19, \vee v$ & 11,79 & $r 4,7 \wedge$ & $1 \cdot \varepsilon$ & العلمي & |التخصص & \\
\hline $1 Y, 7$. & rq,q. & $\wedge, 9 r$ & $r \cdot, l$. & 9,01 & $19, \mathrm{rq}$ & 11,97 & $r v, 7 \wedge$ & $I r V$ & الأدبي & الأكاديمي & \\
\hline $1 \%, q$. & rq, & $9, r 0$ & $r \cdot, r \cdot$ & $9, v \leq$ & $19,0 \leqslant$ & $11, \wedge 1$ & rV,rr & rrI & \multicolumn{2}{|c|}{ الكلي } & \\
\hline $10, \cdot 1$ & $r q, Y q$ & $\Lambda, 94$ & $19,1$. & $1 \cdot, r v$ & $1 \wedge, 1 \mathrm{~V}$ & $10, \leqslant 9$ & $Y \square, V Y$ & $11 \mathrm{~V}$ & ذكر & الجنس & \multirow{7}{*}{ 离. } \\
\hline $10, \cdot 1$ & $r V, r v$ & $11,7 \leq$ & Y Y. & $1 \cdot, r r$ & $\mid \wedge, Y T$ & $1 \leq, r \wedge$ & $r \leqslant, 70$ & $11 \leq$ & أنثى & & \\
\hline $1 \leq, \wedge 1$ & $r \wedge, \vee \wedge$ & 9,19 & $19, Y 1$ & 9,94 & $11, .9$ & $10,1 \mathrm{r}$ & rq, ৭r| & $11 \leq$ & الأول الثانوي & \multirow{2}{*}{ الار استي } & \\
\hline$|0, r|$ & $r v, \wedge v$ & $11, \varepsilon r$ & $r_{1, r o}$ & $1 \cdot, v \leqslant$ & $|\wedge, r|$ & $1 \leq, \vee 7$ & $r \leq, 0$. & $11 \mathrm{~V}$ & الثانوي & & \\
\hline $10, Y \leq$ & $r \wedge, 0$. & $1 \cdot, 0 r$ & $r \cdot, \cdots$ & $\mid 1,, \cdot \leq \leqslant$ & $1 \mathrm{~V}, 7 \mathrm{~V}$ & $1 \varepsilon, \wedge r$ & $r \bullet, r r \mid$ & $1 \cdot \varepsilon$ & العلمي & | التخصص | & \\
\hline $1 \leq, 94$ & $r \wedge, 1 \wedge$ & $1,, \mu_{0}$ & $r \cdot, T$ & $1,0 \mathrm{~V}$ & $1 \wedge, 7 \leqslant$ & 10,11 & $r q, \cdot \lambda$ & IrV & الأدبي & الأكاديمي & \\
\hline $10,0 \leq$ & $r \wedge, r r$ & $1 \cdot, \leqslant 1$ & $r \cdot r r$ & $1 \cdot, r r$ & $\mid \wedge, r$. & $1 \leq, 90$ & $r \theta, v \cdot$ & rrI & \multicolumn{2}{|c|}{ الكلي } & \\
\hline \multicolumn{12}{|c|}{ 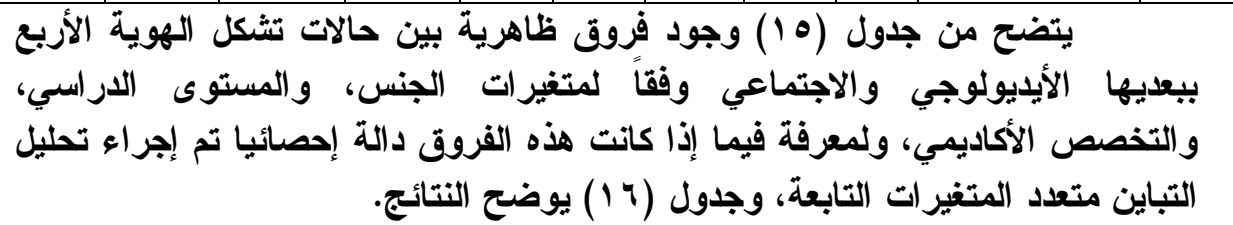 } \\
\hline
\end{tabular}




\section{جدول (17)}

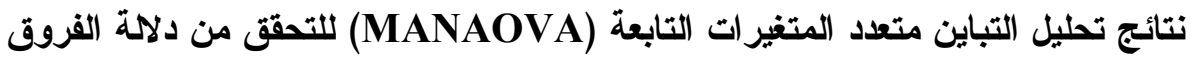

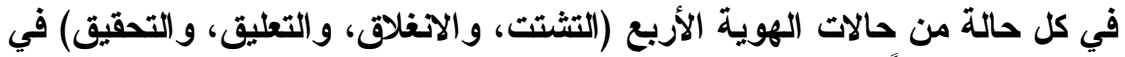

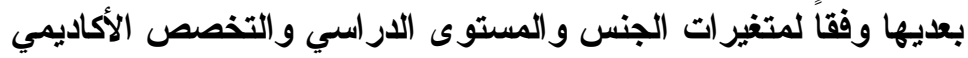

\begin{tabular}{|c|c|c|c|c|c|}
\hline مستوى الالاكة & لارجات & الافتر اضية & ف & تريس تلنج & المتغير \\
\hline$\cdot, \Delta \Delta r$ & 119 & $\Lambda$ & $\cdot, \wedge 7$ & $\cdot, \cdot r$ & الجنس \\
\hline., $97 r$ & 119 & $\Lambda$ & $1,9$. & $\cdot, \cdot V$ & الار اسستوى \\
\hline., $1 \leq 7$ & 119 & $\Lambda$ & $1,0 \varepsilon$ &., .9 & الأكاديمي \\
\hline
\end{tabular}

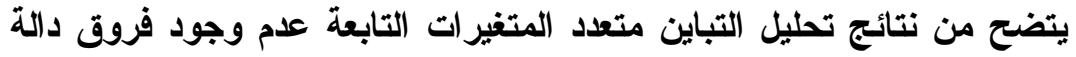

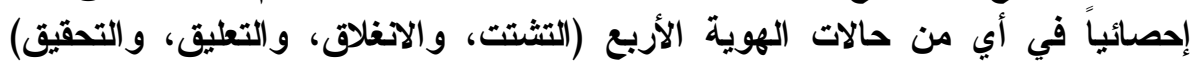

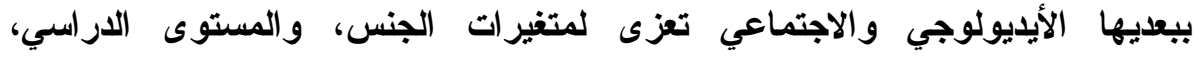

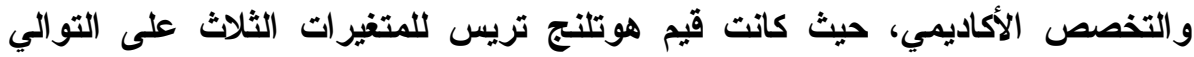

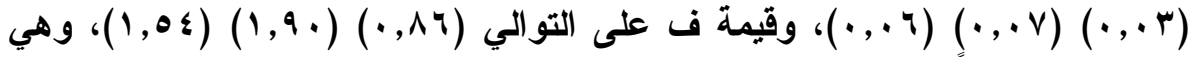

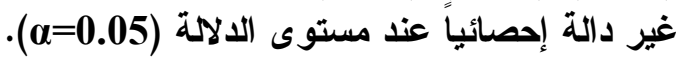

- نتائج السؤال الخامس: هل توجد فروق دالة إحصائياً في المرونة

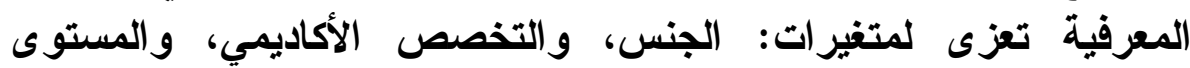

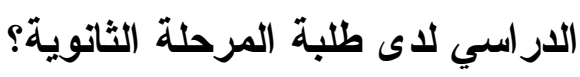

للإجابة عن السؤال الخامس تم حساب المتوسطات الحسابية والاحر افات

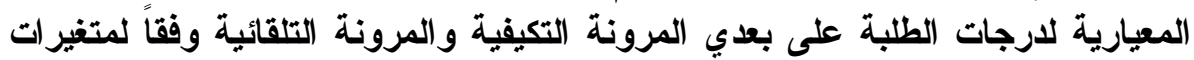

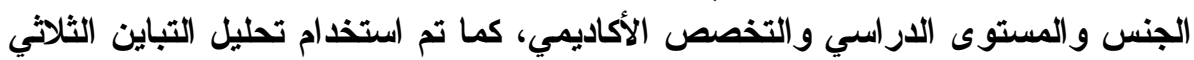

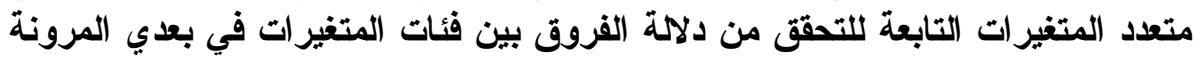

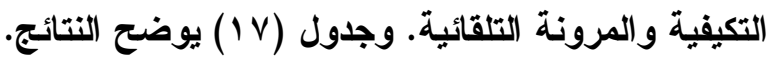


مجلة كلية التربية، جامعة الأزهر، العدد: (9 19 الجزء الثالث) يوليو لسنة 1 أ بام

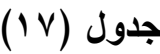

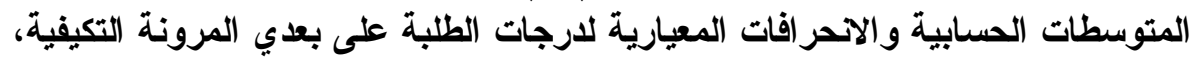

\begin{tabular}{|c|c|c|c|c|c|c|}
\hline الالحعراف & الحسابي & التلقائية & التكيفية & العدد & الفئات & المتغير \\
\hline 1,01 & $r, \cdot r$ & 1,00 & $r, \cdot \varepsilon$ & $11 \mathrm{~V}$ & ذكر & \multirow[t]{2}{*}{ الجنس } \\
\hline $1, \leqslant 7$ & $r, . \theta$ & $1, \leqslant 0$ & Y, qV & $11 \leq$ & أنثى & \\
\hline $1,0$. & $r, 11$ & $1,0 r$ & $r, \cdot \varepsilon$ & $11 \leqslant$ & الأول الثانوي & \multirow{2}{*}{ الدر استوى } \\
\hline $1, \leqslant V$ & $r, 9 V$ & $1, \leqslant 9$ & $r, 9 V$ & $11 \mathrm{~V}$ & الثاني الثانوي & \\
\hline 1,01 & $r, 1 r$ & $1,0 \leqslant$ & $r, .0$ & $1 \cdot \varepsilon$ & العلمي & التخصص \\
\hline $1, \leqslant V$ & $r, q V$ & $1, \leqslant V$ & r, qV & ITV & الأدبي & الأكاديمي \\
\hline $1, \leqslant \wedge$ & $r, \cdot \varepsilon$ & $1,0$. & $r, \ldots$ & rrI & \multicolumn{2}{|c|}{ الكلي } \\
\hline
\end{tabular}

يتضح من جدول (IV) وجود فروق ظاهرية في المرونة التكيفية والمرونة

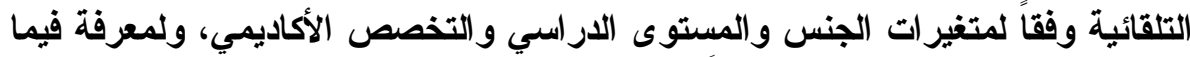
إذا كاتت هذه الفروق دالة إحصائياً؛ تم إجراء تحليل التباين متعدد المتغيرات التابعة والتئ، وجدول (1/1) يوضح النتائج.

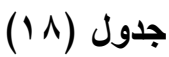

نتائج تعليل التباين متعدد المتغيرات التابعة (MANAOVA) للتحقى من دلاية الفروق

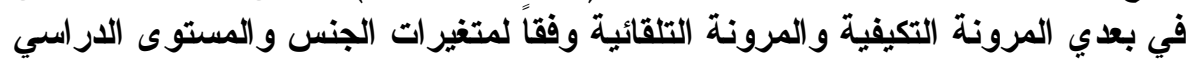

\begin{tabular}{|c|c|c|c|c|c|}
\hline مستوى الدلاكة & للحرية & الأنر اضرية & ف & تريس & المتغير \\
\hline., 1.0 & YYT & $r$ & $r, Y \wedge$ & $\cdot, \cdot r$ & الجنس \\
\hline •, $Y Y \varepsilon$ & FYT & $r$ & $1,0$. & $\cdot, \cdot 1$ & المستوى الاراسي \\
\hline$\cdot, \leqslant 11$ & YYY & $r$ & $\cdot, \wedge 9$ & $\cdot, \cdot 1$ & التخصص الأكاديمي \\
\hline
\end{tabular}

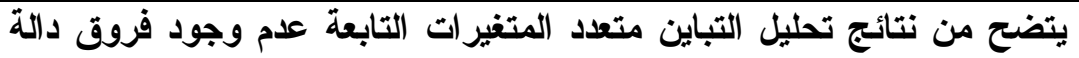

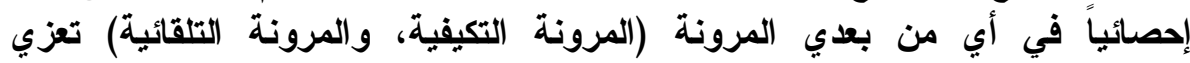

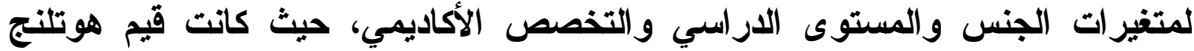

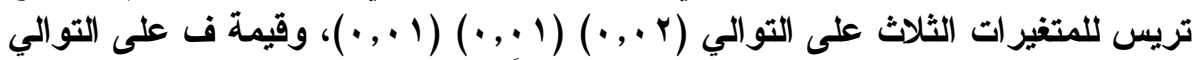

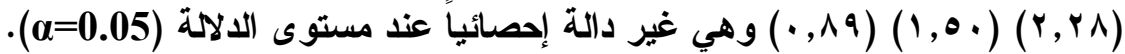


مناقشة النتائج::

يمكن تفسير نتيجة السؤال الأول (والتي تثبر إلى أن أكثر حالات تثكل الهوية

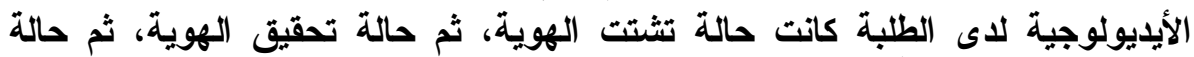

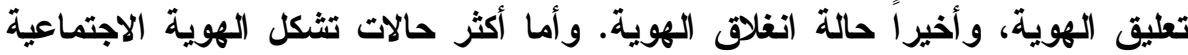
لاى الطلبة كانت حالة تحقيق الهوية، ثم حالة تثتت الهوية، ثم حالة تعليق الهوية،

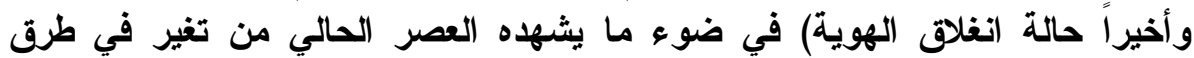
التربية التي تتجه نحو النمط الديمقراطي سواء في مجال التربية والتعليم أو التنشئة

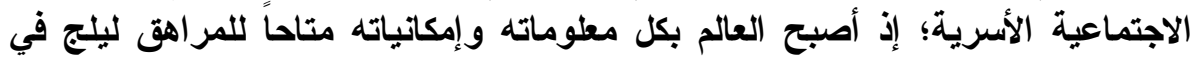
معطياته المختلفة، لذلك فإن الهوية المغلقة أو المعلقة لم تظهر بوضوح التهاتئة في عينة

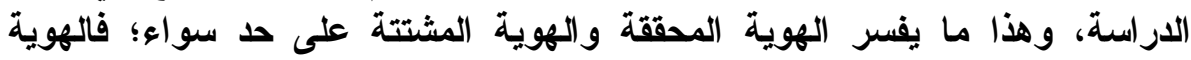
المحققة تعاملت مع وسائل الاتصال الحديثة ونهلت منها ما يناسبها، لذلك اتجهت

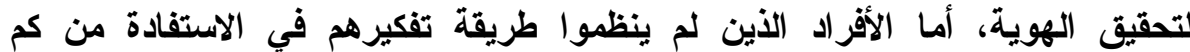

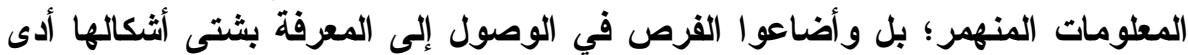
ذلك بهم إلى اضطراب هويتهم وتثتتها. وهذه النتيجة خالفت نتائج دراسة فئة عثامنة

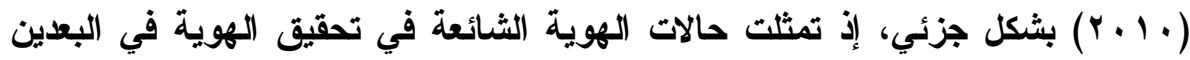

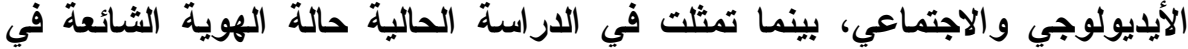

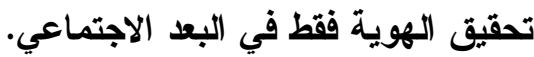

أما نتيجة السؤال الثاني (والتي تثير إلى أن مستوى المرونة التئية التيفية، والمرونة التكيفية لاى الطلبة كان متوسطاً بشكل عام) فيمكن تفسيرها بأن عينة

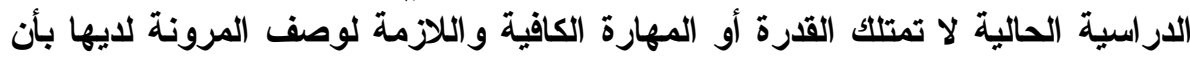

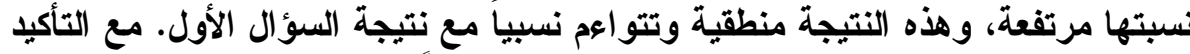

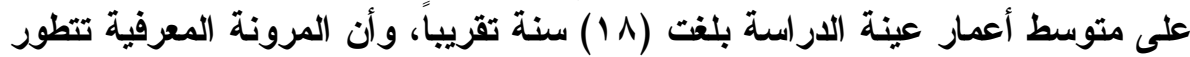

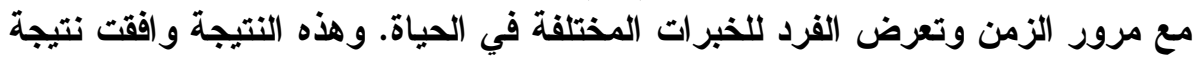

دراسة مور، ومالينوسكي (Moore, \& Malinowski, 2009).

وجاعت نتيجة السؤال الثالث منطقية؛ والتي تثير إلى وجود ارتباط إيجابي دال

إحصائياً بين تحقيق الهوية الأيديولوجية وكل من المرونة التكيفية والمرونة التلقائية

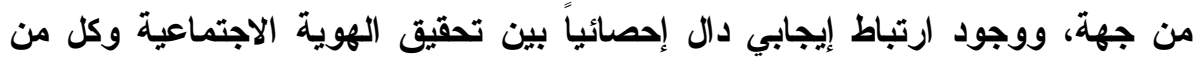
المرونة التكيفية والمرونة التلقائية من جهة أخرى، فزيادة كل من المرئة المرونة التلقائية

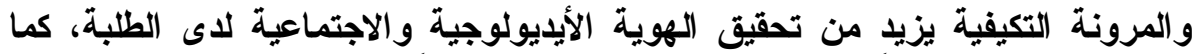
يتضح من النتائج أيضاً؛ وجود ارتباط سلبي دال إحصائياً بين بقية حالات الاتية تثكل الهوية الهوية

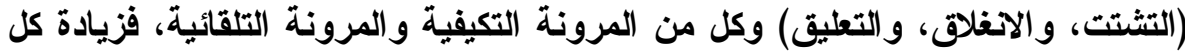

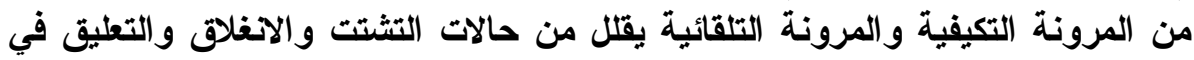




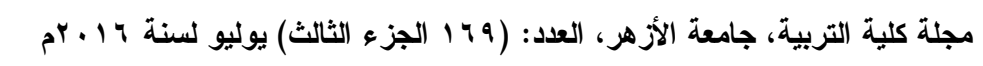

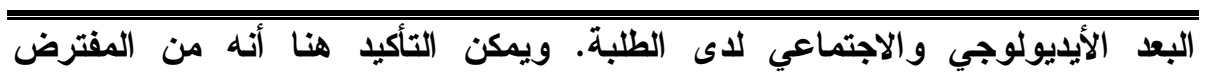

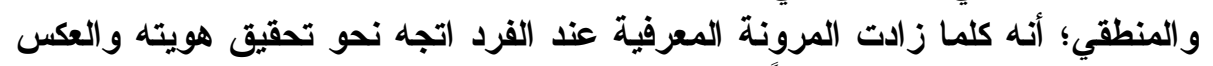

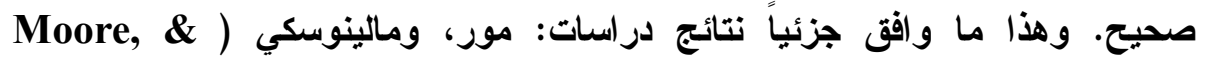

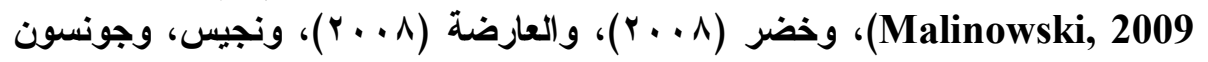
Slugoski, ) (Njus, \& Johnson, 2008) .(Marcia, \& Koopman, 1984

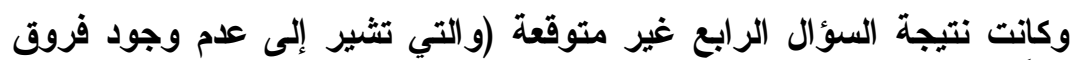

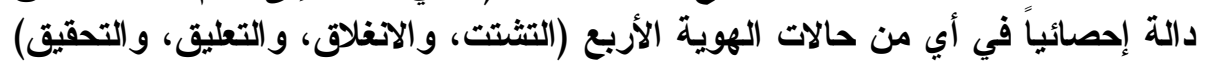

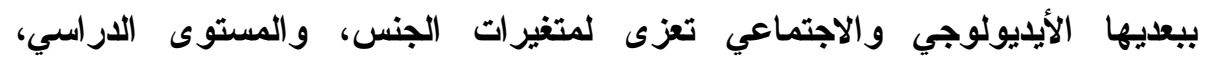

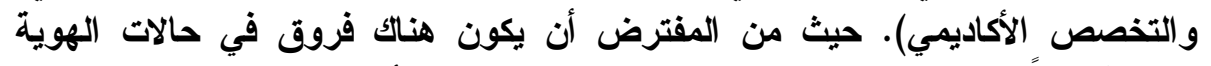

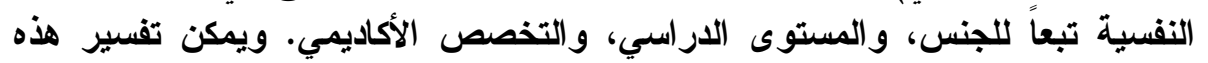

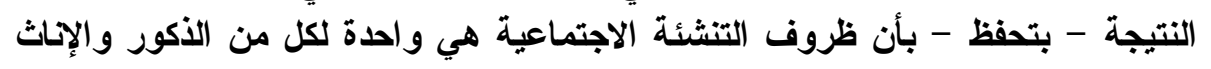

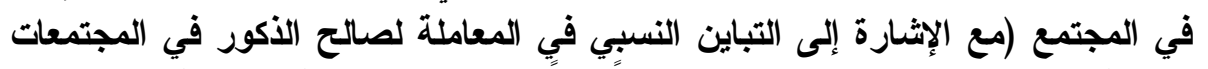

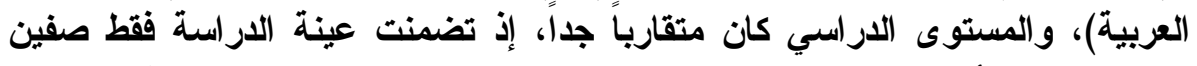

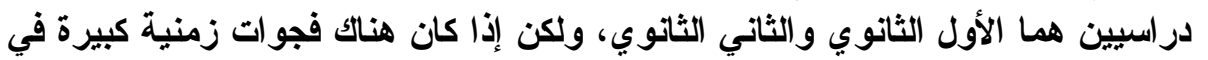

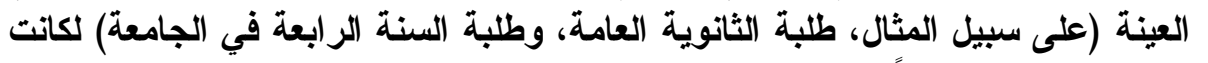

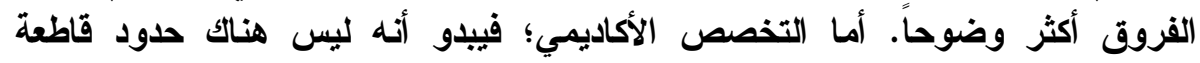

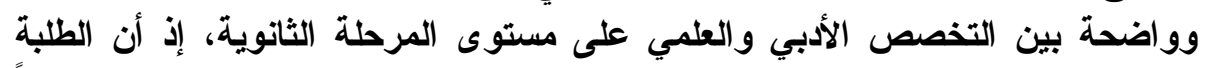

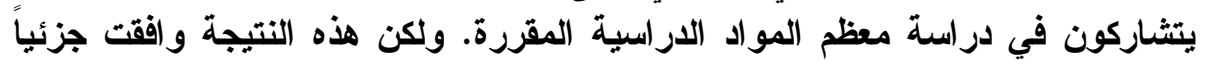

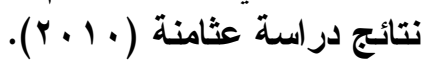

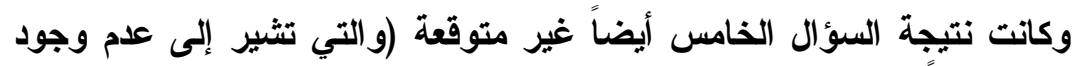

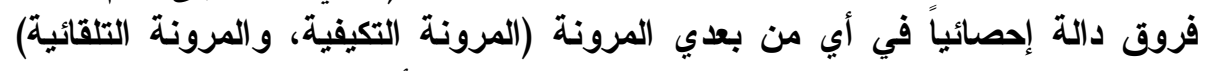

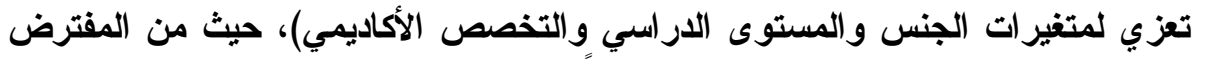

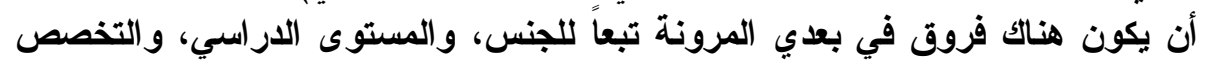

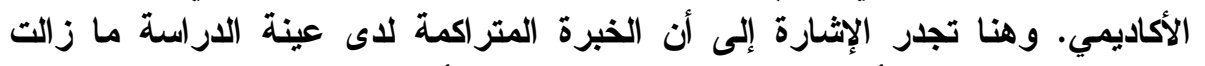

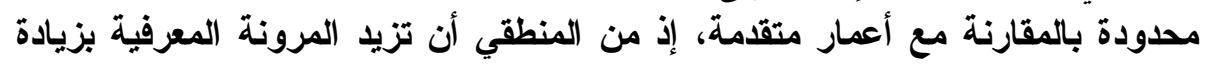

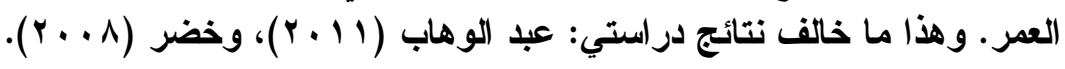




\section{مجلة كلية التربية، جامعة الأزهر ، العلد: (179 الجزء الثالث) يوليو لسنة 17 ابـام}

التوصيات:

في ضوء النتائج التي تم التوصل إليها؛ يقلم الباحث مجموعة التوصيات

- ربط دراسة حالات الهوية النفسية بمتغيرات ذات علاقة؛ لمعرفة العلاقة بينهما، مثل:

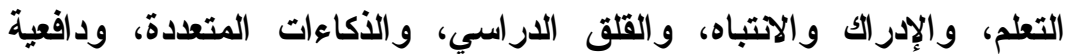

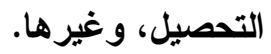

- ربط دراسة المرونة المعرفية بمتغيرات ذات علاقةة؛ لمعرفة العلاقة بينهما، مثل:

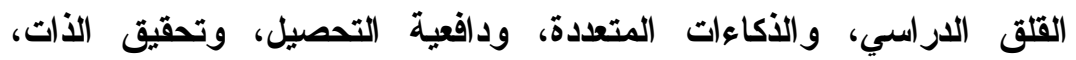

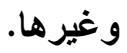

- تدريب الطلبة على المرونة المعرفية من خلا ورش عمل فئ لما لها من مردود إيجابي على جوانب متعددة في شخصياتهم.

- نشر ثقافة المرونة المعرفية، والهوية المتحققة/ المنجزة من خلال توفير مراجع وكتب ودر اسات تتعلق به.

- دراسة المرونة المعرفية لاى عينات بمراحل دراسية مختلفة.

- دراسة حالات الهوية النفسية لاى عينات من ثقافات مختلفة (عربية وغربية). 
مجلة كلية التربية، جامعة الأزهر ، العلد: (19 17 الجزء الثالث) يوليو لسنة 1 أبام

$$
\text { مر اجع الاراسة: }
$$

- أبو حطب، فؤاد عبد اللطيف (11) + (1). القدرات العقلية (ط7). القاهرة: مكتبة الأنجلو

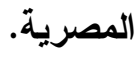

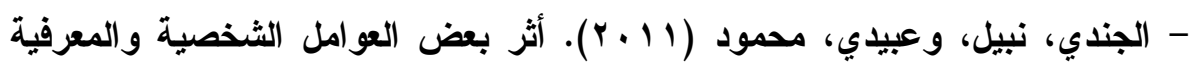
على تثكيل هوية الأنا لاى الثباب الفلسطينيين في مدينة القدس. مجلة جامعة الخليل

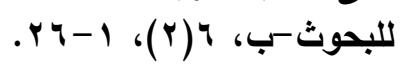

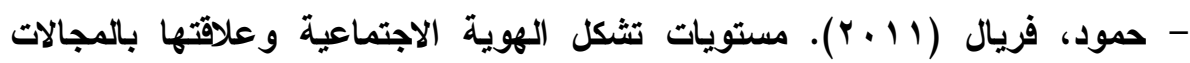

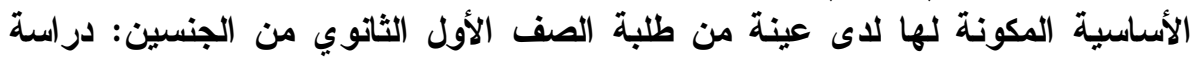

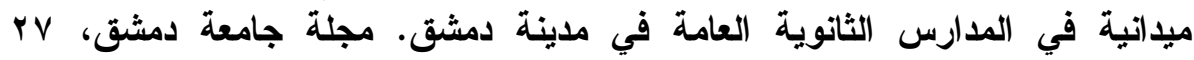

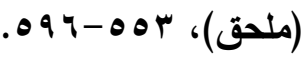

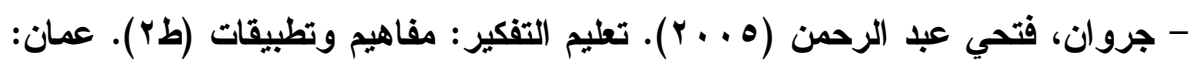

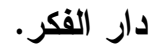

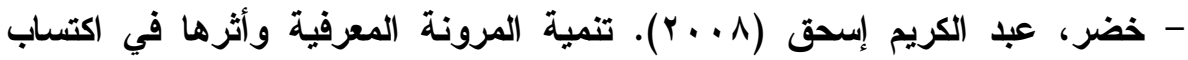

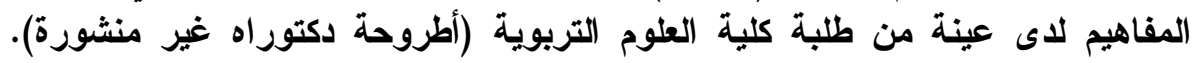
جامعة اليرموك، إربد، المثلكة الأردنية الهاثمية.

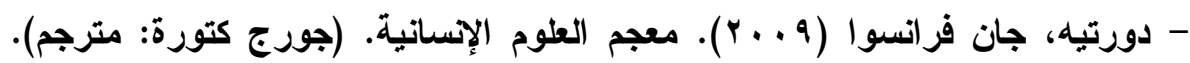
بيروت: المؤسسة الجامعية للاراسات (مجد)، أبو ظبي: هيئة أبو ظبي للثقافة و التراث

- روشكا، ألكسندر (9199). الإبداع العام والخاص. (غسان عبد الحي أبو فخر: مترجم). الكويت: المجلس الوطني للثقافة والفنون والآداب.

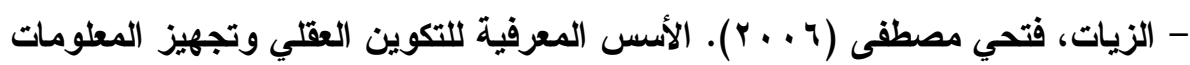

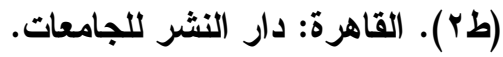

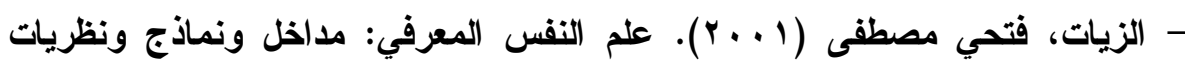
(جr) ( القاهرة: دار النشر اللجامعات.

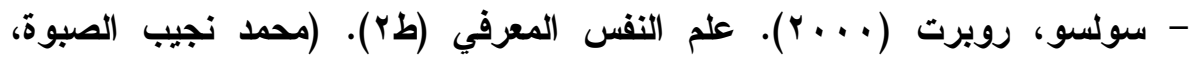
ومصطفى محمد كامل، ومحمد الحساتين الاق: مترجمون). القاهرة: مكتبة الأنجلو

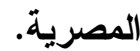

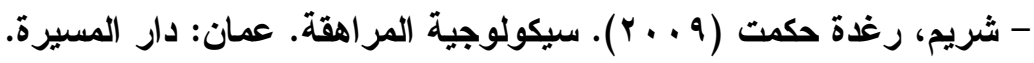




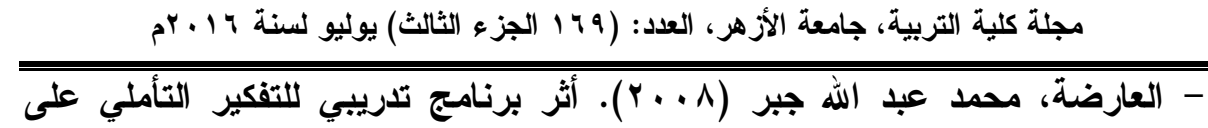

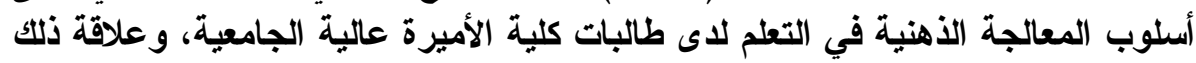

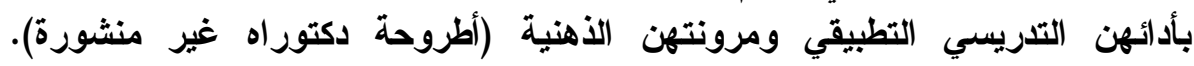
الجامعة الأردنية، عمان، المملكة الأردنية الهاشمية.

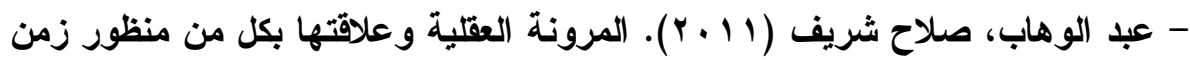

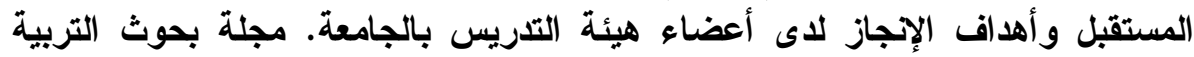

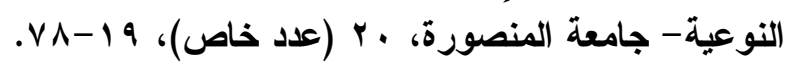

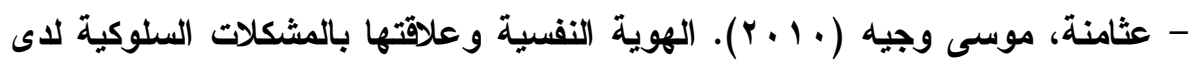

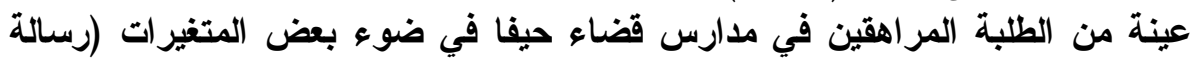
ماجستير غير منشورة). جامعة اليرموك، إربد، المملكة الأردنية الهاشمية.

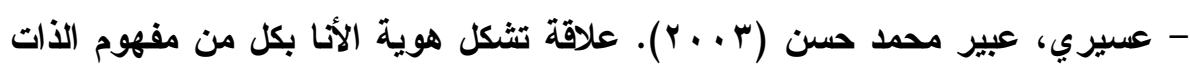

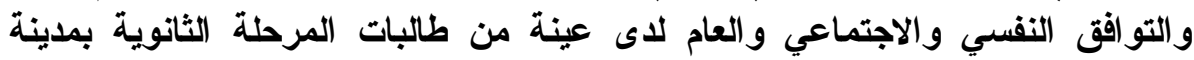
الطائف (رسالة ماجستير غير منشورة). جامعة أم القرى، مكة المكرمة، المملكة العربية السعودية.

- الغامدي، حسين عبد الفتاح (Y. . . . T). المقياس الموضوعي لتشكل هوية الأنا. مكة

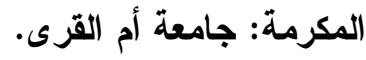

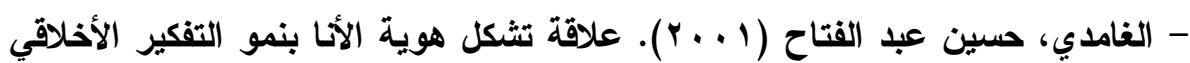

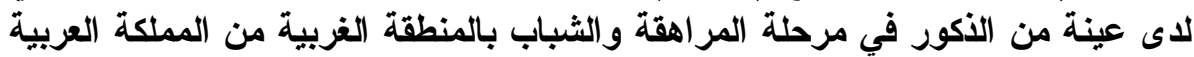

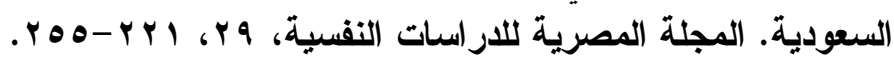
- كوزن، بيتز ( • • ب). البحث عن الهوية: الهوية وتثتتها في حياة إيريك إيركسون وأعماله. (سامر جميل رضوان: (بتر مترجم). العين: دار الكتاب الجامعي.

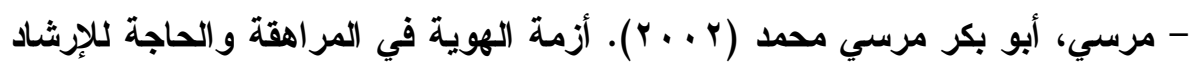
النفسي. القاهرة: مكتبة النهضة بكرة المصرية.

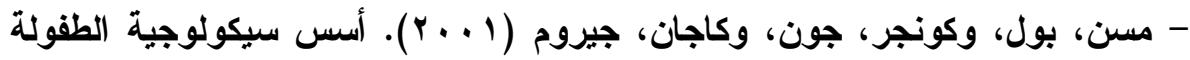
و المراهقة (ط؛). (أحمد عبد العزيز سلامة: مترجم). الكويت: مكتبة الفلاح.

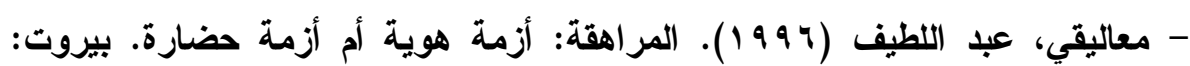
شركة المطبوعات.

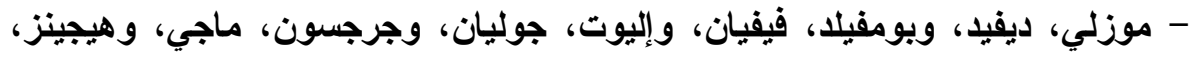

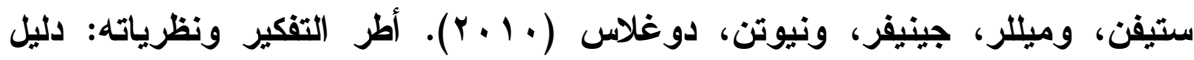
للتدريس والتعلم والبحث (طץ). (جابر عبد الحميد جابر : مترجم). عمان: دونئ دار المسيرة. 


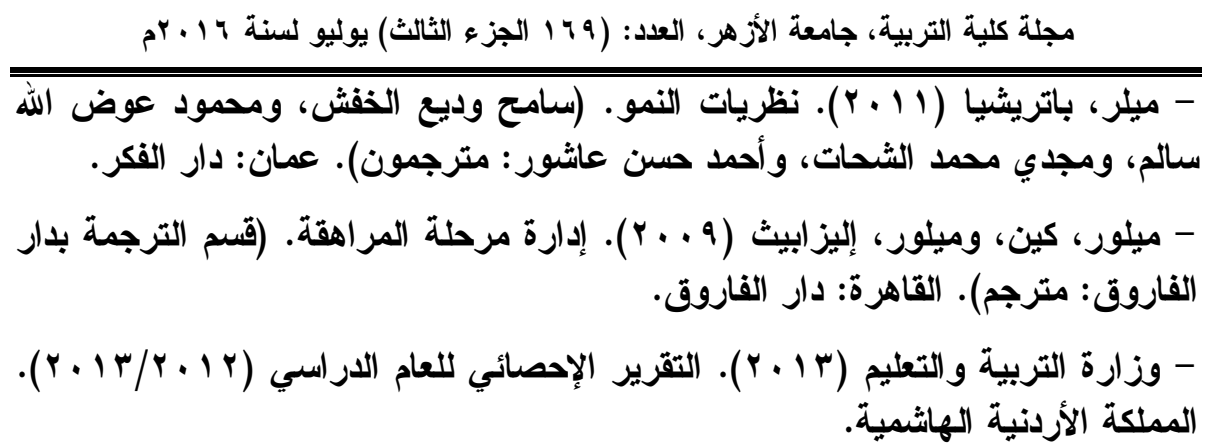

-Adams, M. L. (2003). Identity and intimacy as predictors of adolescent adjustment (Unpublished Master's thesis). Florida International university, Miami, Florida.

-Adams, G. R. (1998). The objective measure of ego identity status: A reference manual. Retrieved March 1, 2013, from https://www.uoguelph.ca/ gadams/OMEIS_manual.pdf

-Basak, R., \& Ghosh, A. (2008). Ego-identity status and its relationship with self-esteem in a group of late adolescents. Journal of the Indian Academy of Applied Psychology, 34(2), 337344.

-Bosma, H. A., \& Gerlsma, C. (2005). From early attachment relations to the adolescent and adult organization of self. In $J$. Valsiner, \& K. Connolly (Eds.), Handbook of developmental psychology (2nd Ed) (pp. 450- 488). London: SAGE Publications Inc.

-Ellis, H. C., \& Hunt, R. R. (1993). Fundamentals of cognitive psychology (5th Ed.). Boston: McGraw-Hill.

-Kroger, J. (2004). Identity in adolescence: The balance between self and others (3rd Ed). London: Routledge.

-Kroger, J. (2006). Identity development during adolescence. In G. R. Adams, \& M. D. Berzonsky (Eds.), Blackwell handbook of adolescence (2nd Ed) (pp. 205-226). Oxford, UK: Blackwell.

-Kroger, J., \& Marcia, J. E. (2011). The identity statuses: Orgins, meanings, and interpretations. In S. J. Schwartz, K. Luyckx, \& V. L. Vignoles (Eds.), Handbook of identity theory and research (pp. 31-53). New York: Springer Science+Business Media. 


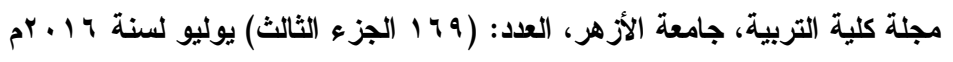

-Marcia, J. E. (1980). Identity in adolescence. In J. Adelson (Ed.), Handbook of adolescent psychology (pp. 159-187). New York: Wiley.

-Marcia, J. E. (1993). The ego identity status approach to ego identity. In J. E. Marcia, A. S. Waterman, D. R. Matterson, S. L. Archer, \& J. L. Orlofsky (Eds.), Ego identity: A handbook for psychological research (pp. 3-21). New York: Springer-verlag.

-Moore, A., \& Malinowski, P. (2009). Meditation, mindfulness and cognitive flexibility. Consciousness and Cognition, 18(1), 176186.

-Njus, D., \& Johnson, D. R. (2008). Need for cognition as a predictor of psychosocial identity development. The Journal of Psychology, 142(6), 645-655.

-Papalia, D. E., Olds, S. W., \& Feldman, R. D. (2001). Human development (8th Ed.). Boston: McGraw-Hill.

-Santrock, J. W. (2005). Adolescence (10th Ed.). Boston: McGraw-Hill.

-Schwartz, S. J., Donnellan, M. B., Ravert, R. D., Luyckx, K., \& Zamboanga, B. L. (2013). Identity development, personality, and well-being in adolescence and emerging adulthood: Theory, research, and recent advances. In I. B. Weiner (Series Ed.), and R. M. Lerner, A. Easterbrooks, \& J. Mistry (Vol. Eds.), Handbook of psychology, vol. 6: Developmental psychology (pp. 339-364). New York: John Wiley and Sons.

-Slugoski, B. R., Marcia, J. E., \& Koopman, R. F. (1984). Cognitive and social interactional characteristics of ego identity statuses in college males. Journal of Personality and Social Psychology, 47(3), 646-661. 


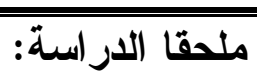

ا ـ مقياس حالات الهوية النفسية. عزيزي الطالب/ عزيزتي الطالبة،،، السلام عليكم ورحمة الله وبركاته،،، نضع بين يديك مقياساً يسأل عن حالات الهوية النفسية. والمطلوب تعبئته، وأخذ الملاحظات الآتية بعين الاعتبار: • قرأ كل فقرة، ثم اسأل نفسك، هل ينطبق مضمونها عليك؟ وما درجة ذلك؟؟. • • أجب عن جميع الفقرات بوضع إثارة (×) تحت الإجابة التي تنطبق عليها كل • اعلم أنه لا توجد إجابة صحيحة وأخرى خاطئة.

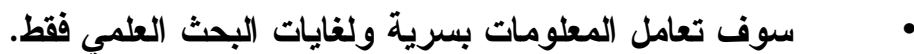

أولاً: معلومات أساسبية


مجلة كلية التربية، جامعة الأزهر، العدد: (9 19 الجزء الثالث) يوليو لسنة 1 أ بام

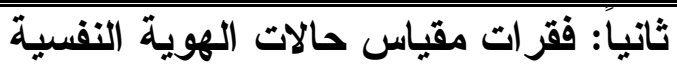

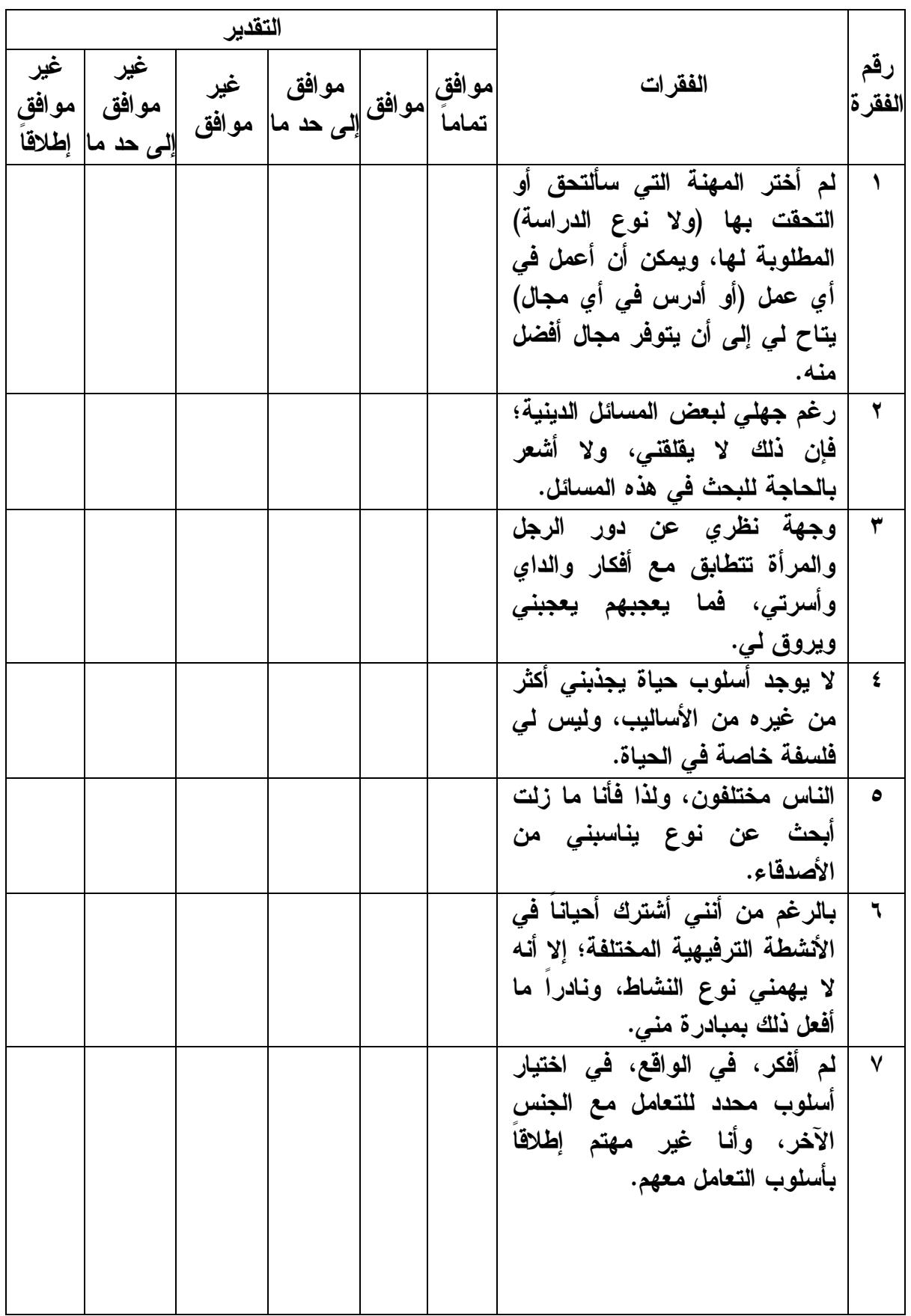


مجلة كلية التربية، جامعة الأزهر، العدد: (9 19 الجزء الثالث) يوليو لسنة 1 أ بام

\begin{tabular}{|c|c|c|c|c|c|c|c|}
\hline \multicolumn{6}{|c|}{ التقدير } & \multirow[b]{2}{*}{ الفقر ات } & \multirow[b]{2}{*}{ رقم } \\
\hline غو إفيز & 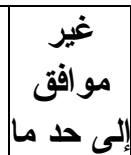 & غوافث & | مو افقى حد ما & مو افق & تموامًا تما & & \\
\hline & & & & & & 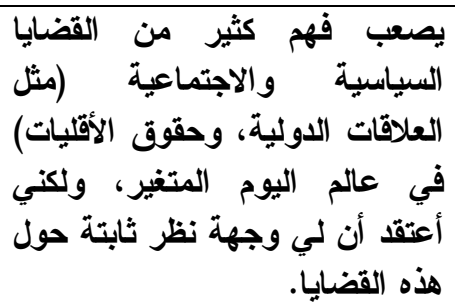 & $\Lambda$ \\
\hline & & & & & & 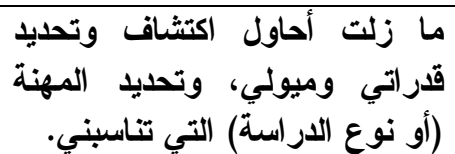 & 9 \\
\hline & & & & & & 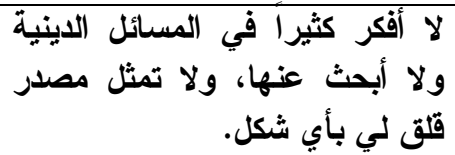 & 1. \\
\hline & & & & & & 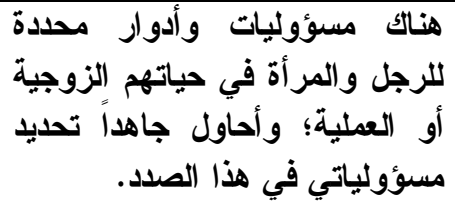 & 11 \\
\hline & & & & & & 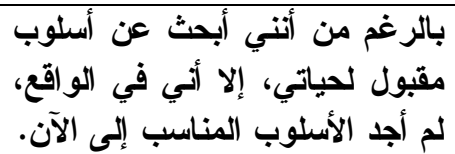 & Ir \\
\hline & & & & & & 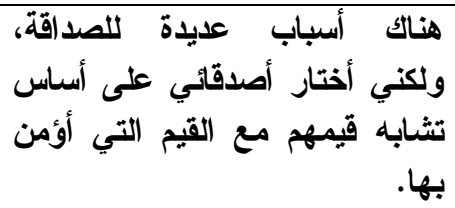 & 14 \\
\hline & & & & & & 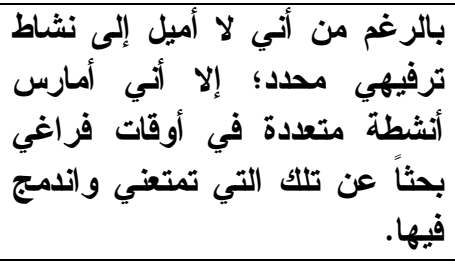 & 18 \\
\hline & & & & & & 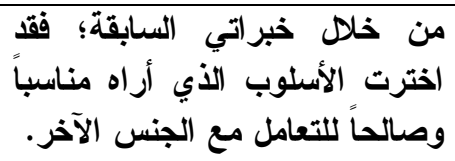 & 10 \\
\hline
\end{tabular}




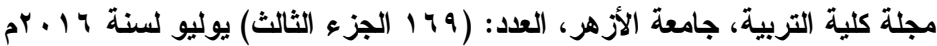

\begin{tabular}{|c|c|c|c|c|c|c|c|}
\hline & & ثدير & & & & & \\
\hline غو إفيز & غير |إلى حد ما & غوافث & إلى حد مافق & موافق & تماماً تمو افت & الفقر ات & رقم \\
\hline & & & & & & 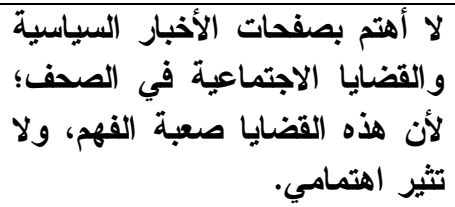 & 17 \\
\hline & & & & & & 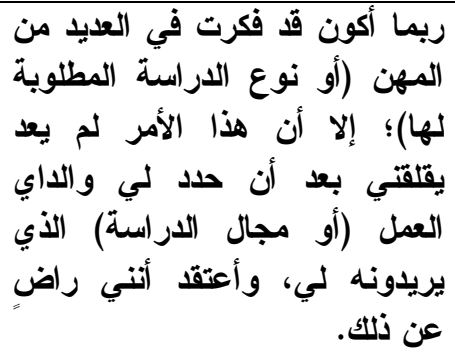 & IV \\
\hline & & & & & & 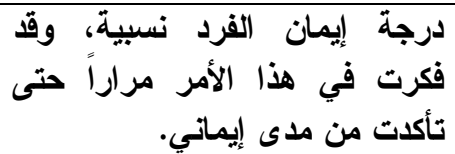 & 11 \\
\hline & & & & & & 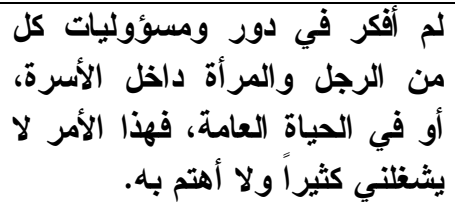 & 19 \\
\hline & & & & & & 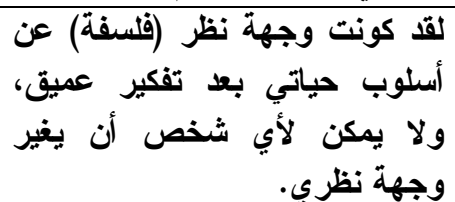 & $r$. \\
\hline & & & & & & 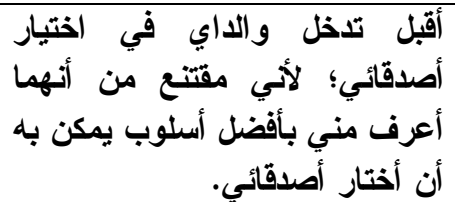 & YI \\
\hline & & & & & & 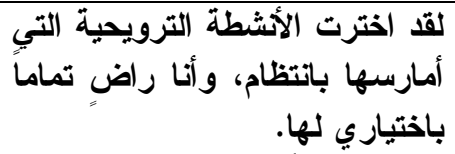 & rr \\
\hline & & & & & & 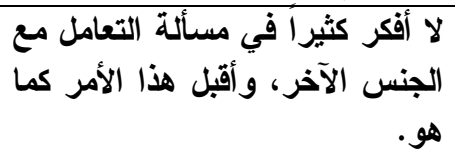 & $r r$ \\
\hline
\end{tabular}


مجلة كلية التربية، جامعة الأزهر، العدد: (9 19 الجزء الثالث) يوليو لسنة 1 أ بام

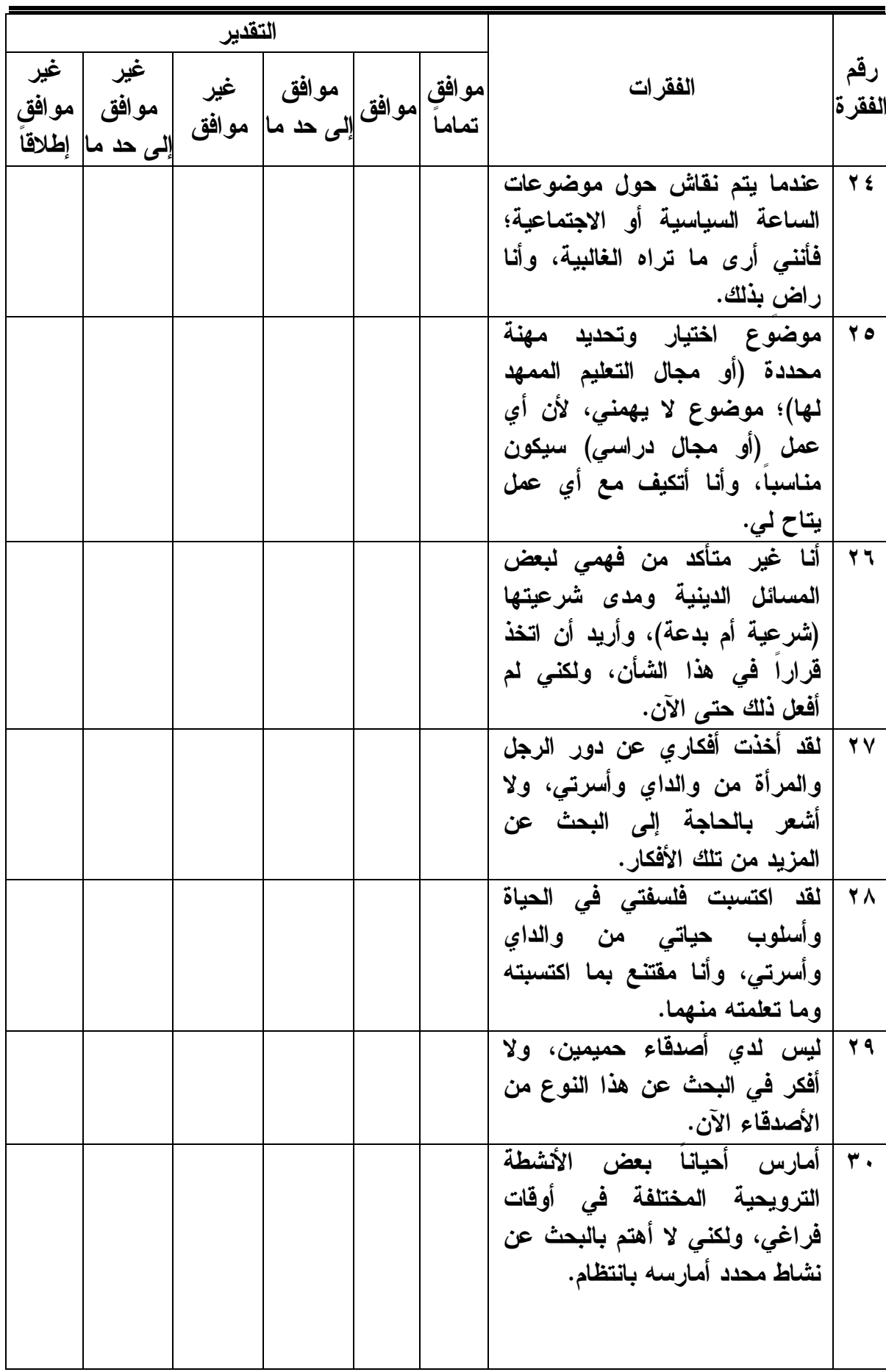


مجلة كلية التربية، جامعة الأزهر، العدد: (9 19 الجزء الثالث) يوليو لسنة 1 أ بام

\begin{tabular}{|c|c|c|c|c|c|c|c|}
\hline & & تاير & & & & & \\
\hline غو إفير & |إلى حو افث مير & غوافث & مو افق & مو افق & تماماً & الفقر ات & رقمّم \\
\hline & & & & & & 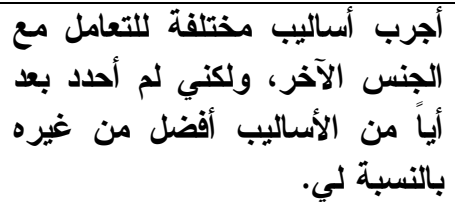 & P \\
\hline & & & & & & 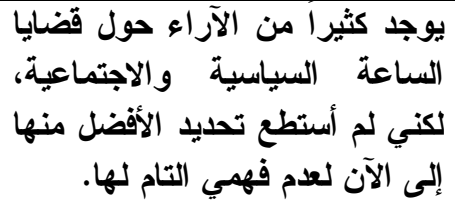 & rr \\
\hline & & & & & & 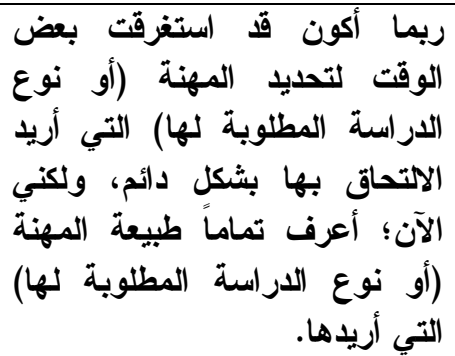 & $r r$ \\
\hline & & & & & & 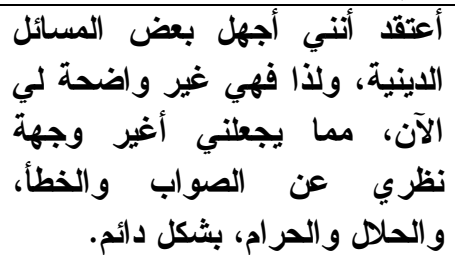 & $r \varepsilon$ \\
\hline & & & & & & 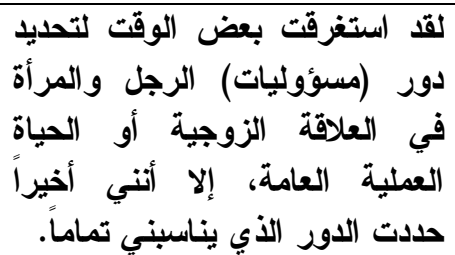 & ro \\
\hline & & & & & & 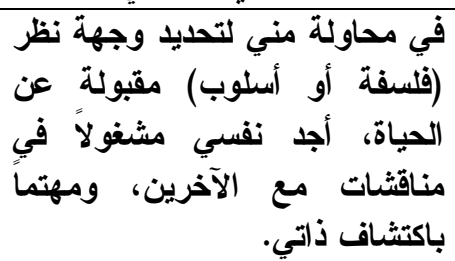 & $r q$ \\
\hline & & & & & & وأختار الأصدقاء الأين يوافق عليهم & $r v$ \\
\hline
\end{tabular}


مجلة كلية التربية، جامعة الأزهر، العدد: (9 19 الجزء الثالث) يوليو لسنة 1 أ بام

\begin{tabular}{|c|c|c|c|c|c|c|c|}
\hline & & ثدير & & & & & \\
\hline غو إفيز & غير |إلى حد ما & غوافق & |إلى حد مافق & مو افق & تماماً تمو افت & الفقر ات & رقم \\
\hline & & & & & & 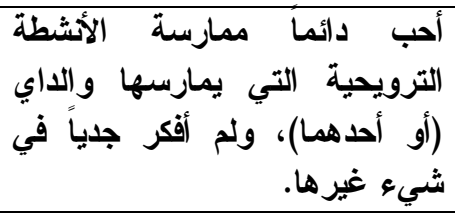 & $\mathrm{r \Lambda}$ \\
\hline & & & & & & 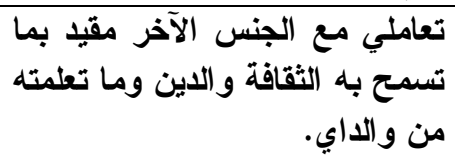 & $r q$ \\
\hline & & & & & & 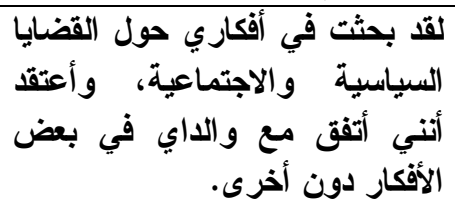 & $\varepsilon$ \\
\hline & & & & & & 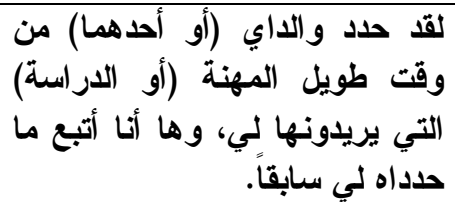 & $\leqslant 1$ \\
\hline & & & & & & 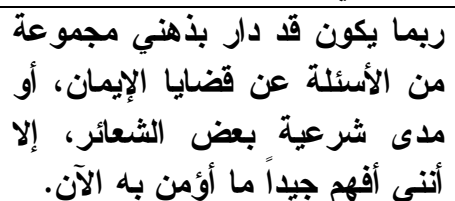 & $\varepsilon r$ \\
\hline & & & & & & 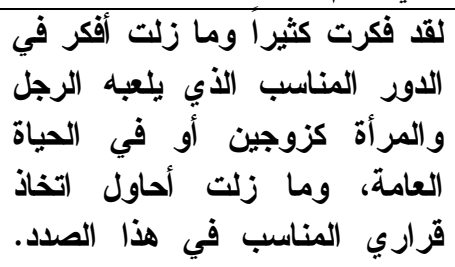 & $\varepsilon r$ \\
\hline & & & & & & 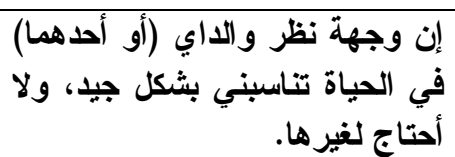 & $\varepsilon \varepsilon$ \\
\hline & & & & & & 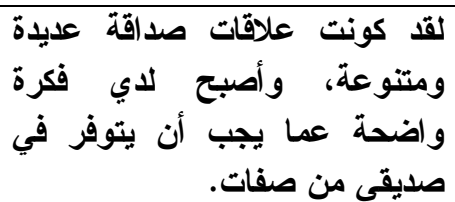 & $\leqslant 0$ \\
\hline
\end{tabular}

- 9r. - 
مجلة كلية التربية، جامعة الأزهر، العدد: (9 19 الجزء الثالث) يوليو لسنة 1 أ بام

\begin{tabular}{|c|c|c|c|c|c|c|c|}
\hline & & ثاير & & & & & \\
\hline غو إفير & غير إفى حد ما & غوافث & مو افق & مو افق & تموامًا & الفقر ات & رقمر \\
\hline & & & & & & 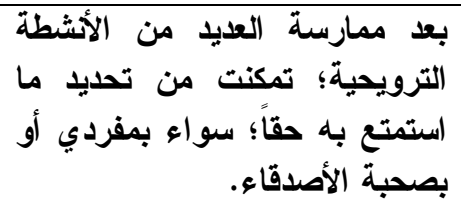 & $\leq 7$ \\
\hline & & & & & & 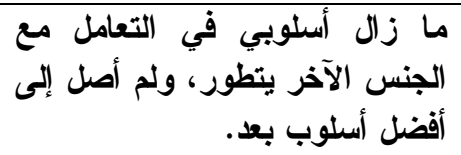 & $\leqslant V$ \\
\hline & & & & & & 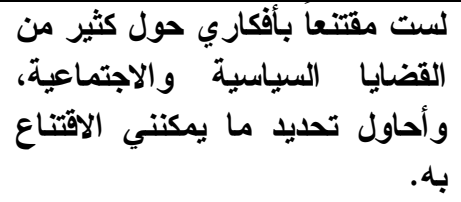 & $\leqslant \Lambda$ \\
\hline & & & & & & 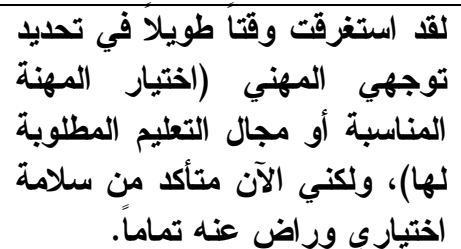 & $\varepsilon 9$ \\
\hline & & & & & & 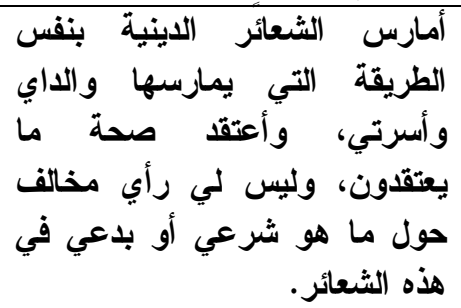 & 0. \\
\hline & & & & & & 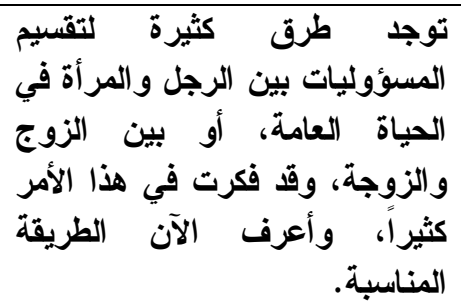 & 01 \\
\hline & & & & & & 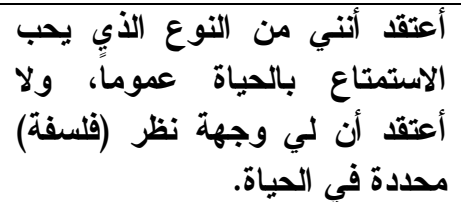 & Or \\
\hline
\end{tabular}


مجلة كلية التربية، جامعة الأزهر، العدد: (9 19 الجزء الثالث) يوليو لسنة 1 أ بام

\begin{tabular}{|c|c|c|c|c|c|c|c|}
\hline & & ثدير & & & & & \\
\hline غو إفيز & 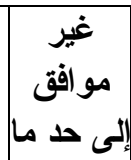 & غوافث & إلى حد مافق & مو افق & تماماً تمو افت & الفقر ات & رقم \\
\hline & & & & & & 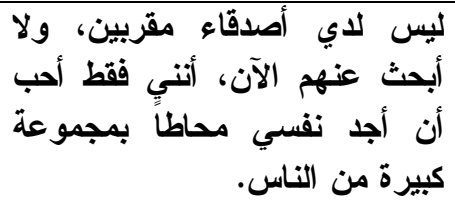 & or \\
\hline & & & & & & 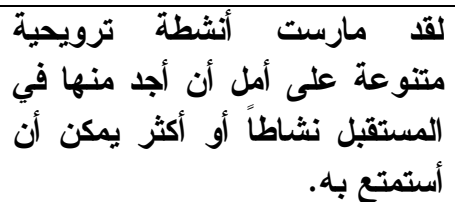 & O\& \\
\hline & & & & & & 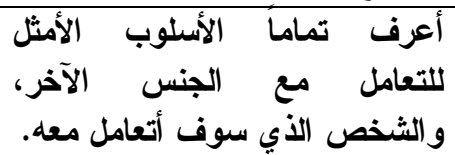 & 00 \\
\hline & & & & & & 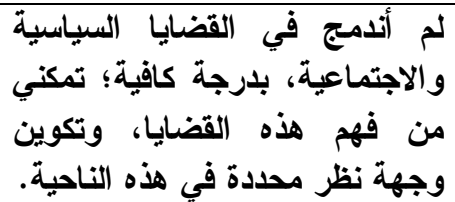 & 09 \\
\hline & & & & & & 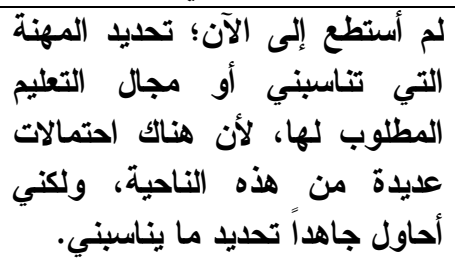 & OV \\
\hline & & & & & & 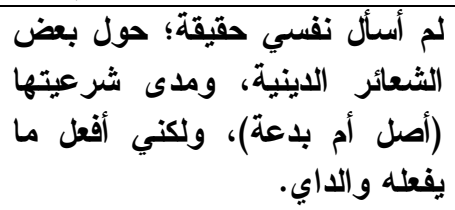 & $\Delta \Lambda$ \\
\hline & & & & & & 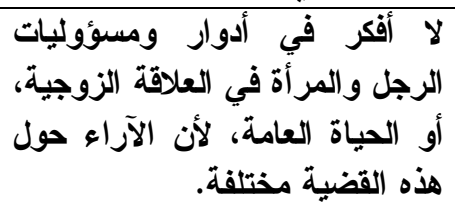 & 09 \\
\hline & & & & & & فلمد تفكير عميق؛ تمكنت من تلكوين & 7. \\
\hline
\end{tabular}


مجلة كلية التربية، جامعة الأزهر ، العدد: (9 19 الجزء الثالث) يوليو لسنة 1 أ بم

\begin{tabular}{|l|l|l|l|r|r|r|}
\hline \hline & & & \\
\hline \\
\hline
\end{tabular}


r ب مقياس المرونة المعرفية.

عزيزي الطالب/ عزيزتي الطالبة،،، السلام عليكم ورحمة الله وبركاته،،، نضع بين يديك مقياساً يسأل عن المرونة المعرفية. والمطلوب تعبئته، وأخذ الملاحظات الآتية بعين الاعتبار : الائ

• قرأ كل فقزة، ثم اسأل نفسك، هل ينطبق مضمونها عليك؟ وما درجة ذلك؟؟.

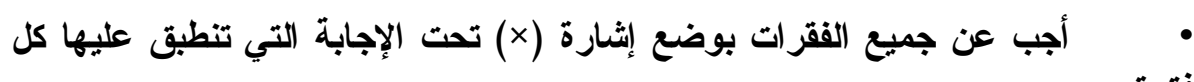

• اعلم أنه لا توجد إجابة صحيحة وأخرى خاطئة.

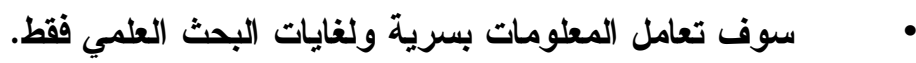

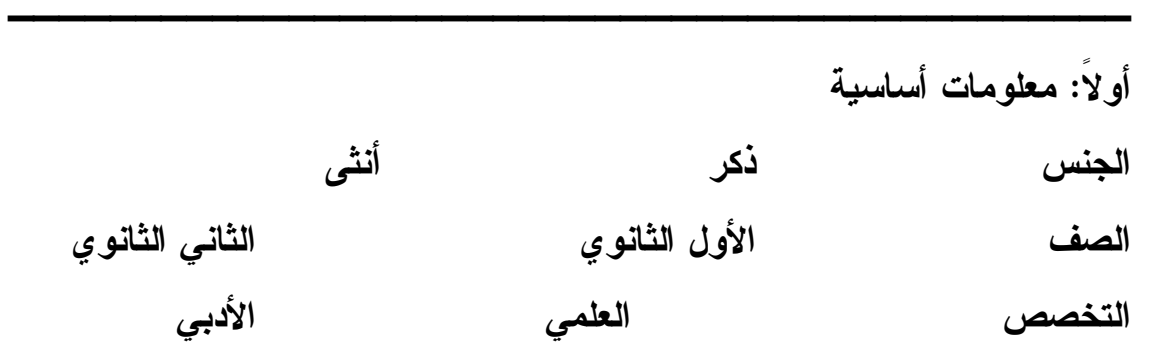

ثانياً: فقزات مقياس المرونة المعرفية

\begin{tabular}{|c|c|c|c|c|c|c|c|}
\hline \multicolumn{6}{|c|}{ التقدير } & \multirow[b]{2}{*}{ الفقرات } & \multirow[b]{2}{*}{ الفقرة } \\
\hline غولير & |إلى حو مافق ما & موافير & |إلى حو مافق & موافق & تماماً & & \\
\hline \multicolumn{8}{|c|}{ المرونة التكيفية } \\
\hline & & & & & & أكي أصل على إعلى لعادة بناء المشكلة؛ & 1 \\
\hline & & & & & & 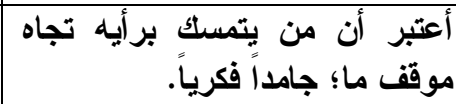 & $r$ \\
\hline & & & & & & المثكنية تغيير وجهتي الذهنية حول & $r$ \\
\hline & & & & & & 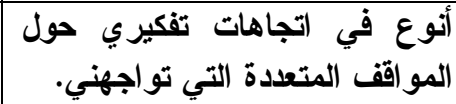 & $\varepsilon$ \\
\hline
\end{tabular}

- 
مجلة كلية التربية، جامعة الأزهر، العدد: (9 19 الجزء الثالث) يوليو لسنة 1 أ بام

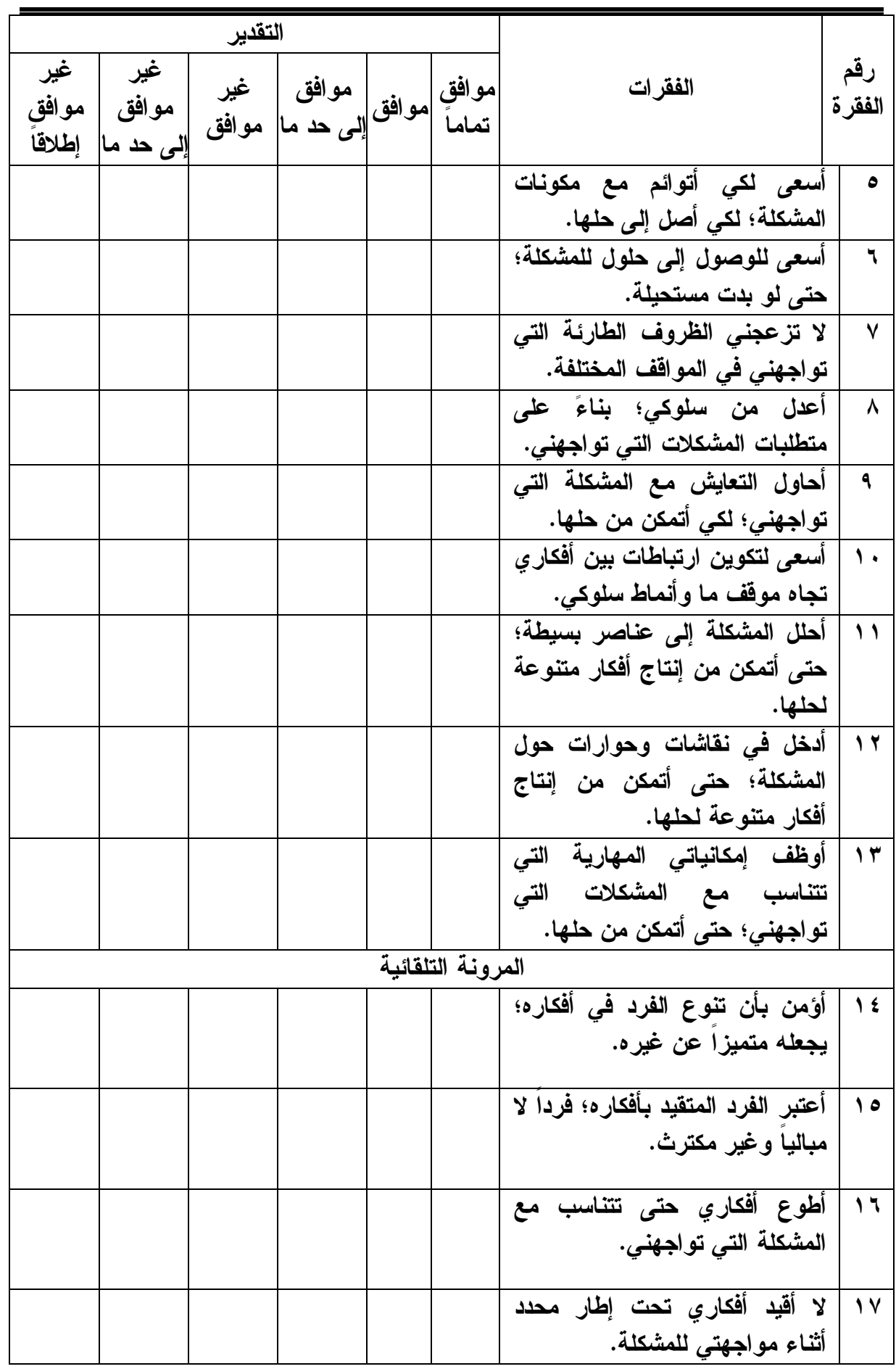

- 
مجلة كلية التربية، جامعة الأزهر، العدد: (9 19 الجزء الثالث) يوليو لسنة 1 أ بام

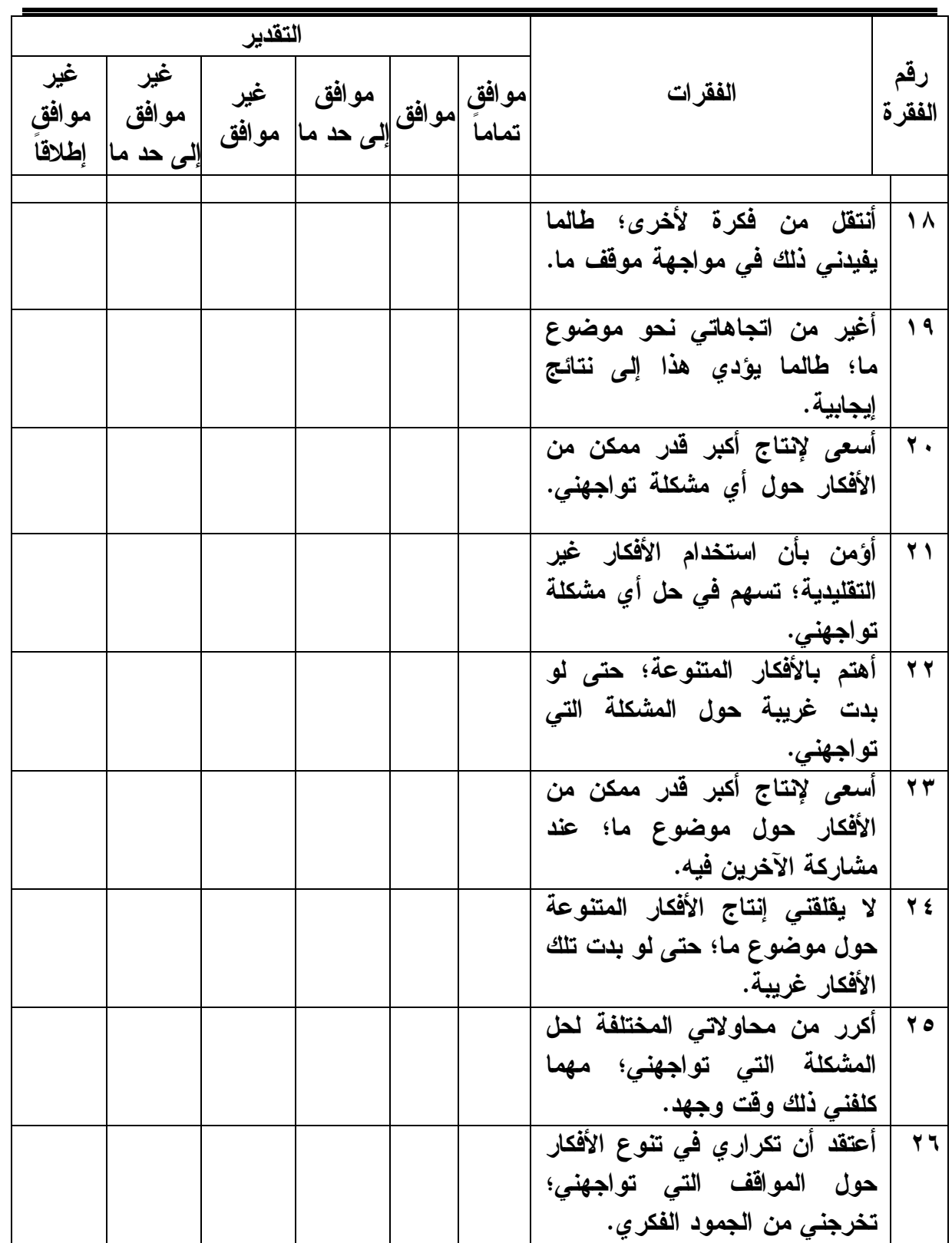

